\title{
Copyright
}

by

Zheng Jiang Leitter

2018 
The Dissertation Committee for Zheng Jiang Leitter certifies that this is the approved version of the following dissertation:

\section{The Effect of Identifying Intangible Assets in an Acquisition on Investors' Judgments}

\section{Committee:}

Lisa L. Koonce, Supervisor

Susan Broniarczyk

D. Eric Hirst

Ross Jennings

Brian J. White 


\title{
The Effect of Identifying Intangible Assets in an Acquisition on Investors' Judgments
}

\author{
by \\ Zheng Jiang Leitter
}

\author{
Dissertation \\ Presented to the Faculty of the Graduate School of \\ The University of Texas at Austin \\ in Partial Fulfillment \\ of the Requirements \\ for the Degree of \\ Doctor of Philosophy
}

The University of Texas at Austin

May 2018 


\section{Dedication}

To Mom and Dad, and to my loving husband Mark 


\section{Acknowledgements}

I greatly appreciate the thoughtful comments and guidance of my dissertation committee: Lisa Koonce (chair), Brian White, Eric Hirst, Ross Jennings, and Susan Broniarczyk. I am grateful to Eric Chan, Skylar DeTure, Jeffrey Hales, Steven Kachelmeier, Colin Koutney, Lilian Mills, Brian Monsen, Hun Tong Tan, Shankar Venkataraman, Xinyu Zhang, and Ronghuo Zheng for their helpful comments. I thank the participants at the 2016 FASAC meeting, the 2016 FASB PhD conference, the workshop participants at the University of Texas at Austin, the Georgia Institute of Technology, and the Nanyang Technological University for their insightful discussions. I gratefully acknowledge funding from the Eugene and Dora Bonham Endowment Fund and the Department of Accounting at the McCombs School of Business.

I cannot express enough gratitude to my dissertation chair, Lisa Koonce, whose invaluable guidance and support has shaped me into who I am today. Through her diligence, sincerity, and integrity, Lisa exemplifies a role model, not only for being a successful scholar, but also for being a well-rounded and wholesome person. Through her caring and mentoring, I have become a better person on both professional and personal levels. I am also fortunate to have received training and support from our strong experimental group, especially Brian White and Steve Kachelmeier. I thank all accounting faculty at UT for their collective effort in teaching and supporting me through the program.

I have had a most wonderful Ph.D. program experience, indebted to the many great friends I have made through the program. Xinyu Zhang has been my best friend, with whom I have laughed and cried, and many times regained my confidence from, through 
her encouragements and companionship. As part of the endearing Bullpen Family, Colin Koutney and Prasart Jongjaroenkamol have also given me tremendous support. Ying Huang has been a close confidant with whom I have shared many ups and downs. There are many more friends that I owe this unforgettable experience to, and I am grateful that they have been part of my journey.

Finally, I thank my parents Wenhui Hu and Yang Jiang, who not only gave me life, but also sacrificed everything for my growth and education. I thank Robert Sweo for guiding me towards the path to become an academic. I thank Donna Bobek Schmitt for introducing behavioral accounting research to me. Last but not least, I thank my husband Mark Leitter for his unconditional support and love. Without Mark, I would not be where I am today. 


\title{
The Effect of Identifying Intangible Assets in an Acquisition on Investors' Judgments
}

\author{
Zheng Jiang Leitter, Ph.D. \\ The University of Texas at Austin, 2018
}

Supervisor: Lisa Koonce

Standard setters struggle with the costs and benefits of requiring separate recognition of intangible assets in business combinations. Scholarly research on the consequences of separately identifying intangible assets versus subsuming intangibles into goodwill is limited. In this study, I experimentally test the effect of separately identifying intangibles on investors' judgments about an acquisition, and whether this effect is moderated by providing a narrative disclosure that contains the strategic reasons for the acquisition. I predict and find that separately identifying intangibles enables investors to more easily envision how an acquiring company can benefit from an acquisition, increasing investors' judgments about the valuation, future prospects, and investment desirability of the acquiring company. When intangibles are subsumed into goodwill, though, providing a strategic narrative acts as a substitute for intangible identification, with similar effects on investors' judgments. Thus, my results show that providing investors with either the separate identification of what the companies acquire or the strategic reasons for the combinations can help investors better understand and foresee the favorableness of such business decisions. These results should be informative to standard setters, managers, and researchers. 


\section{Table of Contents}



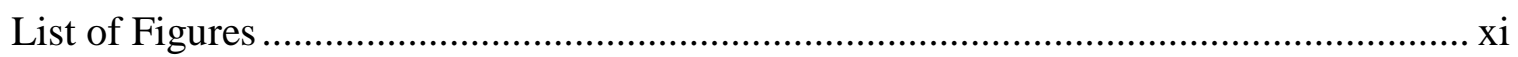

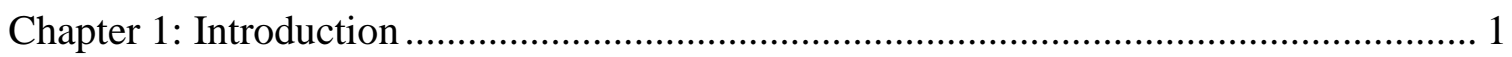

Chapter 2: The Evolving Concept of Goodwill and Intangibles........................................ 9

2.1 History of Accounting for Goodwill and Intangible Assets..................................... 9

2.2 Debate about the Current Accounting Standards for Intangible Assets .................. 19

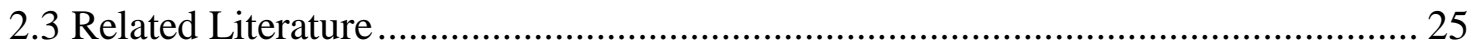

Chapter 3: Narrative Disclosure for Business Combinations .......................................... 31

3.1 Disclosure Requirement for Business Combinations............................................. 31

3.2 Strategic versus Non-Strategic Narratives ................................................................ 34

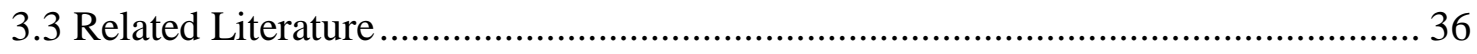

Chapter 4: Theory and Hypotheses ............................................................................. 39

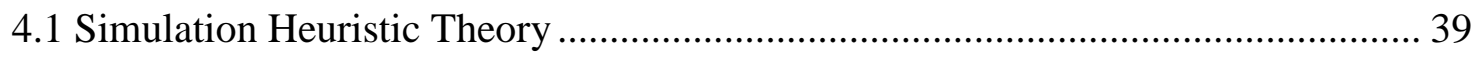

4.2 Main Effects of Intangible Identification and Strategic Narrative .......................... 41

4.3 Interactive Effect of Intangible Identification and Strategic Narrative................... 43

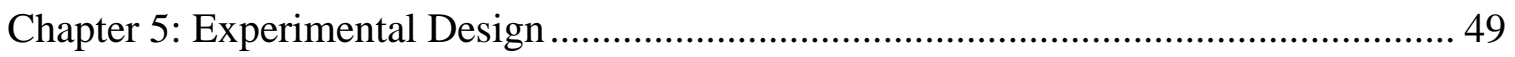

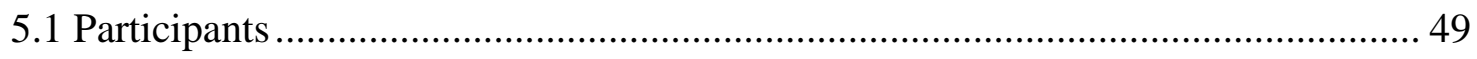

5.2 Case Materials, Design and Manipulations ............................................................. 50 


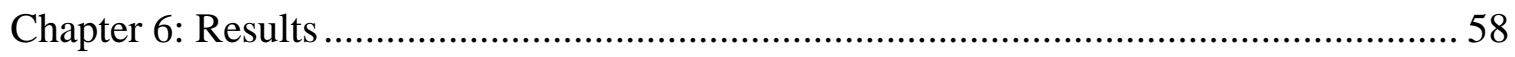

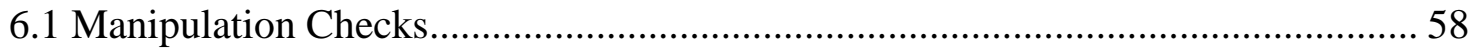

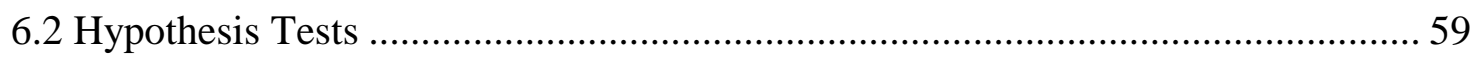

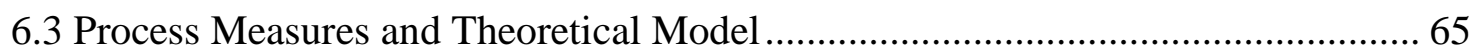

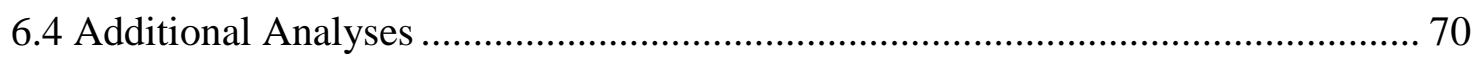

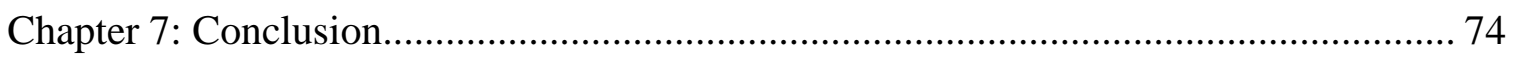

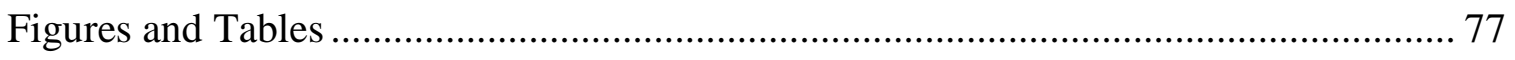

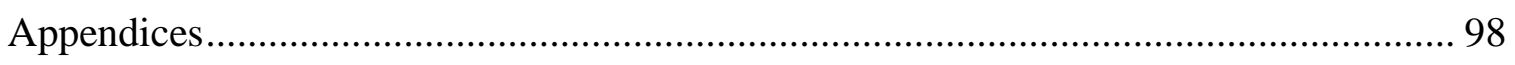

Appendix A: Examples of Narrative Disclosures about Acquisitions ........................... 99

Appendix B: Experimental Materials........................................................................ 100

Appendix C: Intangible Assets Categorized as Hard, Semi-Soft, and Soft ................ 105

Appendix D: Dependent Measures ………………….............................................. 106

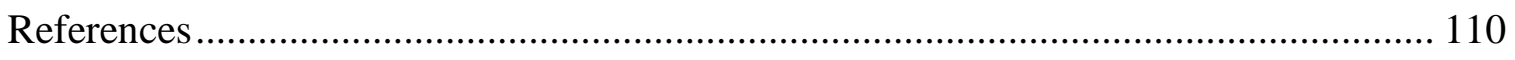

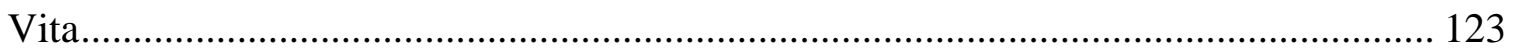




\section{List of Tables}

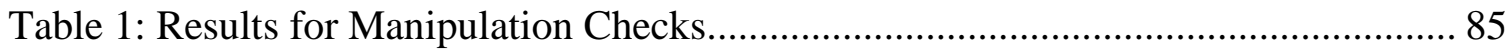

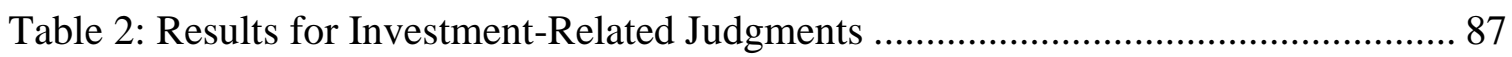



Table 4: Pre- and Post-Manipulation Investment-Related and Likelihood to Benefit

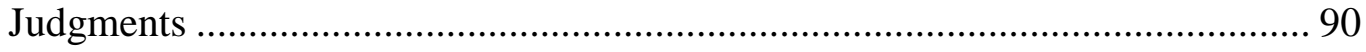

Table 5: Other Simulation Process Measures .......................................................... 92

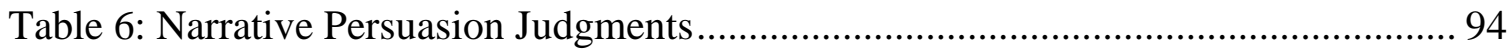

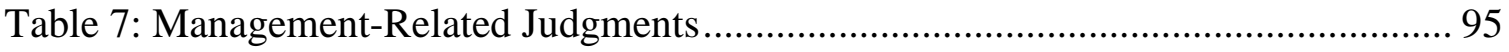

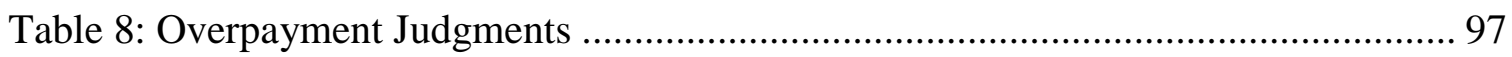




\section{List of Figures}

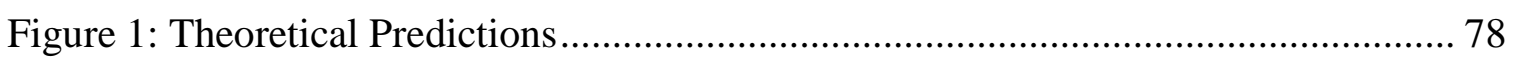

Figure 2: Theoretical Model ................................................................................... 80

Figure 3: Results for Post-Manipulation Investment-Related Judgments ......................... 81

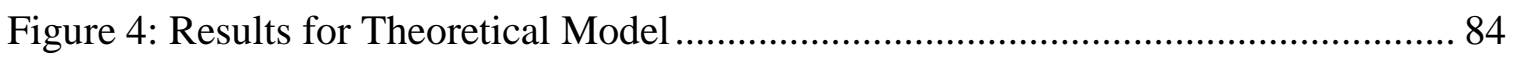




\section{Chapter 1}

\section{Introduction}

Financial reporting standards in the U.S. require that for business combinations, acquiring companies must identify and recognize all identifiable intangible assets acquired, based on their estimated fair values (FASB 2007). ${ }^{1}$ Intangible assets include not only goodwill but also those assets that lack physical substance or financial embodiment and are identifiable by being separable or arising from contractual or other legal rights (FASB ASC Master Glossary; Lev 2001; FASB 2007). ${ }^{2}$

Firm managers have communicated concerns about the cost and complexity of separately identifying these intangibles as well as the reliability of their measurement (FASB 2013). Investors also have expressed mixed views on whether these intangible assets are relevant to their decisions (FASB 2014a). Recognizing the aforementioned issues, standard setters are now considering the costs and benefits of separately identifying and recognizing identifiable intangible assets in business combinations (FASB 2013, 2016), as well as possible alternative accounting treatments for such acquired intangible assets (FASB 2014a, 2014b, 2016).

In this thesis, I investigate how separately identifying intangible assets acquired in business combinations affects investors' judgments about the acquisition. I focus on the effect of separate identification of intangible assets, because identification is a necessary

\footnotetext{
${ }^{1} \mathrm{~A}$ business combination is a transaction or other event in which an acquiring company obtains control of one or more other businesses (FASB ASC Master Glossary).

${ }^{2}$ In this thesis, the term 'intangible assets' refers to non-goodwill intangible assets only, and the terms 'intangibles' and 'intangible assets' are used interchangeably.
} 
first step before measurement and recognition of those assets. ${ }^{3}$ I also investigate how an accompanying narrative provided by the acquiring company might interactively influence the effect of separate intangible identification on investors' judgments.

My study is important for at least three reasons. First, intangible assets are a key driver of both the U.S. and global economies in the twenty-first century where patents, brand names, and other non-physical assets have become key to firm and economy growth (Lev 2001). These intangibles are an important reason why firms acquire other companies. A recent study of business combinations by a global investment bank reveals that goodwill and other intangible assets combined constitute over 70 percent of all acquired assets. Specifically, on average, over 35 percent of the purchase consideration per business combination is allocated to intangible assets, while another 36 percent is allocated to goodwill. The dollar values associated with these percentages are quite large and, per business combination transaction, average around $\$ 498$ and $\$ 512$ million for goodwill and intangible assets, respectively (Griffin, Miles, Stefanowski, and De Simone 2017). Another recent industry report by an international advisory group indicates that U.S. companies are accumulating alarmingly high goodwill balances onto their financial statements. In the year of 2015 alone, over $\$ 458$ billion of goodwill was added to U.S. companies' balance sheet (Nunes, Roland, Todorova, and Warner 2016). As mergers and acquisitions have pushed to an all-time high, surpassing the pre-crisis peak in 2007 (Fontanella-Khan and Massoudi

\footnotetext{
${ }^{3}$ To identify an intangible asset is to acknowledge the existence of an identifiable intangible asset (FASB 2001b, 2007). After identification, an intangible asset would be measured at its acquisition-date fair value (FASB 2007). After measurement, recognition would occur; recognition is the process of making a journal entry to formally incorporate an intangible asset into the financial statements (FASB 1984, 2007). Thus, an intangible asset cannot be recognized without first being identified and then measured.
} 
2015), understanding how investors use information about intangibles acquired in business combinations becomes ever more important.

Second, as noted earlier, standard setters are now re-thinking the current accounting for business combinations and acquired intangible assets (FASB 2013, 2014b, 2016). They have considered alternatives that range from separately identifying and recognizing all intangible assets to subsuming some or all intangible assets into goodwill. By providing scholarly evidence on how two of these alternatives affect investors' judgments about the acquisition, my study provides timely insights to their deliberations.

Third, limited research exists regarding the investor consequences of separately identifying intangible assets in business combinations. To my knowledge, no prior research has studied the identification effect in an isolated fashion. Most of the prior research in this area focuses on the effect of intangible assets dollar balances, which involves both identification (i.e., whether firms subsume intangibles into goodwill) and measurement (i.e., how firms value intangible assets) issues. For example, while research shows that investors react negatively to abnormally high goodwill balances from business combinations (Paugam, Astolfi, and Ramond 2015), it is unclear whether this reaction is caused by managers' strategic undervaluation of intangible assets (i.e., a measurement issue) or subsuming intangible assets into goodwill (i.e., an identification issue). Thus, by providing scholarly evidence on how identifying intangible assets influences investors' judgments, my study provides new insights to the literature.

To theorize about the effect of separate intangibles identification on investors' judgments about a business acquisition, I rely on what psychology research calls the 
simulation heuristic (Kahneman and Tversky 1982). This heuristic occurs when individuals think about, or mentally simulate, how an event could occur (Thompson, Hamilton, and Petrova 2009) and then use the ease of that simulation to make predictive judgments about the event (Sloman and Lagnado 2015). Drawing on this theory, I hypothesize that if firms separately identify intangible assets (versus subsume them within goodwill), investors will find it easier to simulate how an acquiring company can benefit from the business acquisition. Moreover, I hypothesize that the ease of this simulation will be moderated by the type of accompanying narrative that the acquiring firm provides about their acquisition, although the direction of that moderation is unclear ex ante.

To elaborate, I predict that the effect of providing a strategic narrative- one that discusses the strategic reasons for the acquisition such as goals, plans to achieve such goals, and expected benefits-will have either a complementary or substitutional effect on investors' reactions to separate identification of intangibles. If the effect is complementary, then the effect of separately identifying intangibles on investors' judgments will be even greater when a strategic narrative also is provided. In contrast, if the effect is substitutional, then investors' judgments will be positively affected by the presence of either separately identifying intangibles or a strategic narrative. ${ }^{4}$

To test my hypotheses, I use an experiment with a $2 \times 2$ between-participants design. An experiment allows me to manipulate the variables of interest while controlling other

\footnotetext{
${ }^{4}$ I define complementary and substitutional effects as follows: if two factors are complementary, then the effect of either factor will be stronger when the other factor also is present. Some might refer to the complementary effect as an amplifying effect. On the other hand, if two factors are substitutional, then the effect of either factor will be weaker when the other factor also is present. Some might refer to the substitutional effect as an attenuating effect.
} 
factors (Libby and Luft 1993; Kadous and Zhou 2016). For example, by focusing on the identification of intangible assets without the contaminating effects of measurement and recognition, I can create a setting in which to isolate the effects of separate identification of intangibles. An experiment also allows me to collect additional process measures about ease of simulation - measures that are difficult to infer from archival data.

My two manipulations are: (1) whether intangible assets are (versus are not) identified separately from goodwill, and (2) whether the acquiring company provides a strategic (versus non-strategic) narrative when announcing the acquisition. The intangibles separately identified from goodwill are six assets that are typically difficult to sell or license independent of other assets of a business, making their usefulness and relevance more questionable to investors (FASB 2014a, 2016). The strategic narrative describes the goal, benefits, and mechanism by which the acquired assets will be useful to the acquiring firm, presumably facilitating the success of the acquisition. The non-strategic narrative merely contains positive descriptions of the target and the acquiring companies. Both types of narratives are currently found in practice.

Results show that compared with subsuming intangibles into goodwill, separately identifying intangible assets enables investors to more easily envision how an acquiring company can benefit from an acquisition. Judging that a beneficial acquisition outcome is more likely, investors have more favorable judgments about the valuation, future prospects, and investment desirability of the acquiring company. However, providing a strategic narrative moderates this effect in a direction consistent with a substitutional effect. That is, investors have more favorable judgments about the outcome of the acquisition when either 
the intangibles are separately identified or when a strategic narrative is provided. The positive effect of either factor on investors' judgments is smaller when the other factor is also present. This substitutional nature of the effects suggests that having either piece of information can significantly affect how investors predict the acquiring company's postacquisition performance.

My study makes several contributions. First, my findings can provide insights to standard setters on how to treat acquired identifiable intangible assets in business combinations. At the June 2016 meeting of the Financial Accounting Standards Advisory Council, members expressed concerns over the relevance of recognizing acquired intangible assets on the balance sheet (FASAC 2016). My results suggest a previously undocumented effect associated with separate identification of intangible assets: it alone can enable investors to better envision an acquiring company's potential future actions, almost as if they are explicitly informed about the company's strategic intentions of such an acquisition. For business combinations where the availability of information often is asymmetric (i.e., managers have the informational advantage as they hold a significant amount of private information), this ability to infer strategic planning information facilitated by separate identification of intangibles is likely useful for investors to predict how an acquiring company might perform post-acquisition. Thus, my findings provide evidence supporting the information relevance of identifying acquired intangible assets. As debate continues regarding whether certain intangible assets should be subsumed into goodwill (FASB 2017), my results should be of interest to standard setters in their efforts to resolve this issue. 
Second, my study adds to the limited research on how separate identification of intangible assets influences investors' evaluations of business combinations. As mentioned before, most of the prior research in this area focuses on the effect of intangible assets balances, which combines the effect of both identification (i.e., whether firms subsume intangibles into goodwill) and measurement (i.e., how firms value intangible assets) issues (e.g. Paugam et al. 2015). By isolating the effect of separate intangible identification, my study broadens the literature on the consequences of presenting separate information about intangibles.

Third, my study provides the new insight that the accounting for a business combination may interact with how the transaction is described by management. As information about business combinations is more opaque than most other corporate transactions (Officer, Poulsen, and Stegemoller 2009), additional disclosures about the transaction, especially those that convey information about the strategic reasons for the transaction, are particularly important to investors. My findings show that providing investors with such disclosures, alone or along with separate identification of the acquired intangible assets, can help investors understand the companies' strategic intentions, foresee the favorableness of the acquisition decisions, and project the companies' future performances.

The remainder of this dissertation is organized as follows. Chapter 2 reviews the evolving concept of goodwill and intangible assets, including an overview of the history of goodwill and intangibles accounting, a discussion of the current debate about goodwill and intangibles, and related literatures. Chapter 3 discusses the narrative disclosures for 
business combinations, including an overview of disclosure requirements, a discussion about strategic versus non-strategic narratives, and the related literatures. Chapter 4 outlines the theory and hypotheses development. Chapter 5 discusses the experimental design. Chapter 6 reports the results of the experiment. Chapter 7 provides concluding remarks. 


\section{Chapter 2}

\section{The Evolving Concept of Goodwill and Intangibles}

The purpose of this chapter is to provide a historical overview of the accounting for goodwill and intangibles. In doing so, it should become apparent that over the decades, standard setters have struggled with how to account for goodwill as well as intangibles, with a number of issues particularly prominent: (1) the definition of goodwill-including whether it exists as an asset, what it is comprised of, and whether intangibles should be subsumed within it, (2) the useful life of goodwill (i.e., whether and how to amortize it), (3) whether and how to recognize internally generated intangibles, and (4) the measurement method for externally acquired intangible assets (i.e., allocation of purchase price versus fair value assignment). It is precisely standard setters' struggle with how to account for goodwill and intangibles that makes my thesis relevant to standard setters. That is, by providing scholarly evidence on how investors think about a business combination that involves goodwill and other intangible assets, my study provides important input to standard setters as they continue to debate about whether to include certain acquired intangibles into goodwill.

This chapter is organized as follows. First, I provide a historical summary of the accounting for goodwill and related intangibles. Next, I discuss the key issues of the current debate about the standards for intangible assets. Last, I review the related literature.

\subsection{History of Accounting for Goodwill and Intangible Assets}

Accounting for goodwill and intangible assets changed dynamically over the past century. The definition of goodwill has morphed over time, and the accounting treatment 
of goodwill adapted accordingly. As noted above, several issues were particularly prominent: (1) the definition of goodwill (whether it exists and, if so, what is included in it), (2) the useful life of goodwill, (3) whether and how to recognize internally generated intangibles, and (4) the measurement method for externally acquired intangible assets (i.e., allocation of purchase price versus fair value assignment).

The concept of goodwill first started to appear in the late 19th century. With increasing separation of a firm's ownership from its management due to increasing corporation sizes, "the development of goodwill paralleled the development of business enterprise" (Hughes 1982, pp. 18-19). At first, the definition of goodwill was an estimated amount representing the excess earning power of the firm (Freeman 1921). At the time, this excess earning power had four possible sources: externally acquired via an acquisition of another company, internally generated via advertising expenses, early operating losses, and arbitrary writeups of certain assets (Garcia 2007). Goodwill was capitalized with frequent subsequent write-ups in practice. The investing public criticized this practice due to the questionable methods and arbitrary assumptions such as number of useful years and discount rate used in valuation models (Hatfield 1909; Freeman 1921).

For the next thirty or so years, the debate continued over goodwill and its useful life. Some argued that goodwill gave rise to an exaggerated firm value and, thus, should be immediately written off (Dicksee and Tillyard 1906). Others argued that a gradual and systematic amortization was more consistent with the valuation methods based on the capitalization of a finite series of excess earnings (Hatfield 1909). Despite these arguments, in 1913 the U.S. tax administration adopted a position that goodwill was to be neither 
amortized nor written-off, due to the unpredictability of its duration (Brazell, Dworin, and Walsh 1989; Garcia 2007). Thus, at that time, goodwill (as well all intangible assets) had indefinite useful life on balance sheets.

After the Great Depression, the creation of the Securities Exchange Commission (SEC) in 1934, and a shift towards more accounting conservatism in the post-financial-collapse era, the valuation basis of goodwill shifted to historical cost. In 1944, the Committee on Accounting Procedure (CAP) published Accounting Research Bulletins (ARB) No. 24, Accounting for Intangible Assets. In this Bulletin, the cost principle was officially established for goodwill valuation, which forbade the recognition of internally-generated goodwill, capitalization of early losses, and arbitrary write-ups. As a result, of the original four possible sources for goodwill, only purchased goodwill remained recognizable.

In ARB No. 24, standard setters also separated intangible assets into two types: (a) those that had a finite useful life limited by law, regulations, agreement, or nature (such as patents, copyrights, and licenses), and (b) those that had no such limited term of existence with no indication of limited life (such as goodwill, trade names, and perpetual licenses). While the cost of type (a) intangibles was amortized, the cost of type (b) intangibles was carried continuously unless its term became evidently limited, or its value became impaired. For type (b) intangibles (e.g. goodwill), firms also had the discretion to either amortize it over a reasonable period of time (with the approval of the shareholders) or write it off completely against any existing capital or earned surplus, even though the value of the asset was unimpaired. Though goodwill appeared to have an indefinite life, this regime ultimately allowed firms to have discretion in deciding the useful life of goodwill. 
Therefore, companies had considerable amount of discretion over accounting treatment of goodwill in this period.

A decade later, ARB No. 40 was issued by the CAP. This Bulletin introduced two types of business combinations: (1) pooling-of-interests, and (2) purchase. When a business combination was a purchase type, the assets acquired were recognized on the financial statements of the acquirer at fair value, and purchased goodwill was recognized (CAP 1950). In contrast, when a business combination was a pooling type, no purchased goodwill was recognized.

The idea of pooling was used for business combinations between companies of similar sizes. The notion was that they would be "pooled" together as one new entity, instead of one purchasing the other. Accordingly, assets of both companies were retained together in the new entity's balance sheet and, thus, no purchased goodwill would be recognized. This method was a fundamental challenge to the goodwill definition. Goodwill would not exist for two firms merging together, because no one acquired the other (CAP 1950). As a result, with the introduction of the pooling method, the existence of goodwill as an asset became dependent on the type of business combination. This dependency was further exacerbated with the weakened criteria distinguishing pooling-of-interests from the purchase method which was later introduced by ARB No. 48 and which allowed firms more discretion for treating any combination involving a stock-for-stock exchange as either pooling or purchase (CAP 1957).

In 1959, the Accounting Principles Board (APB) was formed to replace the Committee on Accounting Procedure. The Board published Accounting Principles Board Opinions 
(APB) No. 16 and 17 in 1970 to amend the previous accounting standards on business combinations and intangible assets (APB 1970a, 1970b). APB No. 16 did not allow a practice of accounting that had emerged from the prior standards - namely, the "part purchase, part pooling" practice — and required one accounting method to be applied for the entire business combination. The Board also further clarified the conditions for pooling versus purchase method (APB 1970a, paragraphs 45 to 48). As a result of the clarification of conditions, any business combinations that did not qualify for the pooling method had to use the purchase method for the entire transaction. These changes restricted firms' discretion over whether to recognize goodwill, and seemingly solidified the existence of goodwill as an asset.

Further, the Board required all identifiable assets acquired (including contracts, patents, franchises, customer and supplier lists, and favorable leases), either individually or by type and whether or not shown in the financial statements of the acquired company, to be allocated a portion of the purchase price of the acquired company, based on their fair values at the date of acquisition (APB 1970b). ${ }^{5}$

In addition, it was the Board's opinion that all intangibles assets should have a finite useful life. Because goodwill was the most common unidentifiable intangible asset, its carrying amount on the balance sheet would almost inevitably become zero at some future date. The concern of the Board was that the end of goodwill's useful life would be set arbitrarily by companies. As a result of this potential problem, the Board itself arbitrarily

\footnotetext{
${ }^{5}$ In cases when there might be a "negative goodwill" - when the fair values of the identifiable assets acquired less liabilities exceeded the purchase price - companies had to proportionately reduce the values allocated to assets, so that the purchase price remained as the recognized total value of all acquired net assets (APB 1970a). That is, for bargain purchases, the allocated values to intangible assets were not equivalent to their fair values.
} 
settled on a maximum of forty years for goodwill amortization with the straight-line amortization amount charged to current-period earnings (APB 1970b). This accounting treatment of goodwill was a drastic change from standard setters' previous approaches. Though amortization was always an option for companies (since ARB No. 24), goodwill amortization had never been required. Thus, at this point in time, companies had no alternatives to avoiding goodwill amortization (other than their transaction qualifying for the pooling-of-interest combination method). The view that an arbitrary useful life was a "necessary evil" was a departure from previous discussions on goodwill valuation. In a sense, it resonated with much earlier scholars who argued that goodwill did not exist in perpetuity (i.e., Guthrie 1898).

Over the next thirty years, the debate continued about the appropriate accounting for goodwill. With the formation of a new standard setting board-the Financial Accounting Standards Boards (FASB) — in 1973, views about the appropriate accounting measurement basis started to shift again. Specifically, the issuance of Statement of Financial Accounting Concepts (SFAC) No. 7 on using present value in accounting measurement indicated a shift from focusing heavily on historical cost measurement to fair value measurement (FASB 2001a). Despite this new focus, it nevertheless took the FASB five years from 1996 to 2001 to reform accounting for goodwill and intangible assets, as outlined in Statement of Financial Accounting Standards (SFAS) Nos. 141 and 142 (FASB 2001b, 2001c).

Under SFAS No. 142, the pooling method was completely abolished (FASB 2001c), leaving only the purchase method for business combinations. The elimination of the pooling method was a result of FASB's concerns over the conceptual deficiencies and 
practical abuses of the pooling method (FASB 1998), political pressure from SEC's concerns over pooling misuse (Turner 1999), and professionals" judgments that "few if any combinations are consistent with the conceptual view of a pooling-of -interests" (Wahlen et al. 1999, p. 300). ${ }^{6}$ By eliminating the pooling method, now all business combinations would necessarily have the potential to have goodwill recognized on the balance sheet. Indeed, the new FASB standard effectively established goodwill as an asset.

Under the same regime, SFAS 142 also returned to the notion that goodwill had an indefinite useful life and, thus, should no longer be subject to yearly amortization (FASB 2001c). This treatment was initially against FASB's intention, as they proposed to require amortization for all acquired goodwill (FASB 1999). However, this proposition met with strong oppositions among the lobbying firms, joined by some members of Congress (US House 2000; US Senate 2000). The FASB then proposed to abolish goodwill amortization and stated in SFAS 142 that goodwill and intangible assets were not wasting assets per APB 17, and should have indefinite useful lives with an annual impairment test (FASB 2001c). Severe concerns were raised, though, over the unverifiable fair-value estimates and assumptions that would necessarily be used in goodwill impairment tests (FASB 2001d; Wahlen et al. 1999; AAA 2001). Indeed, some scholars viewed the elimination of goodwill amortization as the FASB's compromise to appease those who wanted to keep the pooling-

\footnotetext{
${ }^{6}$ The latter view was supported by academic research providing evidence that on average, the accounting acquisition premium - the excess of the offer price over the book value of the target firm's net assets - was larger for pooling transactions than for purchase transactions (e.g. Robinson and Shane 1990; Nathan 1988). This difference in acquisition premia directionally contradicted the rationale for the pooling method, leaving the larger acquisition premia off the financial statements (due to use of the pooling method). Therefore, in 1999, the Financial Accounting Standards Committee of the American Accounting Association concluded that there was "no academic research that supports the use of the pooling method of accounting for business combinations" (Wahlen et al. 1999, p. 301).
} 
of-interest method. That is, the elimination of goodwill amortization and the use of impairment testing arguably gave companies more discretion over goodwill via the subjectivity involved in impairment tests, as compared with the more rigid requirement of amortization (Ramana 2008).

For intangible assets, the adoption of SFAS 141 and later its revision SFAS 141R marked a significant change in how intangible assets were to be recognized and measured. Prior to SFAS 141, little attempt was made to identify specific intangible assets - virtually all intangibles were folded into goodwill (Halsey and Hopkins 2017). Per SFAS 141R, though, an intangible asset was identifiable (and thus, to be measured and recognized) if it was either (1) separable, or (2) arose from contractual or other legal rights, regardless of whether those rights were transferable or separable. Most interestingly (and pertinent to this thesis), this broad definition allowed the recognition of many more intangible assets compared with the previous regimes.

Additionally, prior to SFAS 141R, business-combination accounting was a process of first determining the purchase price and then attempting to allocate the purchase price to the acquired assets (FASB 2001b). This cost-allocation process resulted in some assets and liabilities being valued at amounts other than their fair values at the acquisition date, because the cost to be allocated necessarily included acquisition-related costs (i.e., costs incurred to effect the acquisition). These acquisition-related costs were generally material, and thus, this cost-allocation process did not capture the essence of fair value measurement (FASB 2001b, 2007). 
The issuance of SFAS 141R addressed this issue in two ways. First, SFAS 141R required acquisition-related costs to be recognized separately from the actual acquisition. That is, those costs were to be expensed in the period incurred (FASB 2007). Second, SFAS $141 \mathrm{R}$ stated that their objective was to recognize and measure the acquired identifiable net assets of the target at acquisition-date fair value (FASB 2007). ${ }^{7}$ This requirement of fair value measurement over the previous purchase price allocation process revealed that standard setters fundamentally believed that: (1) fair value measurement of individual identifiable intangible assets was sufficiently reliable so that separate recognition of those intangibles at acquisition had merit, and (2) identifiable intangible assets valuation was independent from the total amount paid for acquisition in a business combination (Halsey and Hopkins 2017). ${ }^{8}$

From an international perspective, the requirements for accounting for goodwill and intangible assets are largely the same as those in the United States. Specifically, in 2012, the International Accounting Standards Board (IASB) issued International Financial Reporting Standards (IFRS) No. 3 (IASB 2012). Like the accounting in the United States, IFRS 3 requires the recognition of all identifiable assets at their acquisition-date fair values. Any difference between the fair value of the consideration transferred to effect the business combination and the net identifiable assets acquired is to be recognized as goodwill. Again, similar to the standards followed in the United States, goodwill has indefinite useful life and is subject to a yearly impairment test (i.e., is not subject to amortization) (IASB 2012).

\footnotetext{
${ }^{7}$ Per SFAS 141R, companies would recognize a gain for any "negative goodwill" instead of reducing the values assigned to the acquired assets (FASB 2007).

8 The "purchase method" terminology, which was previously referenced in SFAS 141, was officially replaced by the reference of "acquisition method" in SFAS 141R (FASB 2001b, 2007).
} 
In 2014, IASB issued International Accounting Standard (IAS) No. 38 to prescribe the accounting treatment for intangible assets (IASB 2014). IAS 38 has one fundamental difference from SFAS 141R. Per IAS 38, an intangible asset should be recognized if and only if: (a) it is probable that the expected future economic benefits that are attributable to the asset will flow to the entity, and (b) the cost of the asset can be measured reliably (IASB 2014). Though the two standards have the same identifiability requirements (i.e., separable or contractual/legal rights), this reliability of measurement recognition requirement per IAS 38 means that fewer intangible assets are recognized under IAS 38 compared with SFAS 141R. ${ }^{9}$

Although goodwill now has indefinite useful life under U.S. and international standards, there is still a considerable amount of support for goodwill amortization domestically and internationally. One common view is that goodwill acquired in a business combination is supported and replaced by internally generated goodwill over time. Therefore, it is argued that amortization may be more appropriate and useful to investors (e.g. EFRAG 2015, IASB 2015), particularly because of concerns over the reliability of impairment model assumptions as well as the cost and complexity associated with impairment testing (AAA 2001; PCC 2013). Not surprisingly, these concerns over reliability, cost, and complexity also exist for intangible assets as well (FASB 2013).

\footnotetext{
${ }^{9}$ Though SFAS 141R discusses measurability (which is largely equivalent to the reliability criterion in the international standard), it is not a formal recognition requirement (FASB 2007). SFAS 142 states that for an intangible asset to be recognized as asset, it must meet the four fundamental asset recognition criteria per the Statement of Financial Accounting Concept No. 5, which include sufficient reliability of measurement (FASB 1984, 2001c). However, this discussion is part of the basis for conclusions, not the actual standard.
} 
As a partial solution to address these concerns, the FASB issued Accounting Standards Updates (ASU) 2014-02 and 2014-18. These updates are applicable only for private companies. Per these updates, private companies can now elect (but are not required to follow) an accounting treatment that allows them to minimize the costs they incur in impairment testing. Specifically, they are allowed to amortize goodwill for up to 10 years and, key to my thesis, allowed to subsume into goodwill certain identifiable intangible assets, such as customer-related intangible assets and noncompetition agreements (FASB 2014a, 2014c). For private companies that elect to subsume into goodwill the acquired intangible assets, they must also adopt the goodwill amortization method. ${ }^{10}$ This discretion that private firms now have is strikingly similar to the situation back in 1944, when ARB No. 24 allowed firms to amortize their goodwill with approval of their stockholders.

In sum, there is a fairly long history of frequent changes in the accounting for goodwill and intangible assets. Perhaps not surprisingly, the debate about the appropriate accounting treatment for goodwill and intangibles continues, and it is this current debate that is particularly relevant to my research question in this thesis. The next subsection discusses the key issues of this current debate and the potential alternatives that standard setters have considered recently.

\subsection{Debate about the Current Accounting Standards for Intangible Assets}

Current accounting standards require all public companies to recognize any identifiable intangible assets that are purchased as part of a business combination transaction. These

\footnotetext{
${ }^{10}$ Companies that adopt goodwill amortization do not have to elect to subsume the intangible assets (FASB 2014c).
} 
identifiable intangibles are recognized separately from goodwill. According to SFAS 141R (ASC 350), an intangible asset is identifiable if it is either: (1) separable, or (2) arises from contractual obligations or other legal rights, regardless of whether those rights are transferable or separable. Currently, five categories of identifiable intangible assets are recognized within the financial statements: marketing-related, customer-related, artisticrelated, contract-based, and technology-based (FASB 2007, pp. 41-48). Not all intangibles are recognized, though. For example, human capital and organizational structure, which can be important resources to the acquiring companies, currently remains as part of goodwill (Lev 2001).

Although current U.S. accounting standards require all public companies that engage in business combination transactions to recognize any identifiable intangible assets (FASB 2007), there is still a considerate amount of debate over whether this treatment is appropriate. Due to perceived high cost and complexity involved in identifying and measuring intangible assets, many firm managers oppose separate recognition of intangibles in business combinations. The investor community, though more supportive of separate recognition, has mixed views about the relevance of separately recognized intangible assets.

From the perspective of public companies, many managers argue that separate recognition of intangibles is too costly and complex to be worthy of the effort to recognize separately. Specifically, firm managers maintain that both the identification and measurement of intangible assets are more costly than that for tangible assets, due to difficulty in testing assumptions such as the cost of capital (Roland and Kernick 2014). 
Firms also incur significant costs associated with hiring external valuation experts to identify and value the intangibles, and incur higher audit fees to verify the existence and valuation of those intangibles (FASB 2013). Moreover, company managers indicate that identifying intangible assets is a noisy process with uncertainties and errors, which may prevent correct valuation by investors (e.g. Francis and Schipper 1999; Kanodia, Sapara, and Venugopalan 2004; Skinner 2008).

The FASB has acknowledged the validity of the cost and complexity issues. In its PostImplementation Review (PIR) for SFAS 141R, the FASB concludes that: "the FASB did not anticipate this level of complexity...costs to apply Statement 141R are much higher than the Board expected... the standard did not improve reliability and representational faithfulness of business combination information." The review further notes that the Board should improve the consideration of costs and benefits for requiring recognition of intangible assets (FASB 2013, pp. 11, 12 and 15). In an effort to partially address the cost and complexity issues, U.S. standard setters have recently allowed an exception to SFAS 141R, but only for private companies (FASB 2013; FASB 2014a; PCC 2014), as previously discussed. Those companies are allowed (but are not required) to subsume into goodwill certain intangible assets, such as customer-related intangibles and non-compete agreements (FASB 2014a).

In addition to the cost and complexity issues, identifying and recognizing intangible assets can have a negative impact on the earnings of these companies through their required amortization. Not surprisingly, such an impact can adversely affect the managers who work for these firms. Lower earnings often lead to lower firm manager compensation (Shalev, 
Zhang, and Zhang 2013). Company managers can avoid this situation by allocating more of the acquisition purchase price to goodwill instead of identifiable intangibles (Zhang and Zhang 2017). Such behavior is not consistent with the spirit of current accounting standards.

Although such behavior is not consistent with current accounting standards, my conversations with several firm managers at Fortune 500 companies reveal that there are indeed such incentives to subsume intangible assets into goodwill. ${ }^{11}$ The managers with whom I spoke indicated that such accounting would be difficult for auditors to identify, as the total amount allocated to goodwill in an acquisition is typically allocated to different reporting units post acquisition, thereby making it less likely that such accounting would be detected. ${ }^{12}$ Indeed, one manager stated, "We just throw it all in goodwill-it all disappears afterwards anyway." This behavior is consistent with prior research which documents that compared with pre-SFAS 141 when both goodwill and intangible assets were amortized, managers in the post-SFAS 141 era allocate more of the purchase price to goodwill relative to intangible assets (Zhang and Zhang 2017), especially when those managers have earnings-related incentives (Shalev, Zhang, and Zhang 2013). ${ }^{13}$

\footnotetext{
${ }^{11}$ These conversations occurred during a Financial Accounting Standards Advisory Council (FASAC) meeting in 2016. To protect their anonymity, I cannot reveal more details about the individuals or their companies.

${ }^{12}$ For impairment testing, auditors can test whether the goodwill balance at each reporting unit is overstated or whether any recognized intangible asset valuation is overstated (FASB 2011, 2012). Arguably, it is difficult for auditors to identify and test any unrecognized intangible assets subsumed into goodwill, especially after goodwill dissipates into different reporting units, unless there exists an extensive paper trail indicating the existence of identifiable intangible assets.

${ }^{13}$ If the business combination transaction is taxable, subsuming intangibles into goodwill does not affect the tax deductibility of the acquired assets. Per IRS Section 197, goodwill and other intangible assets are all subject to tax amortization for up to 15 years (IRS 2016). If the transaction is not taxable, both goodwill (nonexistent for tax purposes) and intangible assets will have zero tax basis, with the assumption that the target companies cannot and do not recognize internally-generated intangible assets. Thus, subsuming intangibles into goodwill does not impose tax disadvantages onto companies.
} 
While many firm managers oppose separate recognition of intangible assets from business combinations, the investor community has mixed views about the relevance of identified intangible assets-with some favoring separate recognition and others not favoring such treatment. Investors generally agree that intangible assets with certain attributes, such as those that are separately exchanged, legally protected, separately transferable, and provide discrete cash flows, are more relevant than other intangibles (PCC 2013, 2014; FASB 2014a). For example, analyst reports about two recent business combinations - namely, Microsoft's acquisition of Nokia and Lenovo's acquisition of Motorola Mobility — indicate that the acquired licenses and patents were key factors that the analysts considered when evaluating the opportunities and risks of the transactions (Weiss, Gorham, and Lowe 2013; Pitz et al. 2014). This viewpoint is consistent with prior research on the value-relevance of internally generated intangible assets (see Wyatt 2008 for a more-comprehensive review of this literature). Briefly, this research reports that certain intangible related costs, such as software and research and development costs, have positive associations with stock prices, presumably because they provide insights about the underlying economics of the firm (e.g. Lev and Sougiannis 1996; Aboody and Lev 1998; Wyatt 2005; Wyatt 2008).

On the other hand, some investors (and lenders) claim that they do not find relevant the intangible asset information. They maintain that they treat intangible assets no differently than goodwill (PCC 2014; FASB 2014a). According to my conversations with multiple partners from several value investment and private equity firms, some analysts do not consider identified intangibles crucial to their analyses. For example, one partner stated 
that "goodwill and other intangibles are the same to us. We combine them into one measure for our models." Many users also argue that the relevance of the fair value of intangible assets significantly diminishes as time elapses after the acquisition date (PCC 2014; FASB 2014a, 2014b). In sum, some investors argue that separate identification and recognition of intangible assets is costly with little benefit to the relevance of financial reporting, while others think that information about certain intangible assets is relevant and decision useful (PCC 2013, 2014; FASB 2014b).

Recognizing that the intangible issue is still very much unresolved, U.S. standard setters continue to debate this issue. To date, they have considered various alternative accounting treatments for acquired intangible assets (FASB 2014a, 2014b, 2016). These alternatives range from separately identifying and recognizing all intangible assets (i.e., subsuming no intangibles into goodwill), separately identifying and recognizing certain intangible assets from goodwill (i.e., subsuming some intangibles into goodwill), to separately identifying and recognizing no intangible assets (i.e., subsuming all intangible assets into goodwill) (FASB 2014a, 2014b, 2016).

Among all of the alternatives considered, one alternative is particularly interesting and most relevant to my research question —namely, the one that allows firms to subsume all intangibles into goodwill, but with the added requirement that they provide a footnote disclosure with a list (but not measurement) of the acquired identifiable intangible assets 
(FASB 2014b). ${ }^{14}$ This alternative could reduce managers' struggle with measurement issues and the associated costs - the main reasons why managers and investors question the necessity and usefulness of separate intangible information. At the same time, this alternative would allow investors to obtain information about the types of intangible assets acquired.

With standard setters' consideration of allowing firms to subsume some or all acquired intangible assets into goodwill, providing scholarly evidence on the potential consequences of subsuming becomes important. The next subsection reviews the existing, limited literature related to these consequences in more detail.

\subsection{Related Literature}

Scholarly evidence on the consequences of separate identification of intangible assets in business combinations is scant. The limited research in this area focuses on the combined effects of identification, measurement, and recognition of goodwill and other intangible assets (i.e., asset dollar balances).

A recent paper by Paugam, Astolfi, and Ramond (2015) reports that the stock market reacts negatively towards abnormally high goodwill balances. Using their own constructed model to estimate expected goodwill, the authors find evidence consistent with the

\footnotetext{
${ }^{14}$ The proponents of the subsume-all alternative draw the comparison of subsuming intangibles into goodwill to the current accounting for property, plant, and equipment (PP\&E). That is, currently under U.S. accounting, a building is not required to be separated into its components such as heating, ventilation, roof, and so forth, with each of these separate components accounted for differently. Following this comparison, firms should not be required to separate goodwill into its different components, such as various acquired intangible assets. This argument fundamentally views intangibles to be components of goodwill. On the other hand, opponents counter-argue that a more appropriate analogy of goodwill to PP\&E would be to compare goodwill to land instead of a building. To allow subsuming of intangibles into goodwill would be analogous to allowing building, equipment, and other PP\&E assets to be subsumed into land (FASB 2014b). This argument fundamentally views intangibles as inherently distinctive assets apart from goodwill.
} 
argument that investors do not seem to react to the acquiring firm's over-allocation of the acquisition price to goodwill once that information is disclosed, although they do seem to update their own estimates related to whether the firms overpaid for the acquired companies. However, it is difficult to interpret the paper's findings in light of the question I investigate in this thesis, because the researchers are unable to determine whether the acquiring firm's actual over-allocation of the acquisition price to goodwill is a result of subsuming intangible assets into goodwill (i.e., identification and recognition issues) or earnings manipulation from undervaluation of the intangible assets fair values (i.e., a measurement issue). Therefore, from the limited research, the consequences of separately identifying intangible assets apart from goodwill in business combinations remain unclear.

While there is little research on the main issue of interest in this thesis, there is a relatively large literature on the value-relevance of internally generated intangible assets (see Wyatt 2008 for a more-comprehensive review of this literature). Briefly, this research reports that certain intangible related costs, such as software and research and development costs, have positive associations with stock prices (e.g. Lev and Sougiannis 1996; Aboody and Lev 1998). This line of research strengthens the argument that investors indeed care about firms' investment into intangible assets, and related information on such investment could be useful to investors' evaluation of the company.

Despite such investor interest in firm's intangible assets, the measurement of those intangible assets remains as a challenge for decision usefulness of recognized intangible assets. A recent working paper by McInnis and Monsen (2017) finds evidence consistent with the notion that measurement uncertainty could play a key role in the relationship 
between recognized intangible assets and acquiring companies' future operating income. Specifically, they find that for all business combinations from the years 2003 through 2014 (post-SFAS 141), balances of recognized intangible assets have no significant association with acquiring firms' future operating income. However, when isolating those acquirers with lower predicted measurement uncertainty, such as large acquirers or those acquirers with more expertise, the relationship between recorded intangible assets and future operating income becomes positive (McInnis and Monsen 2017). ${ }^{15}$ In sum, these findings strengthen the argument from some managers and investors who claim that separate recognition of intangible assets in business combinations is more problematic than beneficial, given that not all companies are able to reliably measure those intangibles.

Research also shows that managers and analysts care about the negative earnings impact associated with amortizing finite-lived intangible assets. Compared with pre-SFAS 141 when both goodwill and intangible assets were amortized, research shows that managers allocate more purchase price to goodwill relative to intangible assets in the postSFAS 141 time period (Zhang and Zhang 2017). Research also shows that managers that have earnings-related incentives tend to assign less value to intangible assets and more value to goodwill, ostensibly to avoid future negative impacts on earnings (Shalev, Zhang, and Zhang 2013). Using an experiment, research by Hellman, Anderson and Fröberg (2016) finds that analysts could be misled by the different purchase price allocation to goodwill versus intangible assets and have lower evaluations for firms that allocate more purchase

\footnotetext{
${ }^{15}$ These authors also find that the goodwill balances have a significant positive association with future operating income. This result is somewhat surprising given that goodwill acts as a catch-all category. One possible interpretation of this result is that measurement errors could be offsetting within goodwill, making it less prone to overall measurement error than identifiable intangible assets (McInnis and Monsen 2017).
} 
price to intangibles due to the negative earnings effect. Combined, these studies support the notion that managers have incentives to subsume intangible assets into goodwill.

Despite these incentives, granting managers the discretion to recognize (and even revalue) intangible assets does not always lead to negative consequences. In those circumstances where standard setters have allowed managers to have more discretion over recognizing intangible assets - such as during the pre-IFRS era in Australia when revaluation of intangible assets was allowed and amortization of intangible assets was not restricted - managers were encouraged to provide more relevant information to the market through recognition of intangible assets, thus, providing more insights about the underlying economics of their firms (e.g. Dahmash, Durand, and Watson 2009; Wyatt 2005). ${ }^{16}$ Multiple related studies find that after adopting IFRS, the value relevance of the recognized intangible assets seems to have declined for Australian-listed companies (e.g. Chalmers, Clinch, and Godfrey 2008; Ji and Lu 2014).

Yet, managers can still capitalize on what they see as discretion in the recognition of intangible assets. When managers have discretion over the choice regarding recognizing intangible assets, some of them base this choice on their insights into the underlying economics of their firms (Wyatt 2005), while others act on their specific incentives, such as capitalizing more intangible assets when their firms are failing (Jones 2011). Thus, though some managers provide more useful information to the market by wisely exercising

\footnotetext{
${ }^{16}$ Prior to the adoption of AASB 38 in 2005, Australian companies were permitted to both recognize and revalue internally generated identifiable intangible assets. During this pre-IFRS period, Australian firms were required to amortize goodwill over a period for up to 20 years (e.g. Dahmash et al. 2009; Ji and Lu 2014).
} 
their discretion over intangible recognition, others can take advantage of such discretion, making the overall outcome of giving managers more discretion unclear.

On a separate but related note, while little academic research exist on the specific issue of subsuming (or not subsuming) intangible assets into goodwill, there is an established literature on the effect of accounting information disaggregation, which is to separately present the underlying components of one or more items in financial statements (e.g. Maines and McDaniel 2000; Bonner, Clor-Proell, and Koonce 2014; Libby and Emett 2014). The disaggregation literature generally finds positive effects of disaggregation on financial statement users' judgments. Disaggregated information is perceived to be more accurate, credible, reliable, and transparent (Hirst, Koonce, and Venkataraman 2007; Barth and Schipper 2008; Libby and Brown 2012; Chen, Rennekamp and Zhou 2015). It can make certain information more salient (Elliott, Hobson and Jackson 2011; Clor-Proell, Proell, and Warfield 2014), especially when disaggregated information is coordinately presented with cohesive classification (Bloomfield, Hodge, Hopkins, and Rennekamp 2014). In certain contexts, such as leasing and hedging, disaggregation can communicate particularly useful information to investors by helping them distinguish between different types of leases (Hales, Venkataraman, and Wilks 2011) or different levels of strength for hedging relationships (Koonce, Leitter, and White 2017).

Nonetheless, all prior studies in the disaggregation literature include disaggregation of both the accounts and the dollar balances, thereby mixing identification and measurement. That is, no prior study has focused on the disaggregation of the accounts alone, which is the identification issue that is of interest to my research. It is unclear from prior literature 
whether the established effects of disaggregation can persist when the dollar balances are not provided. Thus, prior research on disaggregation does not address the question of whether and how separately identifying intangibles apart from goodwill, without also disaggregating the numerical balances, affects investors' judgments.

In sum, prior research shows that although information about intangible assets could be decision useful to investors (e.g. Wyatt 2008), the usefulness of such information is subject to measurement errors and uncertainties (McInnis and Monsen 2017). Managers are motivated to allocate more purchase price to goodwill instead of intangible assets (e.g. Shalev, Zhang, and Zhang 2013), and investors may not react to such over-allocation (Paugam, Astolfi, and Ramond 2015). Due to the notion that most prior literature related to intangibles and disaggregation combines the effects of both separation of accounts (i.e., identification) and dollar balances (i.e., measurement issues), prior studies do not answer unequivocally the question of whether it is meaningful to separately identify intangible assets, holding constant the measurement issues associated with the recognition of intangibles. 


\section{Chapter 3}

\section{Narrative Disclosure for Business Combinations}

The purpose of this chapter is to provide an overview of the disclosure requirements for firms that acquire other companies. Doing so allows me to demonstrate that firms often do not provide adequate disclosure about the business combinations, especially qualitative information such as the primary reasons for the acquisitions. Providing a scope of what firms are required to disclose motivates the other key variable in my thesis- that is, the type of narrative discussions that firm managers may provide about the business combinations (i.e., strategic versus non-strategic narrative disclosures). In this chapter, I also provide an overview of the relevant research in this area.

\subsection{Disclosure Requirement for Business Combinations}

For many investors, a press release about the business acquisition would be the first time they learn about the transaction. Because these press releases about business acquisitions convey "material news" and thus warrant an 8-K filing, it is not surprising that the SEC separately mandates disclosure of a material business acquisition (also in an 8-K) once an acquisition agreement has been reached. ${ }^{17}$ Required disclosures under the SEC mandate include information about the purchase price, the form of consideration to be exchanged (i.e., stock or cash), the identities of the parties, the date of signing, and a brief

\footnotetext{
${ }^{17}$ SEC indicates that a business acquisition is "significant" if the acquiring company's (1) investments in and advances to the target exceed 10 percent of the company's total assets as of the end of the last fiscal year, or (2) proportionate share of the total assets of the target exceeds 10 percent of the company's total assets, or (3) share of the target's income exceeds 10 percent of the company's total income (SEC 2018b). Acquiring companies are required to file a Form 8-K disclosing the initial and final acquisition terms both when entering into an acquisition agreement and when the deal is consummated (i.e., closed).
} 
description of the terms and conditions (SEC 2004, 2017, 2018a). In many cases, one 8-K filing combines the excerpt of the press release along with the required disclosures.

Although SEC mandates these disclosures for material business acquisitions, the required information does not include qualitative information such as companies' reasoning for such acquisitions. Interestingly, though, this qualitative information (i.e., the primary reason for an acquisition) is part of the disclosure requirement for financial statements. Per SFAS 141R, companies are required to disclose qualitative information about the reasons for material acquisitions in the footnotes to the financial statements (FASB 2007). ${ }^{18}$ However, unlike the SEC filing requirement for the 8 - $\mathrm{K}$ (i.e., the $8-\mathrm{K}$ is filed when the acquisition agreement is reached), companies are not required to disclose this acquisition information in the financial statements until they consummate the transaction with the target company.

Besides the disclosure of the qualitative information, the FASB also requires additional information about material business acquisitions (FASB 2007). Specifically, an acquiring company is required to provide more detailed and comprehensive financial information in its financial statements, including: (1) information related to the allocation of the purchase price to the assets acquired and the liabilities assumed, (2) information related to the nature and the amount of intangible assets that were recognized separate from goodwill (e.g. total amount assigned, major intangible asset classes, useful life, and amortization periods), (3)

\footnotetext{
${ }^{18}$ Whether an individual business combination is considered material for disclosure requirements of financial statements is largely a subjective judgment, as there is no specific guidance (Shalev 2009). Thus, companies have a considerable amount of discretion over whether and how to disclose qualitative information in financial statements regarding business combination transactions.
} 
information related to the goodwill recognized (both the total and the breakdown to the reporting segments), and (4) pro forma information (e.g. revenue and earnings of the combined entity for the comparable prior reporting period). ${ }^{19}$

Because there is no clear-cut materiality threshold for financial statement disclosure and because the SEC's materiality threshold is fairly generous (see footnote 15), it seems that companies, especially those with large total assets and income, have a considerable amount of discretion over whether and how to disclose business combination transactions (Rodrigue and Stegemoller 2007). For a large acquiring company, business combinations worth millions of dollars could be viewed as immaterial and, thus, would not be subject to any filing or disclosure requirements. For example, Amazon's total assets as of 12/31/2017 were around $\$ 131$ billion (Amazon 2018). Using 10 percent of the total assets as a materiality threshold for fiscal year 2017, it follows that any business combination under $\$ 13$ billion could be considered immaterial per SEC's requirement (SEC 2017). Even if Amazon uses a more conservative threshold such as 5 percent of the net assets (i.e., approximately 27.7 billion) as their materiality threshold, it follows that any business combination under $\$ 1.4$ billion still could be considered immaterial.

Many reasons exist regarding why companies might not want to disclose business combination transactions. For example, companies might want to conduct the acquisition quietly, due to concerns of revealing proprietary information or attracting unnecessary

\footnotetext{
${ }^{19}$ For a company that has several business combinations during a reporting period that are individually immaterial but collectively material, the acquiring company is required to disclose aggregate financial information in financial statements. However, companies are not required to disclose qualitative information - such as the name and description of any one target company or the primary reasons for any individual acquisition - if such an acquisition is considered immaterial (FASB 2007).
} 
attention. Managers might want to avoid attention if they engage in business combinations to exploit their overvalued stock (Shleifer and Vishny 2003) or to maintain a positive asset growth trend to solicit investors' optimism (Collins and Kim 2015). Therefore, when a company does not disclose about business combinations, the reasons are not always obvious.

\subsection{Strategic versus Non-Strategic Narratives}

For business combinations deemed material, managers also have considerable discretion over whether and how to disclose them. As mentioned previously, after the completion of the acquisition transaction, public acquiring companies are required to disclose certain qualitative information — such as the primary reasons for the acquisition (FASB 2007). Further, they are required to provide information in their financial statement disclosure related to the allocation of the purchase price, the intangible assets acquired, goodwill, and pro forma information.

Interestingly, research has shown that not all firms disclose the primary reasons for acquisitions. Specifically, Shalev (2009) examines disclosures in annual reports and finds that only 67 percent of the disclosure sample (49 percent of the overall business combinations sample) discloses the primary reasons for a business acquisition in the footnotes to the financial statements. For those that do, the quality of disclosure varies greatly across firms from being boilerplate to elaborative (Shalev 2009).

For firms that disclose the primary reasons for business acquisitions, the form of that disclosure is quite varied. Key to this thesis is that managers commonly discuss business acquisitions in a form of narrative disclosure. Providing such a narrative disclosure can set 
the tone about the transaction, thereby influencing how investors and others view the favorableness of the business combination (Brown, Call, Clement, and Sharp 2017). These discussions can be found in various locations such as press releases, the management discussion and analysis section of the annual reports, and the footnotes to the financial statements.

To illustrate the variability in these narrative disclosures, I provide some examples in Appendix A. These examples are excerpts from various acquisition announcement press releases, because press releases tend to be more timely and descriptive. As shown in the first two narrative examples (Panels A and B of Appendix A), some acquiring companies provide their strategic reasons for the acquisitions in the narratives. These strategic narratives contain discussions about the goals of the acquisition, the plans to achieve such goals, and expected benefits of the acquisition. For example, the PetSmart narrative (Panel A of Appendix B) points out that the goal of the acquisition is to improve the customer experience, that they intend to achieve that goal by using the target company's customer ecommerce service model, and that the expected benefits of acquisition include creating a wider base of customers. In contrast, other companies do not provide strategic reasons for their acquisitions in their narratives. For example, both Amazon and Microsoft (Panels C and D of Appendix B) issued non-strategic narratives that merely comment on their positive views about the target companies. Their narratives do not provide any insights regarding the strategic reasons for the acquisition.

I argue that providing strategic narratives - narratives that discuss the strategic reasons for the acquisition such as goals, plans to achieve such goals, and expected benefits-is 
important. Mergers and acquisitions often result in significant changes to an entity's operation (FASB 2007), and information about business combinations is more opaque than most other corporate transactions, especially when the target firm is private (Officer, Poulsen, and Stegemoller 2009). Arguably, such disclosures about the transaction, especially those that convey strategic information, are particularly important to investors (Amir and Lev 1996; FASB 2001; CICA 2014).

\subsection{Related Literature}

To my knowledge, no prior studies have investigated whether providing a strategic narrative disclosure in a business combination can affect investors' judgments. Somewhat related, though, is a study that examines the amount of firm disclosures surrounding business combinations. The Shalev (2009) study, as noted previously, investigates firms' disclosures in annual reports and finds that only 67 percent of the disclosure sample (49 percent of the overall business combinations sample) discloses the primary reason for a business acquisition in the footnotes to the financial statements. The authors report that firms disclosing more than this information tend to have higher post-acquisition performance, yet investors seem to underreact to the positive information content of this higher disclosure level. Quite interestingly, Shalev (2009) reports that firms disclose less about business combinations when they allocate more of the purchase price to goodwill. Combined, these results show that disclosure of business combination information in annual reports could contain information relevant to investors, yet the market reaction to such information is not well understood given the paucity of research in this area. 
While there is little research on strategic disclosure of business combinations, there are some studies investigating whether managers provide additional narratives for research and development-related expenses and whether the market reacts to such disclosure in that context (e.g. Jones 2007; Merkley 2014). The scholarly evidence in that context shows that despite concerns over disclosing proprietary information, firm managers provide narrative disclosures to supplement earnings information when earnings are less informative about performance. Specifically, managers supplement earnings information with narrative disclosures when the earnings performance is poorer due to large research and development expenses (Merkley 2014) or when firms have lower book-to-market ratios (Jones 2007). Analysts rely upon such narrative disclosures, as research shows that more research and development-related disclosure has a negative association with analyst forecast error and dispersion (Jones 2007). Thus, this line of research supports the notion that while providing intangible-related narrative disclosure may be costly to managers, such disclosure may provide relevant information to the market.

A relatively larger literature exists on features of qualitative disclosures and how such features affect analysts and investors (e.g. Sedor 2002; Rennekamp 2012; Davis, Piger, and Sedor 2012; Allee and DeAngelis 2015; Bozanic and Thevenot 2015). Specifically, this research identifies several features of qualitative disclosures that cause investors and analysts to be more optimistic about firms' future performance. These features include making the disclosure more readable (e.g. Rennekamp 2012), more vivid (e.g. Hales, Kuang, and Venkataraman 2011), presenting information in a scenario instead of list (Sedor 2002), using more positive and evenly distributed tone (Davis, Piger, and Sedor 
2012; Allee and Deangelis 2015), and providing more diverse information (Bozanic and Thevenot 2015).

In sum, although both SEC and FASB require companies to provide disclosures for material business combinations, firms have a considerable amount of discretion over whether and how to disclose these transactions. I identify two types of narrative disclosures - strategic and non-strategic narratives - that firms tend to utilize when discussing business combinations. A strategic narrative contains firms' discussions about the strategic reasons for an acquisition, such as an acquisition goal, a plan to achieve such goal, and expected benefits of the acquisition. A non-strategic narrative does not contain such discussions on strategic reasons.

Research shows that both investors and analysts care about whether firms provide narrative disclosures. Yet, scholarly evidence is particularly scarce regarding how different types of narrative disclosures regarding business combinations can affect investors' judgments. This lack of evidence motivates my investigation regarding how providing strategic versus non-strategic narratives can systematically affect investors' judgments, with or without the separate information of intangible identification. 


\section{Chapter 4}

\section{Theory and Hypotheses}

The purpose of this chapter is to provide the relevant theoretical development for my hypotheses. Doing so allows me to later test these predictions within the context of an experiment. Accordingly, this chapter is organized as follows. First, I provide an overview of the family of psychology theories that I rely upon in this thesis- that is, theories that pertain to the simulation heuristic (Kahneman and Tversky 1982; Sloman and Lagnado 2015). Then, I discuss how I apply this family of related theories to the business combinations context. Specifically, I provide theoretical arguments regarding how separately identifying intangible assets and providing a strategic narrative can individually and jointly affect investors' judgments. Lastly, I propose formal hypotheses and develop a theoretical process model.

\subsection{Simulation Heuristic Theory}

To understand how separately identifying intangible assets (versus subsuming into goodwill) and providing a strategic narrative (versus a non-strategic narrative) can affect investors' judgments, I rely on a family of psychological theories related to the simulation heuristic (Kahneman and Tversky 1982; Sloman and Lagnado 2015). These theories pertain to cognitive elaboration (e.g. MacInnis and Price 1987), concrete versus abstract thinking (e.g. Förster, Friedman, and Liberman 2004; Trope and Liberman 2010), and narrative persuasion (e.g. Green and Brock 2000; Escalas 2006). Taken together, these theories form a basis for understanding how separate identification of intangible assets and 
providing a narrative disclosure might systematically influence investors' judgments about a business acquisition.

In general, mental simulation is the cognitive construction of an imaginative event or series of events (Taylor, Pham, Rivkin, and Armor 1998). It is common for individuals to imagine what will happen in a given situation, and such imagination often involves a mixture of both real and hypothetical events (Kahneman and Tversky 1982). It can involve both past and future events, as individuals imagine how a past scenario could have occurred differently (i.e., counterfactual reasoning) or how a future scenario can unfold (Escalas 2004).

When individuals engage in a mental simulation, they start with an initial state, which often contains details provided by a particular context. A mental simulation can produce numerous different end states. Individuals can construe multiple end states of the simulation given its initial state, the intermediate events, and the connection among the events. They then rely on the ease with which the mental simulation reaches a particular end state to judge the probability of that end state as a real outcome. That is, the easier it is to generate the simulation, the more likely the outcome is perceived to be. In contrast, if the simulation is hard to generate, the outcome is judged less likely to occur (Kahneman and Tversky 1982; Sloman and Lagnado 2015).

Turning to a business combination context, I argue that the initial state in a simulation occurs when the acquiring company announces the business acquisition. The end state relevant to investors is whether the acquisition achieves what it was intended to, which normally is some positive outcome. Although it is also possible for investors to think about 
a negative outcome as a potential end state, research shows that the mental simulation process tends to have a positivity bias (Escalas 2004). That is, people tend to imagine favorable outcomes (see MacInnis and Price 1987).

When thinking about such an end state, I propose that investors are likely to rely on the simulation heuristic and conduct a mental simulation from the initial state at the time of the announcement to the end state of a successful acquisition based on the information available to them about the acquisition. This mental simulation is used to predict how the acquiring company might reach the end state in the future. Therefore, instead of past events, this mental simulation will include the potential future actions the acquiring company might take to reach the end state. Based on these future actions, investors then mentally generate a simulation path from the initial state to the end state. According to the theory, investors would rely on the ease of generating such a simulation path to predict the likelihood of a favorable outcome.

\subsection{Main Effects of Intangible Identification and Strategic Narrative}

Drawing on the aforementioned logic based on the simulation heuristic, I predict that separately identifying intangible assets will make it easier for investors to mentally simulate a positive end state (i.e., successful outcome). Unlike goodwill, which is a general and fairly abstract concept, intangible assets are more specific and concrete. ${ }^{20}$ Concrete and specific concepts have mental representations that are more tangible and easier to think about (e.g. McDougall and Snetsinger 1990; Laroche, Bergeron, and Goutaland 2001).

\footnotetext{
${ }^{20}$ Similarly, tangible assets are likely more specific and concrete in investors' minds than are intangible assets.
} 
Compared with goodwill, concrete and specific intangible assets are more likely to prompt investors to engage in more elaborate thinking (MacInnis and Price 1987). With more elaborate thinking, investors are more likely to think about what potential future actions the acquiring company might take with each individual intangible asset. This elaborate thinking also makes it easier for investors to think about how the acquiring company might use the intangible assets to benefit from the acquisition. Thus, compared with goodwill, separately identifying intangible assets makes it easier for investors to simulate different ways that the acquiring company could benefit from the acquisition.

Therefore, I predict that it will be easier for investors to mentally simulate a positive end state of an acquisition — one in which the acquiring company will benefit from the acquisition - when intangible assets are identified separately from goodwill. An easier simulation will then lead investors to judge that a favorable acquisition outcome is more likely when intangibles are separately identified. Thus, I predict a significant main effect for separately identifying intangible assets on investors' judgments.

Moreover, I predict that providing a strategic narrative also can affect investors' judgments by making it easier to create mental simulations. A strategic narrative-one that contains information about acquisition goals, plans to achieve such goals, and expected benefits - holds the necessary narrative structure to allow a more elaborate mental construction (MacInnis and Price 1987; Green and Brock 2000; Sloman and Lagnado 2015). A more elaborate mental construction should enable investors to think about additional ways that the acquiring company can reap benefits from the target company acquisition. Accordingly, a strategic narrative will facilitate investors to more easily 
generate a concrete and coherent simulation path, compared with a non-strategic narrative that lacks such necessary structure (Escalas 2004, 2006; Zhao, Hoeffler, and Zauberman 2007). Thus, I predict a significant main effect for providing a strategic narrative on investors' judgments.

\subsection{Interactive Effect of Intangible Identification and Strategic Narrative}

While I predict that both separate identification of intangibles and the provision of a strategic narrative should have significant main effects on investors' judgments regarding the merits of a business combination, how the two factors work together is unclear ex ante. One possibility is that the effect of providing both intangible identification and a strategic narrative is additive. If investors consider the information about the acquired intangible assets and the reasons for an acquisition as distinct, they would then simply react more favorably when a strategic narrative is provided (as compared to when a non-strategic narrative is given) and when intangibles are separately identified from goodwill (than when intangibles are subsumed). That is, investors' favorable reactions towards either piece of information will not depend on the presence or absence of the other piece of information. This sort of additive approach is consistent with research by Payne and Bettman (e.g. Payne 1982; Bettman, Johnson, and Payne 1990; Creyer, Bettman, and Payne 1990). These studies show that individuals often use an additive approach as a decision strategy to simplify the task and their decision-making processes.

However, I argue that an interactive effect is more likely. This is because both intangible identification and providing a strategic narrative can affect investors' ease of

mental simulation. As investors cognitively construct different mental scenarios about the 
potential future of the acquiring company, it is unlikely that they will process the two pieces of information as independent and unrelated. Thus, providing intangible identification and a strategic narrative will likely have an interactive effect, though two competing predictions exist for two rather different interactive effects. As explained below, providing both intangible identification and a strategic narrative may: (1) make the effect of either factor even stronger (i.e., a complementary effect), or (2) make the effect of either factor smaller when the other one also is present, effectively making the two factors substitutes (i.e., a substitutional effect).

Under the complementary view, both separately identifying intangibles and providing a strategic narrative are necessary to enable investors to generate more elaborate scenarios about how the acquiring company might benefit from the acquisition (e.g. Pennington and Hastie 1988, 1992; Bertsch, Pesta, Wiscott, and McDaniel 2007). Only when both are present can investors combine the information from the separate intangibles along with the goals and plans provided in the strategic narrative to form plausible links among potential actions that the acquiring company can take. Thus, it will be easier for investors to form a more-concrete and complete simulation path, making the simulation even easier to generate. That is, investors are better able to think about the potential actions that the acquiring company can take when they have information about the separate intangibles to be acquired and the strategic narrative.

Under the complementary view, when a non-strategic narrative is provided, or when a strategic narrative is provided with intangibles subsumed into goodwill, the narrative might not help as much to alleviate investors' difficulty in forming a concrete mental simulation 
about a positive acquisition outcome. That is, if investors find goodwill to be a difficult concept to consider, even with a strategic narrative, it will be difficult for investors to make mental connections to mentally simulate how the acquiring company might use goodwill to achieve goals and benefits from the acquisition. Similarly, when a non-strategic narrative is provided, even with intangible assets separately identified, it will be difficult for investors to see the reasoning and planning behind the acquired assets in order to mentally simulate how the acquiring company might use these assets to benefit from the acquisition. Only when both the strategic narrative and the separately identified intangibles are present can investors mentally construct scenarios in their minds regarding the potential actions that the acquiring company might take, thus creating a coherent mental simulation.

In contrast, under the substitution view, either separate identification of intangibles or providing a strategic narrative alone would be sufficient to allow investors to generate a coherent simulation path regarding a successful acquisition outcome. Under this view, when intangibles are separately identified, investors can mentally unfold how the acquiring company might use these assets in the future. That is, investors can mentally construct scenarios in their minds regarding the potential actions that the acquiring company might take, thus forming a coherent mental simulation based on the separately identified intangible assets. When intangibles are subsumed into goodwill, investors cannot imagine as much about what the acquiring company might do with the asset. Instead, they rely on the information provided in the strategic narrative to construct the future scenarios in their minds. That is, when they read about the company's acquisition goal and a plan to achieve such goal, they can envision how the acquiring company might take steps and actions in 
the future to utilize the acquired assets from the acquisition, even when the asset listed is goodwill only.

To achieve this effect, a strategic narrative by itself needs to have an adequate simulation structure that can enable investors to create a coherent mental simulation. This idea is supported by theory (e.g. Green and Brock 2000; Escalas 2004, 2006), as research finds that goal-directed and process-based narratives can be particularly effective in inducing mental simulations (e.g. Pham and Taylor 1999; Taylor and Pham 1999; Zhao, Hoeffler, and Zauberman 2007). Thus, a strategic narrative containing an acquisition goal and a plan to achieve such goal could have an adequate simulation structure to make investors' mental simulations easier, substituting for intangible identification when it is absent.

Under the substitution view, the incremental effect of providing both pieces of information will be minimal compared with providing either piece of information. When intangible identification is present, investors already can think about the potential actions that the acquiring company can take, making the persuasive effect from the strategic narrative less powerful. Similarly, when a strategic narrative is provided, investors already can form a coherent mental simulation, making the incremental effect of intangible identification minimal. Therefore, under the substitution view, having either piece of information is sufficient enough to enable investors to more easily envision how an acquiring company can take actions to benefit from the acquisition. Providing both should have minimal or no incremental effect on investors' judgments compared with providing either one without the other. 
In sum, theories suggest that separately identifying intangible assets and providing a strategic narrative could have either a complementary or a substitutional effect on the ease with which investors are able to simulate a positive acquisition outcome. According to the simulation heuristic, investors will rely on the ease of simulating an outcome to judge the likelihood of such an outcome. Thus, an easier mental simulation will make investors believe that it is more likely that the acquiring company will benefit from an acquisition. Such beliefs will increase investors' investment-related judgments-valuation, future prospects, and investment desirability—about the acquiring company. I formally propose these two competing predictions as $\mathrm{H} 1$ and $\mathrm{H} 2$ below.

H1 (Complementarity Hypothesis): Both separate identification of intangibles and a strategic narrative will positively affect investment-related judgments compared to subsuming intangibles into goodwill and a non-strategic narrative, respectively. Moreover, the positive effect of either of these factors will be greater when the other is also present.

H2 (Substitution Hypothesis): Both separate identification of intangibles and a strategic narrative will positively affect investment-related judgments compared to subsuming intangibles into goodwill and a non-strategic narrative, respectively. However, the positive effect of either of these factors will be smaller when the other is also present.

Figure 1 illustrates the precise patterns for predictions if the effects of intangible identification and providing a strategic narrative are complementary (Panel A of Figure 1) or substitutional (Panel B of Figure 1). These precise patterns of predictions in the figures reflect a stricter interpretation of the two hypotheses than the wording above. Specifically, the figures show that if the effects are complementary, providing a strategic narrative when intangibles are subsumed will not significantly affect investors' judgments, but providing a strategic narrative in addition to intangible identification will have a significant positive 
effect on investors' judgments. That is, the judgment difference illustrated by $\mathrm{A}$ will be insignificant, while the judgment difference illustrated by B will be significant (Panel A of Figure 1). In contrast, if the effects are substitutional, then providing a strategic narrative with intangibles subsumed will significantly increase investors' judgments, while providing a strategic narrative in addition to intangible identification will have no significant incremental effect on investors' judgments. That is, the judgment difference illustrated by $\mathrm{A}$ will be significant, while the judgment difference illustrated by $\mathrm{B}$ will be insignificant (Panel B of Figure 1).

Figure 2 demonstrates my theoretical model. In this model, both ease of simulation and likelihood to benefit judgments are mediators. These two mediators form one mediating mechanism, through which both the intangible identification and the strategic narrative can interactively affect investors' investment-related judgments. I use an experiment to test my predictions. Chapter 5 provides more details about this experiment. 


\section{Chapter 5}

\section{Experimental Design}

I designed and conducted an experiment to investigate how separately identifying intangible assets and providing a strategic narrative can affect investors' judgments about an acquisition. The benefits of using an experiment are threefold. First, with an experiment, it is possible to control the content of information provided to participants between conditions. An experiment also affords the flexibility to construct narratives containing only specific information relevant to the variables of interest. Second, leveraging the strength of an experiment, the effect of identifying intangible assets can be isolated without introducing confounds, such as those related to measurement. Third, an experiment allows me to collect process variables that can test my theoretical model (Libby and Luft 1993; Kadous and Zhou 2016).

This chapter is organized as follows. First, I describe the recruiting process and the characteristics of the participants. Next, I explain the case materials, the design, and the manipulations. Last, I discuss the experimental procedure and the dependent variables.

\subsection{Participants}

One hundred and twenty individuals who were currently enrolled in either a full-time MBA program (fifty-eight participants) or a Master in Professional Accounting (MPA) program (sixty-two participants) participated in the study. In return, participants were compensated for a fixed payment of $\$ 10$ and a chance to win one of three cash prizes of $\$ 100$. For most participants, the experiment took 10 to 20 minutes. 
The participants had an average of 2.8 years of work experience, of which on average 1.8 years were with business-related capacities such as corporate finance, corporate accounting, public accounting, investment analysts, and management. Eighty-four percent of participants had previously made investments in companies' common stocks, and ninety-five percent planned to invest in the future. ${ }^{21}$

Because goodwill is often an unfamiliar concept to many investors, I sought participants who might be relatively more familiar with the accounting concept of goodwill by having taken numerous accounting courses. My participants had taken an average of 7.6 accounting and 4.2 finance classes. Thus, I deem my participants to have had an adequate amount of accounting education to be at least somewhat familiar with the accounting concept of goodwill. Additionally, participants rated their own general knowledge about mergers and acquisitions on a 101-point scale with endpoints of 0 ("Not at all Knowledgeable") and 100 ("Very Knowledgeable"), as well as a midpoint of 50 (“Somewhat Knowledgeable”). Participants' responses had a mean of 54.33, indicating that the participants were at least somewhat familiar with mergers and acquisitions.

\subsection{Case Materials, Design and Manipulations}

The case materials focused on an all-cash business acquisition transaction involving two retail companies: a headphone company and a shoe company. ${ }^{22}$ In the background

\footnotetext{
${ }^{21}$ The MBA (MPA) participants had an average of 4.6 (1.1) years of work experience, of which on average $3.2(0.5)$ years were with business-related capacities. Ninety-one (seventy-seven) percent of the MBA (MPA) participants had previously made investments in companies' common stocks, and ninety-seven (ninety-two) percent planned to invest in the future. The results of all tests are inferentially identical if I focus on the MBAor MPA-only subsamples.

${ }^{22}$ The choice of using an all-cash business acquisition is to make the acquisition easier to understand. Because cash versus stock acquisition is not an interest of this thesis, using an all-cash business acquisition can reduce complexity by eliminating potential stock-related implications.
} 
information, participants were told that Sterling Inc., a headphone manufacturer and retail company, announced that it would acquire Kit Shoes, a footwear manufacturer and retailer company. Using two retail companies with different products ensures that the reasons for the acquisition were plausible, but not immediately apparent (Aaker and Keller 1990). Participants were told that one-half of the acquisition purchase price ( $\$ 2.58$ billion) was for cash and other physical assets, while the other half was for a list of acquired assets. This amount, $\$ 1.29$ billion, was held constant across conditions. The details of the background information provided to the participants are illustrated in Appendix B, Panel A.

Within the context of this business acquisition scenario, the two manipulations were: (1) whether intangible assets were subsumed into goodwill or identified separately from goodwill (hereafter 'intangible identification'), and (2) whether the acquiring company provided an accompanying narrative disclosure containing strategic reasons for the acquisition or a non-strategic narrative that contained non-strategic discussion (hereafter 'narrative').

For the intangible identification manipulation, participants in the goodwill-only condition were provided with a list of acquired assets that contained only goodwill. In the goodwill-with-intangibles condition, participants were provided with a list of acquired assets that contained goodwill as well as six intangible assets: trade name, trademarks, trade secrets about proprietary processes, in-process research and development, customer relationships, and customer database. See Appendix B, Panels B and C, for the details of this manipulation. 
These six intangible assets were chosen for two reasons. First, the chosen intangible assets are typically more difficult to sell or license independently, making their usefulness and relevance more questionable to investors (FASB 2014a, 2016). ${ }^{23}$ Investigating the effect of identifying versus subsuming these intangible assets thus creates tension and can provide insights that are useful to the standard setters. Second, the chosen intangible assets typically have indefinite useful lives. ${ }^{24}$ Because goodwill is also an asset with indefinite useful life (FASB 2001c), using the chosen intangible assets avoids complications regarding potential amortization. That is, because the chosen intangible assets are likely to have indefinite useful lives, separating them out from goodwill would not affect earnings negatively, keeping constant the economics of the underlying company across conditions.

For the strategic narrative manipulation, participants read one of two statements from the acquiring company's CEO. In the strategic narrative condition, the $\mathrm{CEO}$ was quoted as describing Sterling's goal for the acquisition, their plan to achieve the goal, and the expected benefits of acquisition. In the non-strategic narrative conditions, the CEO was quoted as making positive remarks about the target company, their products, and Sterling's

\footnotetext{
${ }^{23}$ Based on the criterion of separability (i.e., whether intangibles can be easily sold or licensed independently), I propose that intangible assets can be categorized into three categories: hard, semi-soft, and soft, with hard (soft) intangibles being more (less) easily sold or licensed, and semi-soft intangibles falling somewhere between these two extremes. Appendix $\mathrm{C}$ demonstrates my categorization for these three categories. All intangible assets categorized in Appendix $\mathrm{C}$ are from the examples of intangible assets listed in SFAS 141R (FASB 2007, pp. 41-48). For the intangible identification manipulation, I chose six intangible assets from either the semi-soft or the soft categories.

${ }^{24}$ As companies have considerable discretion over the subjective judgments about assets' useful lives, I do not imply that every single company treats all six of my chosen intangibles as indefinite-lived. However, I argue that it is likely for these six chosen assets to be classified as indefinite-lived because their remaining useful lives are difficult to estimate, compared with other more contract-based assets, such as patents or franchise agreements. For example, in-process research and development intangibles assets are classified as indefinite-lived until the completion or abandonment of the associated research and development efforts (FASB 2007, pp. 20-21).
} 
products. None of these remarks conveyed any strategic reasons for the acquisition. See Appendix B, Panels D and E, for the details of this manipulation.

An important design feature is that the language qualities of the two narratives are kept constant. That is, the two statements are almost identical in length (12 lines, 153-154 words). Further, the two narratives are equally readable, positive, vivid, and realistic as statements from CEOs. To check the latter, I conducted a pilot study prior to the administration of the main experiment, with a between-participants design. In it, sixty participants, recruited through the Amazon Mechanical Turk platform, rated the two CEO statements for numerous language attributes including readability, positivity, vividness, and perceived realism as CEO quotes. All pilot participants had prior experience in both investing in common stocks and reading financial statements. Participants provided all responses on 101-point scales with the appropriate labels for 0 and 100 for each question (e.g. for the scale of the positivity question, 0 was labeled "Not at all Positive" and 100 was labeled "Very Positive"). Results from the pilot study show that participants rated the two narrative statements to be comparable in all aforementioned language attributes (all pvalues $>0.15$, untabulated). Therefore, my design ensures that the language qualities do not differ between conditions for the strategic narrative manipulation.

\subsection{Procedure and Dependent Measures}

Participants first read a brief description of Sterling and its upcoming all-cash acquisition of Kit Shoes. Immediately after this (but before being provided with the experimental manipulations), participants rendered initial judgments about the likelihood that Sterling would benefit from this acquisition, Sterling's valuation, future prospects, and 
the desirability of an investment in Sterling. The likelihood to benefit judgments were collected to measure participants' reliance on the simulation heuristic. The valuation, future prospects, and investment desirability judgments were collected as main investmentrelated dependent variables. Collectively, these investment-related judgments measured participants' assessments of and predictions for the acquiring company's post-acquisition performance. Participants made these judgments on 101-point scales, with appropriate labels. Specifically, for likelihood to benefit (0 labeled "Not at all Likely" and 100 labeled "Very Likely"), valuation (0 labeled "Very Low" and 100 labeled "Very High"), future prospects (0 labeled "Very Weak" and 100 labeled "Very Strong"), and investment desirability (0 labeled "Not at all Desirable" and 100 labeled "Very Desirable").

Following these initial judgments, participants were then randomly assigned to one of the four experimental conditions. After viewing the manipulations, participants again made judgments about the likelihood that Sterling would benefit from this acquisition, valuation of Sterling, future prospects of Sterling, and the desirability of an investment in Sterling, on the same 101-point scales described above. By collecting both pre- and postmanipulation judgments, I am able to control for each participant's initial judgments about the acquisition, thereby capturing the strength of each participant's reaction to my manipulations. See Panel A of Appendix D for the exact wording used for the main dependent measures.

After responding to these main dependent variables, participants then responded to a key process measure that was designed to capture their ease of simulation process. Recall that in my theoretical model, the ease of simulation judgments, combined with the 
likelihood to benefit judgments, would form a mediating mechanism from my manipulations to investors' investment-related judgments. Thus, to provide their ease of simulation judgments, participants responded on 101-point scales about how easy or difficult it was for them to think about "ways that Sterling could benefit from this acquisition of Kit Shoes" with 0 labeled "Very Difficult" and 100 labeled "Very Easy."

Participants then provided judgments to a set of questions that were designed to further explain their simulation process. Participants first responded on 101-point scales about how easy or difficult it was for them to think about "potential actions that Sterling could take after this acquisition of Kit Shoes," with 0 labeled "Very Difficult" and 100 labeled "Very Easy." Participants then rated on 101-point scales about the concreteness ( 0 labeled "Very Abstract" and 100 labeled "Very Concrete") and specificity (0 labeled "Very General" and 100 labeled "Very Specific") of their thoughts when they considered the potential actions that Sterling could take after the acquisition. The latter two questions are adapted from a set of questions in Laroche et al. (2001).

Furthermore, to test whether narrative persuasion is part of participants' simulation process, participants responded on 101-point scale that while reading the Sterling CEO's statement, how easy or difficult it was for them to "think about how Sterling could work with Kit Shoes after the acquisition," with 0 labeled "Very Difficult" and 100 labeled "Very Easy." Participants also responded on 101-point scale that while reading the acquired asset list, how useful they thought the acquired asset list could be to Sterling after the acquisition, with 0 labeled "Not at all Useful" and 100 "Very Useful." These two questions are adapted from a set of questions in Escalas (2004). 
For the next set of three questions, participants provided their judgments about Sterling's management. On a 101-point scale, participants rated their judgments about how transparent Sterling's management was about this acquisition (0 labeled "Not at all Transparent" and 100 labeled "Very Transparent"). The emphasis of this question was to capture participants' perception of Sterling's management about this particular acquisition, which was slightly different from the subsequent two questions on participants' overall impressions of Sterling's management. On 101-point scales, participants provided their overall impressions about Sterling's management on trustworthiness (0 labeled "Not at all Trustworthy" and 100 labeled "Very Trustworthy") and competence (0 labeled "Not at all Competent" and 100 labeled "Very Competent").

Lastly, participants provided on a 101-point scale their perceived likelihood that Sterling overpaid for this acquisition (0 labeled "Not at all Likely" and 100 labeled "Very Likely"). If participants were with strong prior assumptions about goodwill, such as equating more goodwill to higher likelihood of overpayment, then this last question would capture the variances in participants' prior judgments about goodwill. See Panel B of Appendix D for the exact wording used for all of these additional measures. ${ }^{25}$

Finally, participants completed manipulation checks and provided demographic information. See section 6.1 for more discussion on the manipulation checks. See Panels

\footnotetext{
${ }^{25}$ Participants also provided two other judgments about the acquisition: (1) the likelihood that the acquired asset list was the main reason for the acquisition, and (2) the likelihood that the CEO preference was the main reason for the acquisition. Participants provided these judgments on 101-point scales, with 0 labeled "Not at all Likely" and 100 labeled "Very Likely." Untabulated results reveal that intangible identification has a significant main effect on participants' judgments about the likelihood that the acquired asset was the main reason for the acquisition. There are no significant effects for the CEO preference question.
} 
$\mathrm{C}$ and D of Appendix D for the exact wording for the manipulation checks and the other post-experimental questions, respectively. 


\section{Chapter 6}

\section{Results}

The purpose of this chapter is to present the statistical results of my experiment. Doing so allows me to test my predictions and then make inferences about the effects of separately identifying intangible assets and providing a strategic narrative on investors' judgments. This chapter is organized as follows. First, I check the effectiveness of my manipulations. Second, I test my two hypotheses and discuss the inferences. Third, I investigate the process variables and the theoretical model. Lastly, I provide some additional analyses.

\subsection{Manipulation Checks}

The results of three questions confirm that the manipulations worked as intended. The results of all tests are inferentially identical if I exclude responses from participants who failed either manipulation check. Panel A of Table 1 reports the frequency tables for both intangible identification and strategic narrative manipulation checks, which are discussed in more detail below.

To confirm that the intangible identification manipulation was successful, participants were asked to indicate the asset list that they had seen previously. They were provided with the two acquired asset lists that corresponded to the goodwill-only and goodwill-withintangibles conditions. Over $98 \%$ of participants (118 out of 120) correctly selected the asset list they were given. These responses are significantly associated with the correct experimental condition $\left(\chi_{(1)}^{2}=43.55, p<0.01\right.$, Panel B of Table 1), indicating a successful intangible identification manipulation. 
To confirm that the narrative manipulation was successful, participants were asked to recall the statement they read earlier and select between two excerpts-one from the nonstrategic narrative condition and one from the strategic narrative conditions. Over 97\% (117 out of 120) correctly selected the statement they were given. These responses are significantly associated with the correct experimental condition $\left(\chi_{(1)}^{2}=45.00, p<0.01\right.$, Panel B of Table 1), indicating a successful manipulation of strategic narrative.

In addition, to confirm that the narrative manipulation contained different levels of strategic commentary, participants indicated their beliefs about how clearly Sterling communicated the company's goal in making the acquisition, methods to achieve the goal, and expected benefits of the acquisition. Participants responded on a 101-point scale with endpoints of 0 ("Not at all Clearly") and 100 ("Very Clearly"). Panel C of Table 1 reports the means of participants' judgments. As expected, participants who read the non-strategic narrative provided a significantly lower mean response (mean of 16.98) than those who read the strategic narrative (mean of $68.83, F_{1,116}=250.54, p$-value $<0.01$, Panel D of Table 1), indicating a successful manipulation. As expected, there were no other significant effects in this analysis.

\subsection{Hypothesis Tests}

My two competing hypotheses predict that the effects of separately identifying intangible assets and providing a strategic narrative are either complementary or substitutional. In statistical terms, both hypotheses imply that there will be a significant two-way interaction between intangible identification and narrative manipulations. However, as previously shown in Figure 1, the predicted patterns of this interaction differ 
between the two hypotheses. As explained in more detail below, the results are more consistent with the substitution hypothesis $(\mathrm{H} 2)$ than the complementarity hypothesis $(\mathrm{H} 1)$. This conclusion can be seen both graphically (see Figure 3) and statistically, as explained below.

Recall that there are three investment-related primary dependent variables for testing my hypotheses: valuation, future prospects, and investment desirability. Because I elicit responses to these variables before and after the two manipulations, I analyze these data using an analysis of covariance (ANCOVA) with the pre-manipulation responses used as a covariate. Results of analyses using the change from pre- to post- manipulation judgments as the dependent measures are inferentially identical to those reported. As expected, the two manipulations have no effect on any pre-manipulation judgments (all p-values $>0.49$, untabulated).

Panel A of Table 2 presents the descriptive statistics containing the least-squares means and standard errors of the post-manipulation valuation, future prospects, and investment desirability judgments. The least-squares means shown are adjusted for participant's premanipulation judgments. ${ }^{26}$ Figure 3 graphs these least-squares means. Panel B of Table 2 shows the ANCOVA tests for the post-manipulation judgments using the pre-manipulation judgments as covariates.

\footnotetext{
${ }^{26}$ Due to the balanced design of my experiment, the standard error of the estimated least-square means for each condition is identical. This consequence occurs because the underlying formula for the standard error of each condition depends on the mean square error (MSE) of the ANOVA and the condition's sample size (Kutner, Nachtsheim, Neter, and Li 2005, pp. 737-743). To show variations of participants' judgments, Table 4 presents the descriptive statistics of the unadjusted pre- and post-manipulation judgments for valuation (Panel A), future prospects (Panel B), and investment desirability (Panel C).
} 
Results show that intangible identification has a significant main effect. Investors judge the valuation of the acquiring company to be significantly higher when intangibles are separately identified from goodwill (mean of 66.40) than when intangible are subsumed into goodwill (mean of 57.18, $F_{1,115}=15.94, p$-value $<0.01$ ). Investors' future prospects and investment desirability judgments about the acquiring company are also higher when intangibles are separately identified (both $F_{1,115}>11.69$, $p$-value $<0.01$ ), indicating that separate intangible identification has an overall positive effect on investors' investmentrelated judgments.

Results also show that narrative has a significant main effect. Investors judge the valuation of the acquiring company to be significantly higher when provided with a strategic narrative (mean of 65.98) than a non-strategic narrative (mean of 57.60, $F_{1,115}=$ 13.21, $p$-value $<0.01)$. Investors' future prospects and investment desirability judgments about the acquiring company also are higher with a strategic narrative (both $F_{1,115}>18.22$, $p$-value $<0.01)$, indicating that providing a strategic narrative has an overall positive effect on investors' investment-related judgments.

Recall that earlier I entertain the possibility that the two factors may have an additive effect instead of an interactive effect on investors' judgments. If that is the case, then there should be no significant interaction between intangible identification and narrative. The results do not support the additive effect, as I observe that intangible identification and narrative have an interactive effect on investors' investment-related judgments. This interactive effect is marginally significant for valuation $\left(F_{1,115}=3.12, p\right.$-value $\left.=0.08\right)$, future prospects $\left(F_{1,115}=2.93, p\right.$-value $\left.=0.09\right)$, and investment desirability judgments 
$\left(F_{1,115}=3.24, p\right.$-value $\left.=0.07\right)$. These results solidify my prediction that investors indeed use the two pieces of information in a related manner. However, how investors use these pieces of information depend on whether the interactive effect is complementary (H1) or substitutional $(\mathrm{H} 2)$, which are my two competing hypotheses.

To test my competing hypotheses, the results show that intangible identification and narrative have an interactive effect on investors' investment-related judgments. This interactive effect is marginally significant for valuation $\left(F_{1,115}=3.12, p\right.$-value $\left.=0.08\right)$, future prospects $\left(F_{1,115}=2.93, p\right.$-value $\left.=0.09\right)$, and investment desirability judgments $\left(F_{1,115}=3.24, p\right.$-value $\left.=0.07\right)$. However, because both of my complementarity and substitution hypotheses predict an interactive effect, the pattern of the interaction is of primary interest.

To test the specific pattern for interaction, I turn to the visual patterns, means for each condition, and the simple effect tests reported in Panels C and D of Table 2. Recall that I predict that the positive effect of either factor-separate intangible identification or providing a strategic narrative-will be greater (complementarity hypothesis) or smaller (substitution hypothesis) when the other factor is also present. Results reveal that the interaction is more substitutional than complementary. This inference is supported by both visualization and statistical analyses.

Specifically, the visual patterns of the three investment-related judgments (Figure 3) are all more consistent with the prediction for the substitution hypothesis (Panel B of Figure 1) than with the complementarity hypothesis (Panel A of Figure 1). Furthermore, statistical analyses show that when intangibles are subsumed into goodwill, providing a strategic 
narrative greatly increases investors' valuation judgments (mean of 63.41) compared with providing a non-strategic narrative (mean of 50.95, $F_{1,115}=14.57$, $p$-value $<0.01$, Panel C of Table 2). When intangibles are separately identified, providing a strategic narrative has no significant effect on investors' valuation judgments (mean of 68.56) compared with providing a non-strategic narrative (mean of $64.35, F_{1,115}=1.74, p$-value $=0.19$, Panel C of Table 2). Similarly, when a non-strategic narrative is provided, separately identifying intangibles significantly increases investors' valuation judgments (mean of 64.35) compared with subsuming intangibles into goodwill (mean of $50.95, F_{1,115}=16.63, p$-value $<0.01$, Panel D of Table 2). When a strategic narrative is provided, the difference in investors' valuation judgments between separate intangible identification (mean of 68.56) and subsuming intangibles into goodwill (mean of 63.41) is insignificant $\left(F_{1,115}=2.48, p\right.$ value $=0.12$, Panel $\mathrm{D}$ of Table 2). Thus, these results show that investors have more favorable valuation judgments when either the intangibles are separately identified or when a strategic narrative is provided. The positive effect of either factor on investors' valuation judgments is smaller when the other factor also is present.

This substitutional pattern replicates for both future prospects and investment desirability judgments. Specifically, when intangibles are subsumed into goodwill, investors' future prospects and investment desirability judgments are significantly higher with a strategic narrative (means of 65.32 and 61.91, respectively) than with a non-strategic narrative (means of 50.68 and 47.22, respectively, both $p$-value $<0.01$, Panel C of Table 2). When intangibles are separately identified, the positive effect of providing a strategic narrative is smaller (means of 70.49 and 65.84 , respectively) compared with a non-strategic 
narrative (means of 64.02 and 59.86, respectively, both $p$-value $>0.05$, Panel C of Table 2). Similarly, with a non-strategic narrative, investors' future prospects and investment desirability judgments are significantly higher when intangibles are separately identified (means of 64.02 and 59.86, respectively) versus subsumed into goodwill (means of 50.68 and 47.22, respectively, both $p$-value $<0.01$, Panel D of Table 2). With a strategic narrative, separately identifying intangibles has no significant effect on increasing investors' future prospects and investment desirability judgments (means of 70.49 and 65.84 , respectively) compared with subsuming intangibles into goodwill (means of 65.32 and 61.91, respectively, both $p$-value $>0.12$, Panel D of Table 2). Thus, these results support the substitution hypothesis (H2) and show that either one of the factors can affect investors' investment-related judgments by itself. When intangibles are subsumed into goodwill, providing a strategic narrative acts as its substitute.

Nevertheless, these results are not strictly consistent with only the substitution hypothesis. Recall that a strict interpretation of the substitution hypothesis is that when both factors are present, there should be no incremental effect compared with when either factor is present without the other. The prediction depicted in Panel B of Figure 1 reflects this strict interpretation. Comparing the patterns of the results in Panels B and C of Figure 3 to the strict-interpretation pattern for the substitution hypothesis in Panel B of Figure 1, the results show that even when intangibles are separately identified, providing a strategic narrative still has an incremental positive effect on two of my three dependent measuresnamely, investors' future prospects and investment desirability judgments. Specifically, compared with a non-strategic narrative (means of 64.02 and 59.86, respectively), 
providing a strategic narrative increases investors future prospects (mean of 70.49) and investment desirability judgments (mean of 65.84), and these increases in judgments are marginally significant (both $p$-value $<0.10$, Panel $\mathrm{C}$ of Table 2). This finding lends some credibility to the complementarity hypothesis, showing that providing both pieces of information increases the favorability of their judgments. However, because the combination of a strategic narrative along with separate intangible identification does not lead to significantly more favorable judgments than a strategic narrative with intangibles subsumed into goodwill (both $p$-value $\geq 0.13$, Panel D of Table 2), it is difficult to argue that the overall pattern of results is consistent with the complementarity hypothesis.

In sum, the results demonstrate that separately identifying intangible assets and providing a strategic narrative can each have a significant main positive effect on investors' valuation, future prospects, and desirability judgments. Moreover, the interactive effects of the two factors are substitutional. That is, the positive effect of either factor is smaller when the other factor is also present.

\subsection{Process Measures and Theoretical Model}

In this section, I explore the mediating role of two process measures: (1) ease of simulation, and (2) likelihood to benefit. Recall that I predict in my theoretical model that these two process measures form a mediating mechanism, through which my two manipulated variables, intangible identification and strategic narrative, affect investors' investment-related judgments. 
Table 3 presents the summary data and accompanying statistical tests for both the ease of simulation and likelihood to benefit judgments. ${ }^{27}$ Results show that separate intangible identification and providing a strategic narrative have a significant interactive effect on the ease with which investors can simulate the ways that the acquiring company can benefit from the acquisition $\left(F_{1,116}=5.54, p\right.$-value $=0.02$, Panel B of Table 3$)$. Similar to the primary dependent measures, the interactive effect is substitutional, as explained below.

Consistent with the substitution hypothesis, results show that when intangibles are subsumed into goodwill, providing a strategic narrative enables investors to simulate more easily (mean of 64.83) than when a non-strategic narrative is provided (mean of 40.00, $F_{1,116}=21.89, p$-value $<0.01$, Panel $\mathrm{C}$ of Table 3$)$. When intangibles are separately identified, providing a strategic narrative does not significantly affect investors' ease of simulation (means of 61.33 versus $54.17, F_{1,116}=1.82, p$-value $=0.18$ ). Similarly, compared with subsuming intangibles into goodwill, separately identifying intangibles makes it easier for investors to think about ways that the acquiring company could benefit from the acquisition only when accompanied by a non-strategic narrative (means of 54.17 versus $40.00, F_{1,116}=7.12, p$-value $\left.<0.01\right)$. When accompanied by a strategic narrative, separately identifying intangibles does not affect investors' ease of simulation (mean of 61.33) compared with subsuming intangibles into goodwill (mean of $64.83, F_{1,116}=0.43$, $p$-value $=0.51$, Panel $\mathrm{C}$ of Table 3 ). Combined, these results indicate that providing either separate intangible identification or a strategic narrative is sufficient to significantly

\footnotetext{
${ }^{27}$ Panel D of Table 4 presents the summary statistics for both the pre- and post-manipulation likelihood to benefit judgments.
} 
increase investors' ease of simulation towards ways that the acquiring company can benefit from the acquisition.

Recall that the simulation heuristic predicts that individuals tend to rely on their ease of simulating a certain outcome to judge the likelihood of such outcome. Consistent with the theory, likelihood to benefit judgments show a similar pattern as ease of simulation. Specifically, intangible identification and narrative have a marginally significant interactive effect on investors' judgments about the likelihood that that the acquiring company will benefit from the acquisition $\left(F_{1,115}=3.03, p\right.$-value $=0.08$, Panel B of Table 3$)$. This effect is also substitutional. When intangibles are subsumed into goodwill, providing a strategic narrative substitutes for separate intangible identification and significantly affects investors likelihood to benefit judgments (means of 64.01 versus $47.15, F_{1,115}=22.05, p$-value $<0.01$, Panel $\mathrm{C}$ of Table 3). When intangibles are separately identified, providing a strategic narrative has a smaller effect (means of 69.05 versus $60.95, F_{1,115}=5.32, p$-value $=0.02$ ). Similarly, intangible identification has a greater effect with a non-strategic narrative (means of 60.95 versus $47.15, F_{1,115}=15.06, p$-value $<0.01$ ) than with a strategic narrative (means of 69.05 versus $64.01, F_{1,115}=2.01, p$-value $=0.16$, Panel $\mathrm{C}$ of Table 3 ).

To further investigate the mediating role of the two process measures, I use structural equation modeling to test my theoretical model (Figure 2). Consistent with the simulation heuristic theory, in this model I predict that two mediators, ease of simulation and the likelihood to benefit judgments, form a mediating mechanism through which the intangible identification and strategic narrative affect investors' investment-related judgments. That is, investors will rely on the ease of simulating an outcome to judge the likelihood of such 
an outcome, and such likelihood judgments will in turn affect investors' valuation, future prospects, and investment desirability judgments.

Figure 4 illustrates the results of the theoretical model. This model has a high overall goodness of fit. The Tucker-Lewis Index (TLI) and Comparative Fit Index (CFI) are 0.98 and 0.99 respectively, indicating that the model improves in fit compared to null models and has an acceptable goodness of fit (e.g. Byrne 1994; Hu and Bentler 1999). This conclusion is confirmed by a $\chi^{2}$ test $\left(\chi_{14}^{2}=22.67, p\right.$-value $\left.=0.20\right)$ and supported by the model's low standardized root mean square residual (SRMR), which equals to 0.03 , indicating that the model has a good fit (e.g. Hu and Bentler 1999; Kline 2015).

The analyses of the model focus on the five links included in the model. Link 1 represents the direct effect of the two manipulations on investors' investment-related judgments, which is a latent factor variable derived from three measured judgmentsvaluation, future prospects, and investment desirability judgments. ${ }^{28}$ Results show that without the mediating path, this direct path (Link 1) from the two manipulated variables to the latent variable is consistent with the substitution hypothesis. Specifically, the coefficient of the interaction effect is significant and negative $(\beta=-7.98, Z=-1.78, p=0.08)$, indicating that when both factors are present, the cumulative effect is diminishing to the

\footnotetext{
${ }^{28}$ A principle component analysis confirms that the three investment-related judgments share one underlying factor (eigenvalue $=2.54$, untabulated). The Cronbach's alpha among these judgments are 0.91 , indicating a high internal coherence among the variables (Peterson 1994). Replacing the latent factor variable with any of the three main dependent variables (i.e., valuation, future prospects, and investment desirability judgments) yields results that are inferentially identical for the model.
} 
effect of either factor by themselves. This negative coefficient further reinforces my interpretation that the two factors are substitutional instead of complementary. ${ }^{29}$

Links 2,3 , and 4 form the mediating path from the two manipulated variables to the main dependent latent variable. Link 2 represents the effect of the two manipulations on investors' ease of simulation judgments. Link 3 represents the effect of ease of simulation on investors' likelihood to benefit judgments. Link 4 represents the effect of investors' likelihood to benefit judgments to the main dependent latent variable (i.e., the investmentrelated judgments). The results of testing the mediating path through Links 2, 3, and 4 show that the two manipulated factors significantly affect ease of simulation (all $p$-value $<0.03$ ), which then has a positively significant effect on likelihood to benefit judgments $(\beta=0.17$, $Z=2.26, p=0.02)$. As one would expect, the likelihood to benefit judgments has a significantly positive effect on investors' investment-related judgments $(\beta=0.53, Z=8.93$, $p<0.01)$.

The main interest of this model is the comparative statistics between the direct link (Link 1) and the indirect link (Link 5). Link 5 represents the indirect path from the two manipulated variables to the main dependent latent variable, while the mediating path is also in the model. Results of a structural equation model analysis illustrate that when the model includes the predicted mediators, the interaction effect of Link 5 becomes completely insignificant $(\beta=-4.07, Z=-1.13, p=0.26)$. These results suggest that the two mediators, ease of simulation and likelihood to benefit judgments, form one mediating

\footnotetext{
${ }^{29}$ If the two factors have a complementary effect, the coefficient of the interaction term would be positive and significant. If the two factors have an additive effect (i.e., not interactive), the coefficient of the interactive term would be non-significant.
} 
mechanism that fully mediates the interactive effect of intangible identification and strategic narrative on investors' investment-related judgments. Therefore, these results validate my theoretical development.

\subsection{Additional Analyses}

In this section, I summarize the analyses of the other measures collected as part of my experiment. These measures provide additional insights into the thought processes of my participants.

Table 5 presents the summary data and accompanying statistical tests for three questions that ask participants to describe the types of thoughts they have when reading and thinking about the experimental case. Specifically, the questions ask how easy or difficult it is for participants to think about potential actions that Sterling could take after their acquisition as well as the concreteness and specificity of those thoughts. As seen in Panel B of Table 5, the results for all three questions show main effects for both intangible identification and strategic narrative (all $p$-values $\leq 0.10$ ).

Focusing on the potential actions question, results demonstrate that it is easier for investors to think about potential actions that the company could take after the acquisition when intangibles are separately identified from goodwill (mean of 58.50) as compared to when the intangibles are subsumed into goodwill (mean of 52.08, $F_{1,116}=2.77, p$-value $=$ 0.10). Moreover, it is easier for investors to think about the potential actions when a strategic (mean of 63.08) versus non-strategic narrative is provided (mean of $47.50, F_{1,116}$ $=16.31, p$-value $<0.01)$. Thus, both variables contribute to the thoughts investors have about potential actions. 
Panel B of Table 5 also presents similar results for the other two questions regarding the abstractness/concreteness and generality/specificity of the thoughts about those actions. That is, investors' thoughts are more concrete and specific when a strategic narrative is provided or when intangibles are separately identified from goodwill, as compared to when a non-strategic narrative is provided (both $p$-values $\leq 0.04$ ), or when intangibles are subsumed into goodwill (both $p$-values $\leq 0.08$ ). Overall, these results indicate that both of the manipulated independent variables differentially influence how investors think about potential actions along with the specificity and concreteness of those thoughts. The content of these action-related thoughts must have been similar between the two independent variables given the primary results presented previously, showing that when forming judgments about the favorableness of the acquisition (i.e., the primary investment-related dependent measures), investors treat these thoughts about actions as substitutes.

Table 6 shows the results of two questions that capture the effect of the narrative on participants' mental simulations as well as the effect of the listed assets acquired on participants' judgments about the usefulness of those acquired assets. Recall that the theory dictates that if a simulation narrative can sufficiently induce individuals to form a coherent simulation, such a narrative can drastically change individuals' beliefs and subsequent evaluations (e.g. Green and Brock 2000; Escalas 2004, 2006). Not surprisingly, the results of the narrative question reveal that the strategic narrative is indeed sufficient in inducing a mental simulation—it enables investors to more easily think about how the acquiring company will work with the target company after the acquisition (mean of 74.25) compared 
with a non-strategic narrative (mean of $41.25, F_{1,116}=78.86, p$-value $<0.01$, Panel B of Table 6).

Turning to the asset usefulness question, the results illustrate that separately identifying intangible assets apart from goodwill does cause investors to believe that the assets acquired will be more useful going forward (mean of 67.00), compared with subsuming intangibles into goodwill (mean of 48.80, $F_{1,116}=21.38, p$-value $<0.01$, Panel B of Table 6). Most interestingly, providing a strategic narrative also positively affects how investors think about asset usefulness, with the acquired assets being judged as more useful when a strategic (mean of 63.30) versus non-strategic narrative is provided (mean of $52.50, F_{1,116}$ = 7.53, $p$-value $<0.01$, Panel B of Table 6). This effect occurs both when intangibles are subsumed (means of 54.93 versus $42.67, p$-value $=0.03$, Panel C of Table 6) and separately identified (means of 71.67 versus 62.33, $p$-value $=0.10$, Panel $\mathrm{C}$ of Table 6).

Table 7 shows that it is the presence of a strategic narrative that largely affects how the investors view the management of the acquiring company. Specifically, when a strategic narrative is provided, investors judge management to be more transparent, trustworthy, and competent, regardless of whether intangible assets are identified (all $p$-value $<0.01$, Panel $\mathrm{C}$ of Table 7). These findings illustrate that a strategic narrative- one that holds an adequate simulation structure by containing a goal and a plan to achieve such goal—not only influences investors' judgments about the potential future outcomes of the business combination, but also investors' perceptions of the management.

Lastly, Table 8 provides the results of a question asking about the likelihood that Sterling overpaid for the acquired company. As expected, investors' overpayment 
judgments show no systematic pattern (Panels B and $\mathrm{C}$ of Table 8). The lack of results for either manipulated variable indicates that the presence or absence of this strategic narrative does not influence concerns about overpayment. Further, the presence or absence of identifiable intangible assets also do not differentially influence investors' thoughts about the likelihood of overpayment. 


\section{Chapter 7}

\section{Conclusion}

This study investigates the effect of identifying acquired intangible assets separately from goodwill on investors' judgments about an acquisition, and the moderating effect of providing a narrative that contains the strategic reasons for the acquisition. Using a controlled experiment, I find that separately identifying intangible assets and providing a strategic narrative have substitutional effects in helping investors more easily envision how the acquiring company can benefit from an acquisition. That is, investors have higher valuation, future prospects, and investment desirability judgments about the acquiring company when intangible assets are separately identified from goodwill. When intangibles are subsumed into goodwill, though, providing a strategic narrative acts as a substitute for intangible identification, with similar effects on investors' judgments.

My study offers insights to standard setters, managers, and researchers. For standard setters, my findings provide scholarly evidence of whether and how separately identifying intangible assets from goodwill compared to subsuming intangibles into goodwill affect investors' judgments about an acquisition. Separate identification of acquired intangible assets allows investors to envision ways that an acquiring company can benefit from the acquisition, almost as if they are explicitly informed about the company's strategic intentions of such an acquisition. My study thus identifies a previously undocumented effect of separate identification of intangible assets that can contribute to standard setters' ongoing debate about the separate recognition of intangible assets in business combinations. 
For managers, my findings might be informative when firms design communication strategies about business combinations with the investors. My results show that additional disclosures about business combinations, especially disclosures that convey information about the strategic reasons for why companies engaged in such transactions, are particularly important to investors. For business combinations where information might be particularly asymmetric between managers and investors, providing investors with either the separate identification of what the companies acquire or the strategic reasons for such combinations can help investors better understand and foresee the favorableness of such business decisions.

For researchers, my study adds to the limited research on how separate identification of intangible assets influences investors' evaluations of business combinations. Most of the prior research in this area focuses on the effect of intangible assets balances, which combines the effect of both identification and measurement issue (e.g. Paugam et al. 2015). By isolating the effect of separate intangible identification, my study broadens the literature on the consequences of presenting separate information about intangibles.

This paper is subject to certain limitations, which in turn raise interesting questions for future research. In my experiment, the narrative manipulation focuses on whether an acquiring company provides strategic reasons for an acquisition, including acquisition goal, a plan to achieve such goal, and expected benefits of acquisition. Several limitations exist with this design. First, in my design, the strategic reasons are congruent with the separately identified intangible assets. Thus, this study does not fully address the question of how investors react when an acquiring company provides a strategic narrative that is 
incongruent with the separately identified intangible assets. Future research could investigate different levels of perceived congruity between the acquired assets and the strategic narrative disclosure to test whether such congruity affects investors' judgments. Second, the strategic reasons in my design include goals, plans, and anticipated benefits of the acquisition. Future research could investigate the effect of a strategic narrative when one or more of these elements are missing.

Furthermore, while my experiment holds constant various language qualities of the two narratives, narratives can vary on many other dimensions. For example, one notable source of variation is the degree of concreteness in narrative disclosures. Based on my observations, some narratives include more boilerplate language, while others are more specific and include examples and quantification. As research shows that concreteness in language matters to investors' judgments (e.g. Elliott, Rennekamp, and White 2015), future research could test whether the degree of concreteness matters in this particular type of disclosure.

Lastly, my study does not formally investigate how investors think about goodwill. Future research could study how investors view goodwill and its theoretical components (e.g. Colley and Volkan 1988; Johnson and Petrone 1998; EFRAG 2014). As standard setters continue to struggle with how to define and treat goodwill (e.g. EFRAG 2016; FASB 2014c, 2016), the concept of goodwill will likely continue to evolve. Therefore, understanding how investors perceive goodwill and its theoretical components can provide useful insights to both standard setters and researchers. 
Figures and Tables 
Figure 1

Theoretical Predictions

Panel A: Prediction if the effects of intangible identification and providing a strategic narrative are complementary

\section{Investment-Related Judgments}

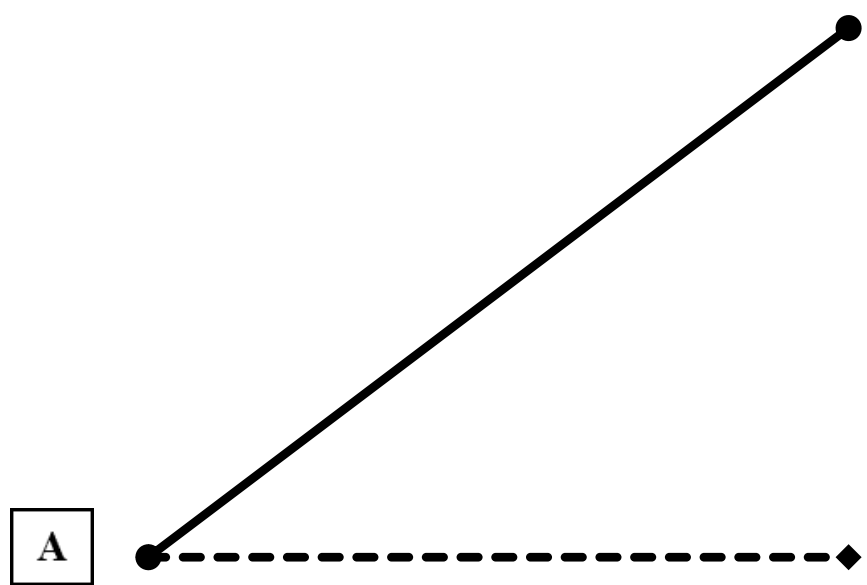




\section{Figure 1 (Continued)}

Panel B: Prediction if the effects of intangible identification and providing strategic narrative are substitutional

\section{Investment-Related Judgments}

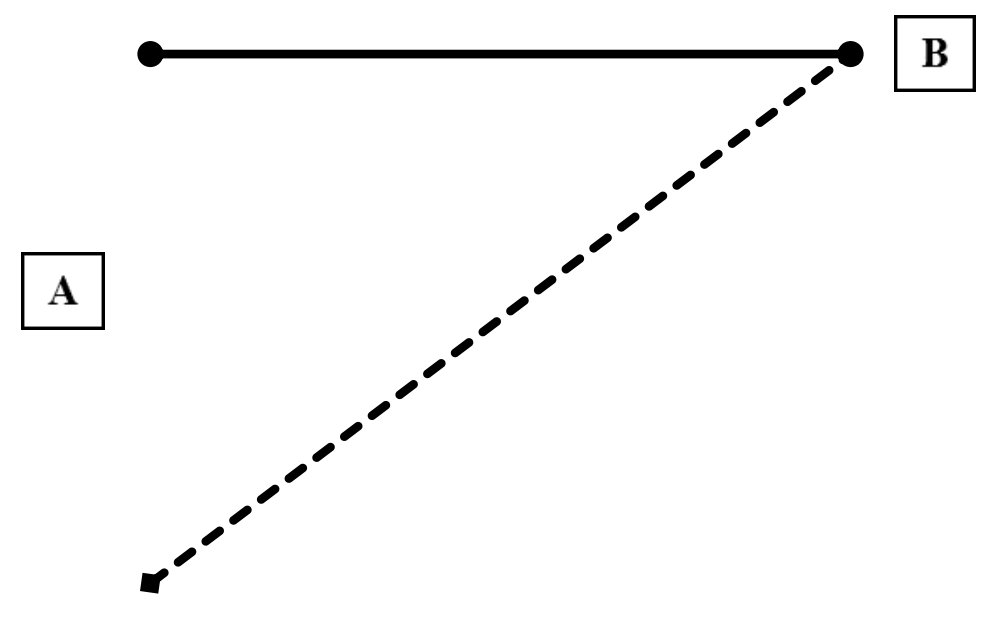

Goodwill Only

Goodwill with Intangibles

$\hookleftarrow$ Non-Strategic Narrative

$\longrightarrow$ Strategic Narrative

FIG. 1- This figure shows the predicted patterns of the two competing hypotheses about the relationship between the effect of separately identifying intangible assets and providing a strategic narrative on investors' investment-related judgments. Panel A shows the predicted pattern of the complementarity hypothesis (H1). Panel B shows the predicted pattern of the substitution hypothesis $(\mathbf{H 2})$. 
Figure 2

Theoretical Model

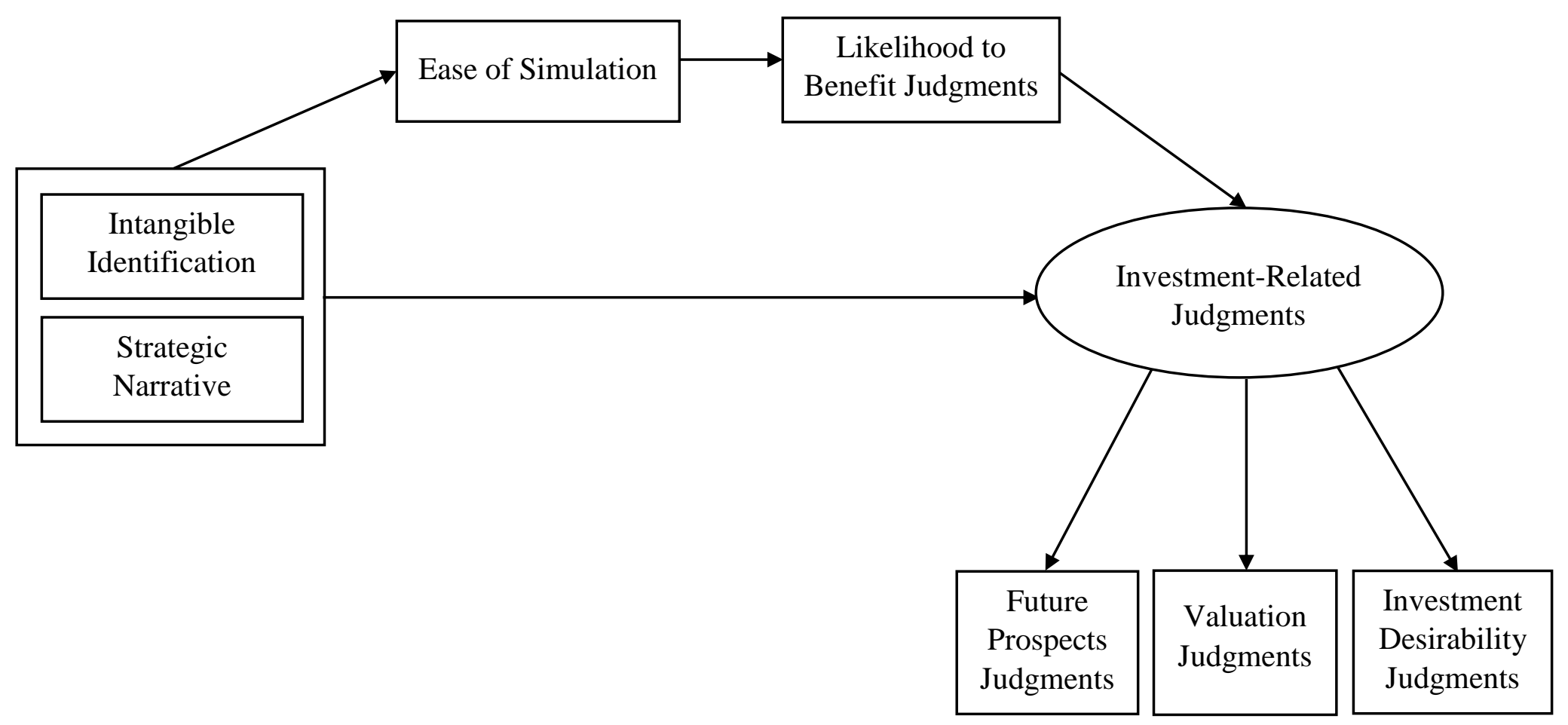

FIG. 2- This figure shows my process-based model of how identification of intangible assets and strategic narrative affect investors' investment-related judgments (future prospects, valuation, and investment desirability judgments) through two mediating judgments (ease of simulation and likelihood to benefit judgments). 
Figure 3

Results for Post-Manipulation Investment-Related Judgments

Panel A: Valuation Judgments

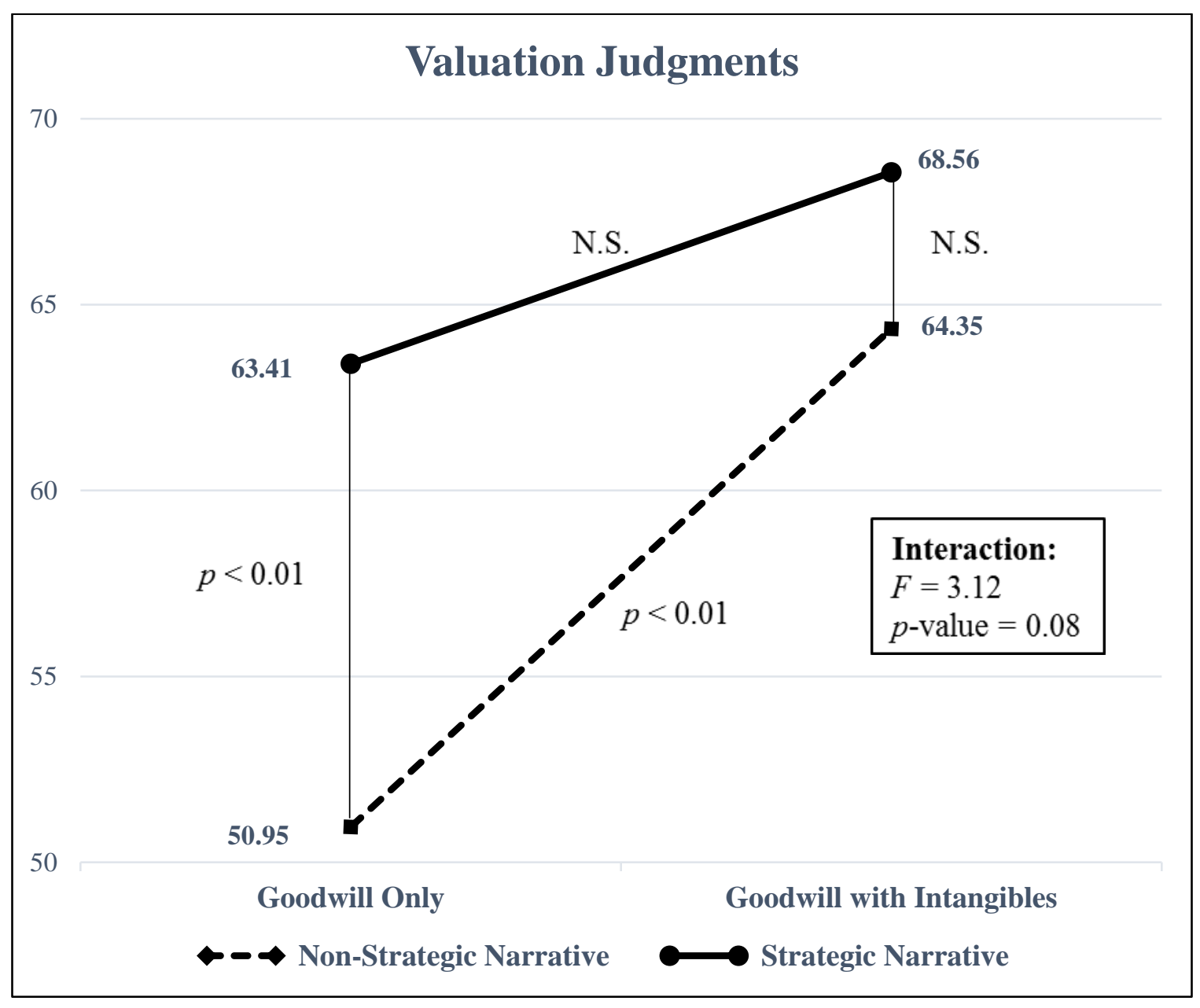


Figure 3 (Continued)

Panel B: Future Prospects Judgments

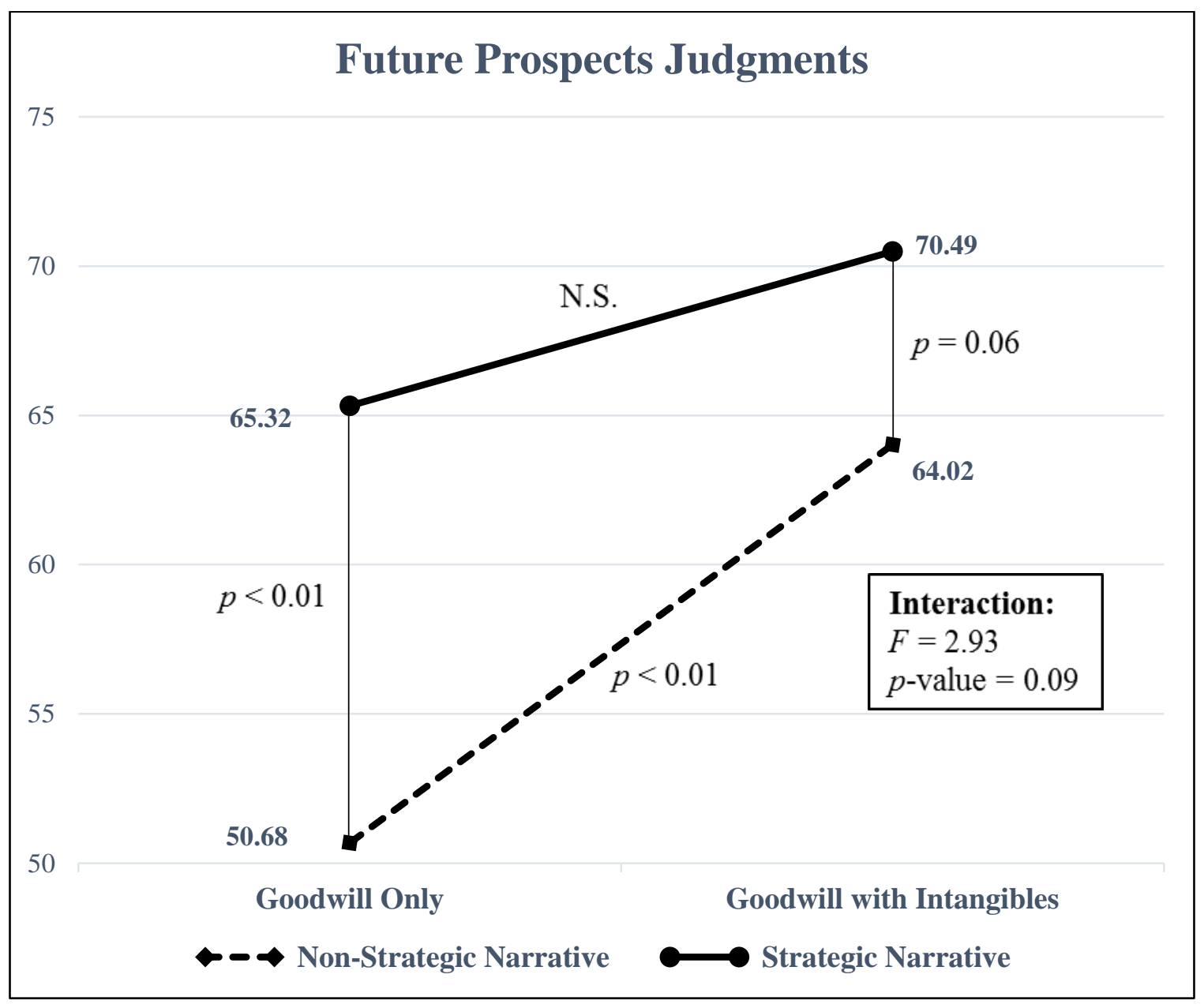




\section{Figure 3 (Continued)}

Panel C: Investment Desirability Judgments

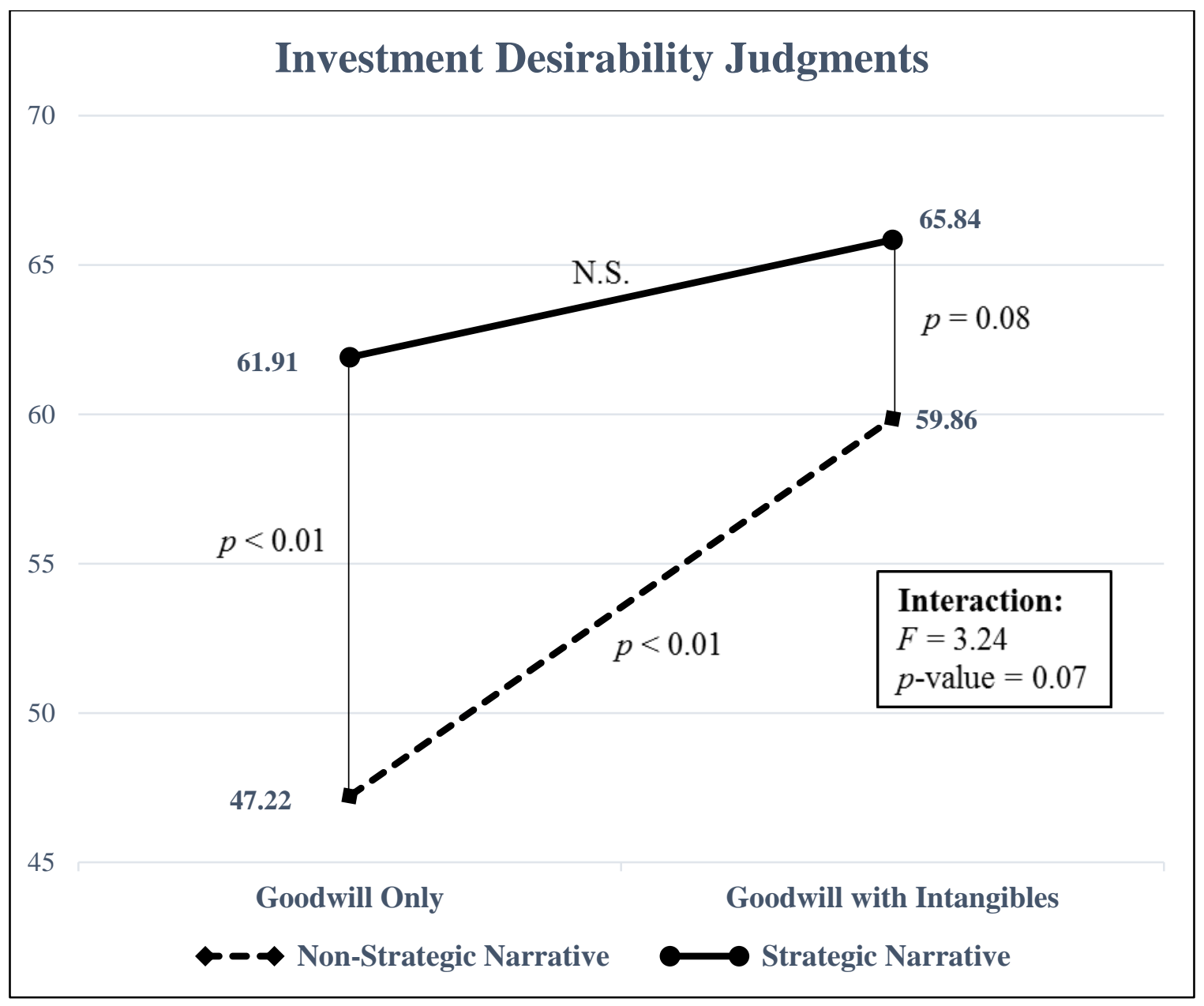

FIG. 3- This figure depicts how investors' investment-related judgments about the valuation (Panel A), future prospects (Panel B), and investment desirability (Panel C) of the acquiring company are affected by separate identification of intangible assets and providing a strategic narrative. Participants provided their valuation judgments by answering the following question: "Given the acquisition information, my valuation of Sterling is __.." The response scale was 0 ("Very Low") and 100 ("Very High"). Participants provided their future prospects judgments by answering the following question: "Given the acquisition information, I believe that Sterling has future prospects." The response scale was 0 ("Very Weak") and 100 ("Very Strong"). Participants provided their investment desirability judgments by answering the following question: "Given the acquisition information, I think an investment in Sterling is "The response scale was 0 ("Not at all Desirable") and 100 ("Very Desirable"). Participants' judgments were made both before and after manipulations. The least-squares means shown are participants' post-manipulation judgments adjusted for their pre-manipulation judgments. See Tables 1 for descriptive and inferential statistics related to the three investment-related judgments. 
Figure 4

Results for Theoretical Model

Link 2

Identification:

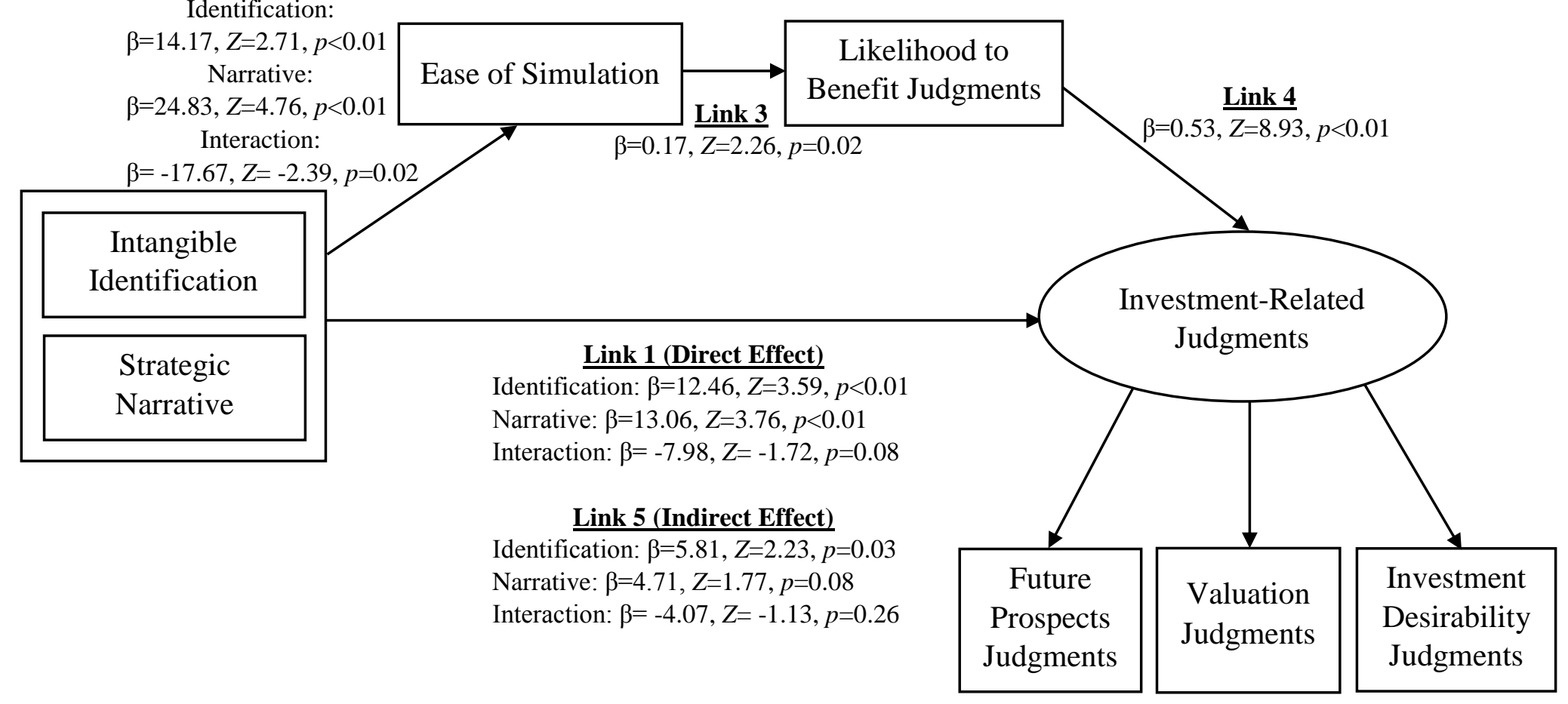

FIG. 4- This figure shows the results of a structural equation model analysis that simultaneously tests the relationships among my manipulated variables (intangible assets identification and strategic narrative), mediating variables (ease of simulation and likelihood to benefit judgments), and a latent variable, investment-related judgments, which is based on my measured primary dependent variables (valuation judgments, future prospects judgments, and investment desirability judgments). Next to each link are path coefficients, $Z$-statistics, and $p$-values. The statistics of Link 1 are from a model without the mediating variables. For simplicity of the model, change measures from pre- to post-manipulation judgments are used. Overall goodness of fit is high, as measured by the Tucker-Lewis Index (0.98) and Comparative Fit Index (0.99), which measure the improvement in fit compared to null models. The goodness of fit is confirmed by various other measures, including a $\chi^{2}$ test $\left(\chi_{14}^{2}=22.67, p=0.20\right)$ and a standardized root mean squared residual of 0.03 , indicating that the model has a good fit. 
Table 1

Results for Manipulation Checks

Panel A: Frequency table of Choice A [Choice B] for intangible identification and strategic narrative manipulation checks

\begin{tabular}{c|ccc|ccc}
\hline & \multicolumn{3}{|c|}{$\begin{array}{c}\text { Intangible Identification } \\
\text { Manipulation Check }\end{array}$} & \multicolumn{3}{c}{$\begin{array}{c}\text { Strategic Narrative } \\
\text { Manipulation Check }\end{array}$} \\
\hline & $\begin{array}{c}\text { Non-Strategic } \\
\text { Narrative }\end{array}$ & $\begin{array}{c}\text { Strategic } \\
\text { Narrative }\end{array}$ & $\begin{array}{c}\text { Row } \\
\text { Means }\end{array}$ & $\begin{array}{c}\text { Non-Strategic } \\
\text { Narrative }\end{array}$ & $\begin{array}{c}\text { Strategic } \\
\text { Narrative }\end{array}$ & $\begin{array}{c}\text { Row } \\
\text { Means }\end{array}$ \\
\hline Goodwill & 30 & 28 & 58 & 0 & 28 & 28 \\
Only & {$[0]$} & {$[2]$} & {$[2]$} & {$[30]$} & {$[2]$} & {$[32]$} \\
Goodwill with & 0 & 0 & 0 & 0 & 29 & 29 \\
Intangibles & {$[30]$} & {$[30]$} & {$[60]$} & {$[30]$} & {$[1]$} & {$[31]$} \\
Column & 30 & 28 & 58 & 0 & 57 & 57 \\
Means & {$[30]$} & {$[32]$} & {$[62]$} & {$[60]$} & {$[3]$} & {$[63]$} \\
\hline
\end{tabular}

Panel B: Maximum likelihood analyses of variance for intangible identification and strategic narrative manipulation checks

\begin{tabular}{l|c|c}
\hline & Intangible Identification & Strategic Narrative \\
\hline Intangible Identification & $\chi^{2}=43.55, p<0.01$ & $\chi^{2}=0.07, p=0.79$ \\
Strategic Narrative & $\chi^{2}=0.39, p=0.53$ & $\chi^{2}=45.00, p<0.01$ \\
Identification $\times$ Narrative & $\chi^{2}=0.39, p=0.53$ & $\chi^{2}=0.07, p=0.79$ \\
\hline
\end{tabular}

Panel C: Communication clarity judgments about strategy-related elements in narratives means [standard deviations]

\begin{tabular}{c|ccc}
\hline & \multicolumn{3}{|c}{ Communication Clarity Judgments } \\
\hline \multirow{3}{*}{ Goodwill Only } & $\begin{array}{c}\text { Non-Strategic } \\
\text { Narrative }\end{array}$ & Strategic & Rarrative \\
& 18.00 & 71.00 & Means \\
\hline \multirow{3}{*}{ Goodwill with } & {$[13.56]$} & {$[21.11]$} & 44.50 \\
Intangibles & $\mathrm{n}=30$ & $\mathrm{n}=30$ & {$[31.92]$} \\
& 16.00 & 66.67 & $\mathrm{n}=60$ \\
& {$[14.76]$} & {$[20.95]$} & 41.33 \\
Column Means & $\mathrm{n}=30$ & $\mathrm{n}=30$ & {$[31.23]$} \\
& 16.98 & 68.83 & $\mathrm{n}=60$ \\
& {$[14.09]$} & {$[20.96]$} & 42.92 \\
& $\mathrm{n}=60$ & $\mathrm{n}=60$ & {$[31.52]$} \\
\hline
\end{tabular}




\section{Table 1 (Continued)}

Panel D: Analysis of variance for judgments of communication clarity about strategyrelated elements in narratives

\begin{tabular}{l|c}
\hline & Communication Clarity Judgments \\
\hline Intangible Identification & $F=0.94, p=0.34$ \\
Strategic Narrative & $F=250.54, p<0.01$ \\
Identification $\times$ Narrative & $F=0.13, p=0.71$ \\
\hline
\end{tabular}

For the intangible identification manipulation check, participants were asked to indicate the asset list that they had seen previously. They were provided with the two acquired asset lists that corresponded to the goodwill-only (Choice A) and goodwill-with-intangibles conditions (Choice B).

For the strategic narrative manipulation check, participants were asked to recall the statement they read earlier. They were provided with two excerpts of statements, one from the strategic narrative conditions (Choice A) and the other from the non-strategic narrative condition (Choice B).

For the communication clarity judgments about strategy-related elements in narrative, participants indicated their beliefs about how clearly Sterling communicated the company's goal in making the acquisition, methods to achieve the goal, and expected benefits of the acquisition. Participants responded on a 101-point scale with endpoints of 0 ("Not at all Clearly") and 100 ("Very Clearly"). 
Table 2

Results for Investment-Related Judgments

Panel A: Post-manipulation valuation, future prospects, and investment desirability judgments: least-squares means [standard errors]

\begin{tabular}{|c|c|c|c|c|c|c|c|c|c|}
\hline & \multicolumn{3}{|c|}{ Valuation Judgments } & \multicolumn{3}{|c|}{ Future Prospects Judgments } & \multicolumn{3}{|c|}{ Investment Desirability Judgments } \\
\hline & $\begin{array}{l}\text { Non-Strategic } \\
\text { Narrative }\end{array}$ & $\begin{array}{l}\text { Strategic } \\
\text { Narrative }\end{array}$ & $\begin{array}{l}\text { Row } \\
\text { Means }\end{array}$ & $\begin{array}{c}\text { Non-Strategic } \\
\text { Narrative }\end{array}$ & $\begin{array}{l}\text { Strategic } \\
\text { Narrative }\end{array}$ & $\begin{array}{l}\text { Row } \\
\text { Means }\end{array}$ & $\begin{array}{l}\text { Non-Strategic } \\
\text { Narrative }\end{array}$ & $\begin{array}{l}\text { Strategic } \\
\text { Narrative }\end{array}$ & $\begin{array}{l}\text { Row } \\
\text { Means }\end{array}$ \\
\hline $\begin{array}{l}\text { Goodwill } \\
\text { Only }\end{array}$ & $\begin{array}{c}50.95 \\
{[2.31]} \\
n=30\end{array}$ & $\begin{array}{c}63.41 \\
{[2.31]} \\
n=30\end{array}$ & $\begin{array}{c}57.18 \\
{[1.63]} \\
\mathrm{n}=60\end{array}$ & $\begin{array}{c}50.68 \\
{[2.38]} \\
n=30\end{array}$ & $\begin{array}{c}65.32 \\
{[2.38]} \\
n=30\end{array}$ & $\begin{array}{c}57.99 \\
{[1.69]} \\
n=60\end{array}$ & $\begin{array}{c}47.22 \\
{[2.42]} \\
n=30\end{array}$ & $\begin{array}{c}61.91 \\
{[2.42]} \\
n=30\end{array}$ & $\begin{array}{c}54.56 \\
{[1.71]} \\
\mathrm{n}=60\end{array}$ \\
\hline $\begin{array}{l}\text { Goodwill with } \\
\text { Intangibles }\end{array}$ & $\begin{array}{c}64.35 \\
{[2.31]} \\
n=30\end{array}$ & $\begin{array}{c}68.56 \\
{[2.31]} \\
n=30\end{array}$ & $\begin{array}{c}66.40 \\
{[1.63]} \\
n=60\end{array}$ & $\begin{array}{c}64.02 \\
{[2.38]} \\
n=30\end{array}$ & $\begin{array}{c}70.49 \\
{[2.38]} \\
n=30\end{array}$ & $\begin{array}{c}67.25 \\
{[1.69]} \\
n=60\end{array}$ & $\begin{array}{c}59.86 \\
{[2.42]} \\
n=30\end{array}$ & $\begin{array}{c}65.84 \\
{[2.42]} \\
n=30\end{array}$ & $\begin{array}{c}62.85 \\
{[1.71]} \\
n=60\end{array}$ \\
\hline $\begin{array}{l}\text { Column } \\
\text { Means }\end{array}$ & $\begin{array}{c}57.60 \\
{[1.63]} \\
n=60\end{array}$ & $\begin{array}{c}65.98 \\
{[1.63]} \\
n=60\end{array}$ & $\begin{array}{l}61.79 \\
{[1.29]} \\
n=120\end{array}$ & $\begin{array}{c}57.35 \\
{[1.69]} \\
\mathrm{n}=60\end{array}$ & $\begin{array}{c}67.90 \\
{[1.69]} \\
n=60\end{array}$ & $\begin{array}{l}62.63 \\
{[1.36]} \\
n=120\end{array}$ & $\begin{array}{c}53.54 \\
{[1.71]} \\
\mathrm{n}=60\end{array}$ & $\begin{array}{c}63.88 \\
{[1.71]} \\
n=60\end{array}$ & $\begin{array}{l}58.71 \\
{[1.36]} \\
n=120\end{array}$ \\
\hline
\end{tabular}

Panel B: Analysis of covariance for post-manipulation valuation, future prospects, and investment desirability judgments

\begin{tabular}{l|c|c|c}
\hline & Valuation & Future Prospects & Investment Desirability \\
\hline Pre-Manipulation Judgments & $F=44.16, p<0.01$ & $F=69.99, p<0.01$ & $F=69.68, p<0.01$ \\
Intangible Identification & $F=15.94, p<0.01$ & $F=15.02, p<0.01$ & $F=11.70, p<0.01$ \\
Narrative & $F=13.21, p<0.01$ & $F=19.57, p<0.01$ & $F=18.23, p<0.01$ \\
Intangible Identification $\times$ Narrative & $F=3.12, p=0.08$ & $F=2.93, p=0.09$ & $F=3.24, p=0.07$ \\
\hline
\end{tabular}

Panel C: Simple effects of narrative for post-manipulation judgments (controlling pre-manipulation judgments)

\begin{tabular}{l|c|c|c}
\hline Effect of strategic narrative given... & Valuation & Future Prospects & Investment Desirability \\
\hline Goodwill only & $F=14.57, p<0.01$ & $F=18.83, p<0.01$ & $F=18.41, p<0.01$ \\
Goodwill with Intangibles & $F=1.74, p=0.19$ & $F=3.68, p=0.06$ & $F=3.05, p=0.08$ \\
\hline
\end{tabular}


Table 2 (Continued)

Panel D: Simple effects of intangible identification for post-manipulation judgments (controlling pre-manipulation judgments)

\begin{tabular}{l|c|c|c}
\hline Effect of intangible identification given... & Valuation & Future Prospects & Investment Desirability \\
\hline Non-strategic narrative & $F=16.63, p<0.01$ & $F=15.62, p<0.01$ & $F=13.61, p<0.01$ \\
Strategic narrative & $F=2.48, p=0.12$ & $F=2.35, p=0.13$ & $F=1.32, p=0.25$ \\
\hline
\end{tabular}

Participants provided their valuation judgments by answering the following question: "Given the acquisition information, my valuation of Sterling is

The response scale was 0 ("Very Low") and 100 ("Very High"). Participants provided their future prospects judgments by answering the following question: "Given the acquisition information, I believe that Sterling has___ future prospects." The response scale was 0 ("Very Weak") and 100 ("Very Strong") Participants provided their investment desirability judgments by answering the following question: "Given the acquisition information, I think an investment in Sterling is_. . The response scale was 0 ("Not at all Desirable") and 100 ("Very Desirable"). The Judgments were made both before and after receiving information about the acquired assets of the acquisition and a statement from Sterling, shown as pre- and post-manipulation judgments. The least-squares means shown are participants' post-manipulation judgments adjusted for their pre-manipulation judgments. For ease of simulation judgments shown in Panel E, participants answered the following question: "Based on the available information, it was for me to think about ways that Sterling could benefit from this acquisition of Kit Shoes." The response scale was 0 ("Very Difficult") and 100 ("Very Easy"). 
Table 3

Simulation Heuristic Measures

Panel A: Ease of simulation judgment means [standard deviations] and post-manipulation likelihood to benefit judgment least-squares means \{standard errors\}

\begin{tabular}{c|ccc|ccc}
\hline & \multicolumn{3}{|c|}{ Ease of Simulation Judgments } & \multicolumn{3}{c}{ Likelihood to Benefit Judgments } \\
\hline & Non-Strategic & Strategic & Row & Non-Strategic & Strategic & Row \\
& Narrative & Narrative & Means & Narrative & Narrative & Means \\
\hline \multirow{2}{*}{ Goodwill } & 40.00 & 64.83 & 52.42 & 47.15 & 64.01 & 55.58 \\
Only & {$[18.01]$} & {$[18.12]$} & {$[21.85]$} & $\{2.51\}$ & $\{2.51\}$ & $\{1.78\}$ \\
& $\mathrm{n}=30$ & $\mathrm{n}=30$ & $\mathrm{n}=60$ & $\mathrm{n}=30$ & $\mathrm{n}=30$ & $\mathrm{n}=60$ \\
Goodwill with & 54.17 & 61.33 & 57.75 & 60.95 & 69.05 & 65.00 \\
Intangibles & {$[23.34]$} & {$[22.20]$} & {$[22.87]$} & $\{2.51\}$ & $\{2.51\}$ & $\{1.78\}$ \\
& $\mathrm{n}=30$ & $\mathrm{n}=30$ & $\mathrm{n}=60$ & $\mathrm{n}=30$ & $\mathrm{n}=30$ & $\mathrm{n}=60$ \\
Column & 47.08 & 63.08 & 55.08 & 54.05 & 66.53 & 60.29 \\
Means & {$[21.87]$} & {$[20.17]$} & {$[22.44]$} & $\{1.78\}$ & $\{1.78\}$ & $\{1.45\}$ \\
& $\mathrm{n}=60$ & $\mathrm{n}=60$ & $\mathrm{n}=120$ & $\mathrm{n}=60$ & $\mathrm{n}=60$ & $\mathrm{n}=120$ \\
\hline
\end{tabular}

Panel B: Analysis of variance (covariance)

\begin{tabular}{l|c|c}
\hline & Ease of Simulation & Likelihood to Benefit \\
\hline Pre-Manipulation Judgments & $N A$ & $F=56.96, p<0.01$ \\
Intangible Identification & $F=2.02, p=0.16$ & $F=14.04, p<0.01$ \\
Strategic Narrative & $F=18.17, p<0.01$ & $F=24.66, p<0.01$ \\
Identification $\times$ Narrative & $F=5.54, p=0.02$ & $F=3.03, p=0.08$ \\
\hline
\end{tabular}

Panel C: Simple effects (controlling pre-manipulation likelihood to benefit judgments)

\begin{tabular}{l|c|c}
\hline Effect of strategic narrative given... & Ease of Simulation & Likelihood to Benefit \\
\hline Goodwill only & $F=21.89, p<0.01$ & $F=22.05, p<0.01$ \\
Goodwill with Intangibles & $F=1.82, p=0.18$ & $F=5.32, p=0.02$ \\
\hline
\end{tabular}

\begin{tabular}{l|c|c}
\hline Effect of identification given... & Ease of Simulation & Likelihood to Benefit \\
\hline Non-strategic narrative & $F=7.12, p<0.01$ & $F=15.06, p<0.01$ \\
Strategic narrative & $F=0.43, p=0.51$ & $F=2.01, p=0.16$ \\
\hline
\end{tabular}

Participants provided their ease of simulation judgments by answering the following question: "Based on the available information, it was for me to think about ways that Sterling could benefit from this acquisition of Kit Shoes." The response scale was 0 ("Very Difficult") and 100 ("Very Easy"). Participants provided their likelihood to benefit judgments by answering the following question: "I believe that Sterling is __ to benefit from this acquisition of Kit Shoes." The response scale was 0 ("Not at all Likely") and 100 ("Very Likely"). The likelihood to benefit Judgments were made both before and after receiving information about the acquired assets of the acquisition and a statement from Sterling. The least-squares means shown are participants' post-manipulation likelihood to benefit judgments adjusted for their premanipulation likelihood to benefit judgments. 
Table 4

Pre- and Post-Manipulation Investment-Related and Likelihood to Benefit Judgments

Panel A: Pre-and post-manipulation valuation judgments: means [standard deviations]

\begin{tabular}{c|ccc|ccc}
\hline & \multicolumn{3}{c|}{ Pre-Manipulation } & \multicolumn{3}{c}{ Post-Manipulation } \\
& \multicolumn{3}{|c}{ Valuation Judgments } & \multicolumn{3}{c}{ Valuation Judgments } \\
\hline & $\begin{array}{c}\text { Non-Strategic } \\
\text { Narrative }\end{array}$ & $\begin{array}{c}\text { Strategic } \\
\text { Narrative }\end{array}$ & $\begin{array}{c}\text { Row } \\
\text { Means }\end{array}$ & $\begin{array}{c}\text { Non-Strategic } \\
\text { Narrative }\end{array}$ & $\begin{array}{c}\text { Strategic } \\
\text { Narrative }\end{array}$ & $\begin{array}{c}\text { Row } \\
\text { Means }\end{array}$ \\
\hline \multirow{2}{*}{ Goodwill } & 52.17 & 53.33 & 52.75 & 51.17 & 64.17 & 57.67 \\
Only & {$[14.37]$} & {$[18.40]$} & {$[16.38]$} & {$[16.06]$} & {$[12.94]$} & {$[15.88]$} \\
& $\mathrm{n}=30$ & $\mathrm{n}=30$ & $\mathrm{n}=60$ & $\mathrm{n}=30$ & $\mathrm{n}=30$ & $\mathrm{n}=60$ \\
Goodwill with & 51.17 & 50.17 & 50.67 & 64.00 & 67.83 & 65.92 \\
Intangibles & {$[17.75]$} & {$[15.67]$} & {$[16.61]$} & {$[15.67]$} & {$[14.30]$} & {$[14.99]$} \\
& $\mathrm{n}=30$ & $\mathrm{n}=30$ & $\mathrm{n}=60$ & $\mathrm{n}=30$ & $\mathrm{n}=30$ & $\mathrm{n}=60$ \\
Column & 51.67 & 51.75 & 51.71 & 57.58 & 66.00 & 61.79 \\
Means & {$[16.02]$} & {$[17.02]$} & {$[16.46]$} & {$[17.01]$} & {$[13.65]$} & {$[15.93]$} \\
& $\mathrm{n}=60$ & $\mathrm{n}=60$ & $\mathrm{n}=120$ & $\mathrm{n}=60$ & $\mathrm{n}=60$ & $\mathrm{n}=120$ \\
\hline
\end{tabular}

Panel B: Pre- and post-manipulation future prospects judgments: means [standard deviations]

\begin{tabular}{c|ccc|ccc}
\hline & \multicolumn{3}{|c|}{ Pre-Manipulation } & \multicolumn{3}{c}{ Post-Manipulation } \\
& \multicolumn{3}{|c}{ Future Prospects Judgments } & \multicolumn{2}{c}{ Future Prospects Judgments } \\
\hline & $\begin{array}{c}\text { Non-Strategic } \\
\text { Narrative }\end{array}$ & $\begin{array}{c}\text { Strategic } \\
\text { Narrative }\end{array}$ & $\begin{array}{c}\text { Row } \\
\text { Means }\end{array}$ & $\begin{array}{c}\text { Non-Strategic } \\
\text { Narrative }\end{array}$ & $\begin{array}{c}\text { Strategic } \\
\text { Narrative }\end{array}$ & $\begin{array}{c}\text { Row } \\
\text { Means }\end{array}$ \\
\hline \multirow{3}{*}{ Goodwill } & 49.83 & 48.67 & 49.25 & 50.50 & 64.50 & 57.51 \\
Only & {$[17.83]$} & {$[16.76]$} & {$[17.17]$} & {$[18.68]$} & {$[13.02]$} & {$[17.45]$} \\
& $\mathrm{n}=30$ & $\mathrm{n}=30$ & $\mathrm{n}=60$ & $\mathrm{n}=30$ & $\mathrm{n}=30$ & $\mathrm{n}=60$ \\
Goodwill with & 51.67 & 50.50 & 51.08 & 64.83 & 70.67 & 67.75 \\
Intangibles & {$[22.87]$} & {$[16.26]$} & {$[19.68]$} & {$[18.31]$} & {$[15.29]$} & {$[16.99]$} \\
& $\mathrm{n}=30$ & $\mathrm{n}=30$ & $\mathrm{n}=60$ & $\mathrm{n}=30$ & $\mathrm{n}=30$ & $\mathrm{n}=60$ \\
Column & 50.75 & 49.58 & 50.17 & 57.67 & 67.58 & 62.63 \\
Means & {$[20.35]$} & {$[16.39]$} & {$[18.41]$} & {$[19.71]$} & {$[14.42]$} & {$[17.90]$} \\
& $\mathrm{n}=60$ & $\mathrm{n}=60$ & $\mathrm{n}=120$ & $\mathrm{n}=60$ & $\mathrm{n}=60$ & $\mathrm{n}=120$ \\
\hline
\end{tabular}


Table 4 (Continued)

Panel C: Pre-and post-manipulation investment desirability judgments: means [standard deviations]

\begin{tabular}{c|ccc|ccc}
\hline & \multicolumn{3}{|c|}{ Pre-Manipulation } & \multicolumn{3}{c}{ Post-Manipulation } \\
& \multicolumn{2}{|c}{ Investment Desirability Judgments } & Investment Desirability Judgments \\
\hline & Non-Strategic & Strategic & Row & Non-Strategic & Strategic & Row \\
& Narrative & Narrative & Means & Narrative & Narrative & Means \\
\hline \multirow{2}{*}{ Goodwill } & 47.67 & 46.67 & 47.17 & 47.83 & 62.00 & 54.92 \\
Only & {$[18.32]$} & {$[20.61]$} & {$[19.34]$} & {$[17.99]$} & {$[15.84]$} & {$[18.26]$} \\
& $\mathrm{n}=30$ & $\mathrm{n}=30$ & $\mathrm{n}=60$ & $\mathrm{n}=30$ & $\mathrm{n}=30$ & $\mathrm{n}=60$ \\
& 45.50 & 46.17 & 45.83 & 59.33 & 65.67 & 62.50 \\
Goodwill with & {$[19.89]$} & {$[18.88]$} & {$[19.23]$} & {$[18.97]$} & {$[13.63]$} & {$[16.69]$} \\
Intangibles & $\mathrm{n}=30$ & $\mathrm{n}=30$ & $\mathrm{n}=60$ & $\mathrm{n}=30$ & $\mathrm{n}=30$ & $\mathrm{n}=60$ \\
& 46.58 & 46.42 & 46.50 & 53.58 & 63.83 & 58.71 \\
Column & {$[18.99]$} & {$[19.59]$} & {$[19.21]$} & {$[19.22]$} & {$[14.77]$} & {$[17.83]$} \\
Means & $\mathrm{n}=60$ & $\mathrm{n}=60$ & $\mathrm{n}=120$ & $\mathrm{n}=60$ & $\mathrm{n}=60$ & $\mathrm{n}=120$ \\
\hline
\end{tabular}

Panel D: Pre- and post-manipulation likelihood to benefit judgment: means [standard deviations]

\begin{tabular}{c|ccc|ccc}
\hline & \multicolumn{3}{|c|}{ Pre-Manipulation } & \multicolumn{3}{c}{ Post-Manipulation } \\
& \multicolumn{3}{|c}{ Likelihood to Benefit Judgments } & \multicolumn{2}{c}{ Likelihood to Benefit Judgments } \\
\hline \multirow{4}{*}{ Goodwill } & Non-Strategic & Strategic & Row & Non-Strategic & Strategic & Row \\
Narrative & Narrative & Means & Narrative & Narrative & Means \\
\hline \multirow{4}{*}{ Only } & 44.83 & 45.50 & 45.17 & 47.00 & 64.17 & 55.58 \\
& {$[23.79]$} & {$[21.67]$} & {$[22.57]$} & {$[19.01]$} & {$[13.39]$} & {$[18.46]$} \\
Goodwill with & $\mathrm{n}=30$ & $\mathrm{n}=30$ & $\mathrm{n}=60$ & $\mathrm{n}=30$ & $\mathrm{n}=30$ & $\mathrm{n}=60$ \\
Intangibles & 46.00 & 44.33 & 45.17 & 61.33 & 68.67 & 65.00 \\
& {$[19.54]$} & {$[18.04]$} & {$[18.67]$} & {$[18.57]$} & {$[15.42]$} & {$[17.32]$} \\
& $\mathrm{n}=30$ & $\mathrm{n}=30$ & $\mathrm{n}=60$ & $\mathrm{n}=30$ & $\mathrm{n}=30$ & $\mathrm{n}=60$ \\
Column & 45.42 & 44.92 & 45.17 & 54.17 & 66.42 & 60.29 \\
Means & {$[21.59]$} & {$[19.78]$} & {$[20.62]$} & {$[19.98]$} & {$[14.49]$} & {$[18.44]$} \\
& $\mathrm{n}=60$ & $\mathrm{n}=60$ & $\mathrm{n}=120$ & $\mathrm{n}=60$ & $\mathrm{n}=60$ & $\mathrm{n}=120$ \\
\hline
\end{tabular}

For valuation judgments, participants answered: "Given the acquisition information, my valuation of Sterling is _." The scale was 0 ("Very Low") and 100 ("Very High"). For future prospects judgments, participants answered: "Given the acquisition information, I believe that Sterling has future prospects." The scale was 0 ("Very Weak") and 100 ("Very Strong"). For investment desirability judgments, participants answered: "Given the acquisition information, I think an investment in Sterling is

The scale was 0 ("Not at all Desirable") and 100 ("Very Desirable"). For likelihood to benefit judgments, participants answered: "I believe that Sterling is to benefit from this acquisition of Kit Shoes." The scale was 0 ("Not at all Likely") and 100 ("Very Likely"). These judgments were made both before and after receiving information about the acquired assets of the acquisition and a statement from Sterling. 
Table 5

Other Simulation Process Measures

Panel A: Means [standard deviations]

\begin{tabular}{|c|c|c|c|c|c|c|c|c|c|}
\hline & \multicolumn{3}{|c|}{ Potential Actions } & \multicolumn{3}{|c|}{ Abstract/Concrete } & \multicolumn{3}{|c|}{ General/Specific } \\
\hline & $\begin{array}{l}\text { Non-Strategic } \\
\text { Narrative }\end{array}$ & $\begin{array}{l}\text { Strategic } \\
\text { Narrative }\end{array}$ & $\begin{array}{l}\text { Row } \\
\text { Means }\end{array}$ & $\begin{array}{l}\text { Non-Strategic } \\
\text { Narrative }\end{array}$ & $\begin{array}{l}\text { Strategic } \\
\text { Narrative }\end{array}$ & $\begin{array}{l}\text { Row } \\
\text { Means }\end{array}$ & $\begin{array}{l}\text { Non-Strategic } \\
\text { Narrative }\end{array}$ & $\begin{array}{l}\text { Strategic } \\
\text { Narrative }\end{array}$ & $\begin{array}{l}\text { Row } \\
\text { Means }\end{array}$ \\
\hline $\begin{array}{l}\text { Goodwill } \\
\text { Only }\end{array}$ & $\begin{array}{c}42.00 \\
{[19.89]} \\
n=30\end{array}$ & $\begin{array}{c}62.17 \\
{[21.81]} \\
n=30\end{array}$ & $\begin{array}{c}52.08 \\
{[23.06]} \\
n=60\end{array}$ & $\begin{array}{c}42.17 \\
{[19.19]} \\
n=30\end{array}$ & $\begin{array}{c}52.17 \\
{[19.64]} \\
n=30\end{array}$ & $\begin{array}{c}47.17 \\
{[19.91]} \\
n=60\end{array}$ & $\begin{array}{c}35.83 \\
{[14.51]} \\
n=30\end{array}$ & $\begin{array}{c}50.00 \\
{[21.21]} \\
n=30\end{array}$ & $\begin{array}{c}42.92 \\
{[19.38]} \\
n=60\end{array}$ \\
\hline $\begin{array}{l}\text { Goodwill with } \\
\text { Intangibles }\end{array}$ & $\begin{array}{c}53.00 \\
{[23.25]} \\
n=30\end{array}$ & $\begin{array}{c}64.00 \\
{[19.36]} \\
n=30\end{array}$ & $\begin{array}{c}58.50 \\
{[21.93]} \\
n=60\end{array}$ & $\begin{array}{c}51.33 \\
{[19.78]} \\
n=30\end{array}$ & $\begin{array}{c}58.17 \\
{[19.59]} \\
n=30\end{array}$ & $\begin{array}{c}54.75 \\
{[19.82]} \\
n=60\end{array}$ & $\begin{array}{c}52.50 \\
{[20.79]} \\
n=30\end{array}$ & $\begin{array}{c}50.50 \\
{[19.04]} \\
n=30\end{array}$ & $\begin{array}{c}51.50 \\
{[19.79]} \\
n=60\end{array}$ \\
\hline $\begin{array}{l}\text { Column } \\
\text { Means }\end{array}$ & $\begin{array}{c}47.50 \\
{[22.16]} \\
n=60\end{array}$ & $\begin{array}{c}63.08 \\
{[20.46]} \\
n=60\end{array}$ & $\begin{array}{c}55.29 \\
{[22.63]} \\
n=120\end{array}$ & $\begin{array}{c}46.75 \\
{[19.87]} \\
n=60\end{array}$ & $\begin{array}{c}55.17 \\
{[19.68]} \\
n=60\end{array}$ & $\begin{array}{c}50.96 \\
{[20.14]} \\
n=120\end{array}$ & $\begin{array}{c}44.17 \\
{[19.66]} \\
n=60\end{array}$ & $\begin{array}{c}50.25 \\
{[19.99]} \\
n=60\end{array}$ & $\begin{array}{c}47.21 \\
{[19.98]} \\
n=120\end{array}$ \\
\hline
\end{tabular}

Panel B: Analysis of variance tests

\begin{tabular}{l|c|c|c}
\hline & Potential Actions & Abstract/Concrete & General/Specific \\
\hline Intangible Identification & $F=2.77, p=0.10$ & $F=4.51, p=0.04$ & $F=6.07, p=0.02$ \\
Strategic Narrative & $F=16.31, p<0.01$ & $F=5.56, p=0.02$ & $F=3.05, p=0.08$ \\
Identification $\times$ Narrative & $F=1.41, p=0.23$ & $F=0.20, p=0.66$ & $F=5.39, p=0.02$ \\
\hline
\end{tabular}

Panel C: Simple effects of narrative

\begin{tabular}{l|c|c|c}
\hline Effect of strategic narrative given... & Potential Actions & Abstract/Concrete & General/Specific \\
\hline Goodwill only & $F=13.66, p<0.01$ & $F=3.92, p=0.05$ & $F=8.27, p<0.01$ \\
Goodwill with Intangibles & $F=4.06, p=0.05$ & $F=1.83, p=0.18$ & $F=0.16, p=0.69$ \\
\hline
\end{tabular}




\section{Table 5 (Continued)}

Panel D: Simple effects of intangible identification

\begin{tabular}{l|c|c|c}
\hline Effect of intangible identification given... & Potential Actions & Abstract/Concrete & General/Specific \\
\hline Non-strategic narrative & $F=4.06, p=0.05$ & $F=3.30, p=0.07$ & $F=11.45, p<0.01$ \\
Strategic narrative & $F=0.11, p=0.74$ & $F=1.41, p=0.24$ & $F=0.01, p=0.92$ \\
\hline
\end{tabular}

The potential actions question asked, "Based on the available information, it was for me to think about potential actions that Sterling could take after this acquisition of Kit Shoes," with responses on 101-point scales with endpoints of 0 ("Very Difficult") and 100 ("Very Easy").

The abstract/concrete question asked, "When I thought about the potential actions that Sterling could take after the acquisition, my thoughts were with responses on 101-point scales with endpoints of ("Very Abstract") and 100 ("Very Concrete").

The general/specific question asked, "When I thought about the potential actions that Sterling could take after the acquisition, my thoughts were , with responses on 101-point scales with endpoints of 0 ("Very General") and 100 ("Very Specific"). 
Table 6

Narrative Persuasion Judgments

Panel A: Narrative simulation and asset usefulness judgments means [standard deviations]

\begin{tabular}{c|ccc|ccc}
\hline & \multicolumn{2}{|c|}{ Narrative Simulation Judgments } & \multicolumn{3}{c}{ Asset Usefulness Judgments } \\
\hline & $\begin{array}{c}\text { Non-Strategic } \\
\text { Narrative }\end{array}$ & $\begin{array}{c}\text { Strategic } \\
\text { Narrative }\end{array}$ & $\begin{array}{c}\text { Row } \\
\text { Means }\end{array}$ & $\begin{array}{c}\text { Non-Strategic } \\
\text { Narrative }\end{array}$ & $\begin{array}{c}\text { Strategic } \\
\text { Narrative }\end{array}$ & $\begin{array}{c}\text { Row } \\
\text { Means }\end{array}$ \\
\hline \multirow{3}{*}{ Goodwill } & 40.00 & 72.33 & 56.17 & 42.67 & 54.93 & 48.80 \\
Only & {$[23.64]$} & {$[15.74]$} & {$[25.73]$} & {$[23.33]$} & {$[20.75]$} & {$[22.75]$} \\
& $\mathrm{n}=30$ & $\mathrm{n}=30$ & $\mathrm{n}=60$ & $\mathrm{n}=30$ & $\mathrm{n}=30$ & $\mathrm{n}=60$ \\
Goodwill with & 42.50 & 76.17 & 59.33 & 62.33 & 71.67 & 67.00 \\
Intangibles & {$[23.88]$} & {$[16.75]$} & {$[26.58]$} & {$[24.27]$} & {$[17.19]$} & {$[21.38]$} \\
& $\mathrm{n}=30$ & $\mathrm{n}=30$ & $\mathrm{n}=60$ & $\mathrm{n}=30$ & $\mathrm{n}=30$ & $\mathrm{n}=60$ \\
Column & 41.25 & 74.25 & 57.75 & 52.50 & 63.30 & 57.90 \\
Means & {$[23.59]$} & {$[16.23]$} & {$[26.09]$} & {$[25.61]$} & {$[20.69]$} & {$[23.80]$} \\
& $\mathrm{n}=60$ & $\mathrm{n}=60$ & $\mathrm{n}=120$ & $\mathrm{n}=60$ & $\mathrm{n}=60$ & $\mathrm{n}=120$ \\
\hline
\end{tabular}

Panel B: Analysis of variance for narrative simulation and asset usefulness judgments

\begin{tabular}{l|c|c}
\hline & Narrative Simulation & Asset Usefulness \\
\hline Intangible Identification & $F=0.73, p=0.40$ & $F=21.38, p<0.01$ \\
Strategic Narrative & $F=78.86, p<0.01$ & $F=7.53, p<0.01$ \\
Identification $\times$ Narrative & $F=0.03, p=0.86$ & $F=0.14, p=0.71$ \\
\hline
\end{tabular}

Panel C: Simple effects for asset usefulness and narrative simulation judgments

\begin{tabular}{l|c|c}
\hline Effect of strategic narrative given... & Narrative Simulation & Asset Usefulness \\
\hline Goodwill only & $F=37.85, p<0.01$ & $F=4.86, p=0.03$ \\
Goodwill with Intangibles & $F=41.04, p<0.01$ & $F=2.81, p=0.10$ \\
\hline \multicolumn{2}{|c}{} \\
\hline Effect of intangible identification given... & Narrative Simulation & Asset Usefulness \\
\hline Non-strategic narrative & $F=0.23, p=0.64$ & $F=12.48, p<0.01$ \\
Strategic narrative & $F=0.53, p=0.47$ & $F=9.04, p<0.01$ \\
\hline
\end{tabular}

The narrative simulation question asked, "While reading the Sterling CEO's statement, it was for me to think about how Sterling could work with Kit Shoes after the acquisition," with responses on 101 point scales with endpoints of 0 ("Very Difficult") and 100 ("Very Easy").

The asset usefulness question asked, "While reading the acquired asset list, I thought that the acquired asset list could be to Sterling after the acquisition," with responses on 101-point scales with endpoints of 0 ("Not at all Useful") and 100 ("Very Useful"). 
Table 7

Management-Related Judgments

Panel A: Means [standard deviations]

\begin{tabular}{c|ccc|ccc|ccc}
\hline & \multicolumn{3}{|c|}{ Management Transparency } & \multicolumn{3}{c|}{ Management Trustworthy } & \multicolumn{2}{c}{ Management Competence } \\
\hline & $\begin{array}{c}\text { Non-Strategic } \\
\text { Narrative }\end{array}$ & $\begin{array}{c}\text { Strategic } \\
\text { Narrative }\end{array}$ & $\begin{array}{c}\text { Mow } \\
\text { Means }\end{array}$ & $\begin{array}{c}\text { Non-Strategic } \\
\text { Narrative }\end{array}$ & $\begin{array}{c}\text { Strategic } \\
\text { Narrative }\end{array}$ & $\begin{array}{c}\text { Row } \\
\text { Means }\end{array}$ & $\begin{array}{c}\text { Non-Strategic } \\
\text { Narrative }\end{array}$ & $\begin{array}{c}\text { Strategic } \\
\text { Narrative }\end{array}$ & $\begin{array}{c}\text { Row } \\
\text { Means }\end{array}$ \\
\hline \multirow{3}{*}{ Goodwill } & 33.83 & 62.67 & 48.25 & 44.50 & 65.67 & 55.08 & 45.17 & 65.33 & 55.25 \\
Only & {$[17.60]$} & {$[18.56]$} & {$[23.08]$} & {$[13.54]$} & {$[14.25]$} & {$[17.43]$} & {$[13.03]$} & {$[14.50]$} & {$[17.03]$} \\
& $\mathrm{n}=30$ & $\mathrm{n}=30$ & $\mathrm{n}=60$ & $\mathrm{n}=30$ & $\mathrm{n}=30$ & $\mathrm{n}=60$ & $\mathrm{n}=30$ & $\mathrm{n}=30$ & $\mathrm{n}=60$ \\
Goodwill with & 42.33 & 67.67 & 55.00 & 51.17 & 62.33 & 56.75 & 51.50 & 64.83 & 58.17 \\
Intangibles & {$[20.83]$} & {$[15.41]$} & {$[22.21]$} & {$[16.38]$} & {$[15.30]$} & {$[16.69]$} & {$[17.67]$} & {$[15.11]$} & {$[17.63]$} \\
& $\mathrm{n}=30$ & $\mathrm{n}=30$ & $\mathrm{n}=60$ & $\mathrm{n}=30$ & $\mathrm{n}=30$ & $\mathrm{n}=60$ & $\mathrm{n}=30$ & $\mathrm{n}=30$ & $\mathrm{n}=60$ \\
Column & 38.08 & 65.17 & 51.63 & 47.83 & 64.00 & 55.92 & 48.33 & 65.08 & 56.71 \\
Means & {$[19.59]$} & {$[17.09]$} & {$[22.81]$} & {$[15.28]$} & {$[14.75]$} & {$[17.01]$} & {$[15.72]$} & {$[14.69]$} & {$[17.33]$} \\
& $\mathrm{n}=60$ & $\mathrm{n}=60$ & $\mathrm{n}=120$ & $\mathrm{n}=60$ & $\mathrm{n}=60$ & $\mathrm{n}=120$ & $\mathrm{n}=60$ & $\mathrm{n}=60$ & $\mathrm{n}=120$ \\
\hline
\end{tabular}

Panel B: Analysis of variance tests

\begin{tabular}{l|c|c|c}
\hline & Management Transparency & Management Trustworthy & Management Competence \\
\hline Identification & $F=4.12, p=0.04$ & $F=0.38, p=0.54$ & $F=1.11, p=0.29$ \\
Strategic Narrative & $F=66.40, p<0.01$ & $F=35.29, p<0.01$ & $F=36.56, p<0.01$ \\
Identification $\times$ Narrative & $F=0.28, p=0.60$ & $F=3.38, p=0.07$ & $F=1.52, p=0.22$ \\
\hline
\end{tabular}

Panel C: Simple effects of strategic narrative

\begin{tabular}{l|c|c|c}
\hline Effect of strategic narrative given... & Management Transparency & Management Trustworthy & Management Competence \\
\hline Goodwill only & $F=37.63, p<0.01$ & $F=30.25, p<0.01$ & $F=26.50, p<0.01$ \\
Goodwill with Intangibles & $F=29.05, p<0.01$ & $F=8.42, p<0.01$ & $F=11.58, p<0.01$ \\
\hline
\end{tabular}




\section{Table 7 (Continued)}

Panel D: Simple effects of identification

\begin{tabular}{l|c|c|c}
\hline Effect of identification given... & Management Transparency & Management Trustworthy & Management Competence \\
\hline Non-strategic narrative & $F=3.27, p=0.07$ & $F=3.00, p=0.09$ & $F=2.61, p=0.11$ \\
Strategic narrative & $F=1.13, p=0.29$ & $F=0.75, p=0.39$ & $F=0.02, p=0.90$ \\
\hline
\end{tabular}

The management transparency question asked, "In my opinion, Sterling's management was about this acquisition," with responses on 101-point scales with endpoints of 0 ("Not at all Transparent") and 100 ("Very Transparent").

The management trustworthy question asked, "In my opinion, Sterling's management is ("Not at all Trustworthy") and 100 ("Very Trustworthy").

The management trustworthy question asked, "In my opinion, Sterling's management is ("Not at all Competent") and 100 ("Very Competent").

" with responses on 101-point scales with endpoints of 0 " with responses on 101-point scales with endpoints of 0 
Table 8

Overpayment Judgments

Panel A: Overpayment judgment means [standard deviations]

\begin{tabular}{c|ccc}
\hline & \multicolumn{3}{|c}{ Overpayment Judgments } \\
\hline & Non-Strategic & Strategic & Row \\
& Narrative & Narrative & Means \\
\hline \multirow{3}{*}{ Goodwill Only } & 62.83 & 60.37 & 61.60 \\
& {$[15.18]$} & {$[18.25]$} & {$[16.69]$} \\
& $\mathrm{n}=30$ & $\mathrm{n}=30$ & $\mathrm{n}=60$ \\
Goodwill with & 63.17 & 57.83 & 60.50 \\
Intangibles & {$[18.50]$} & {$[19.55]$} & {$[19.06]$} \\
& $\mathrm{n}=30$ & $\mathrm{n}=30$ & $\mathrm{n}=60$ \\
Column Means & 63.00 & 59.01 & 61.05 \\
& {$[16.78]$} & {$[18.79]$} & {$[17.85]$} \\
& $\mathrm{n}=60$ & $\mathrm{n}=60$ & $\mathrm{n}=120$ \\
\hline
\end{tabular}

Panel B: Analysis of variance tests for overpayment judgments

\begin{tabular}{l|c}
\hline & Overpayment Judgments \\
\hline Intangible Identification & $F=0.11, p=0.74$ \\
Strategic Narrative & $F=1.42, p=0.24$ \\
Identification $\times$ Strategic & $F=0.19, p=0.67$ \\
\hline
\end{tabular}

Panel C: Simple effects

\begin{tabular}{l|c}
\hline Effect of strategic narrative given... & Overpayment Judgments \\
\hline Goodwill only & $F=0.28, p=0.60$ \\
Goodwill with Intangibles & $F=1.33, p=0.25$ \\
\hline \multicolumn{2}{c}{} \\
\hline Effect of identification given... & Overpayment Judgments \\
\hline Non-strategic narrative & $F=0.01, p=0.94$ \\
Strategic narrative & $F=0.30, p=0.59$ \\
\hline
\end{tabular}

Participants provided their overpayment judgments by answering the following question: "I believe it is that Sterling overpaid for this acquisition." The response scale was 0 ("Not at all Likely") and 100 ("Very Likely"). 
Appendices 


\section{Appendix A: Examples of Narrative Disclosures about Acquisitions}

\section{Panel A: Excerpt from the PetSmart press release on Chewy.com acquisition}

"PetSmart strives to be the trusted partner to pet parents and pets in every moment of their lives," said Michael Massey, president and chief executive officer of PetSmart. "We are focused on improving our customers' experience in-store and online as we continue to execute against our long-term strategic initiatives. Chewy's high-touch customer ecommerce service model and culture centered around a love of pets is the ideal complement to PetSmart's store footprint and diverse offerings. Together, PetSmart and Chewy will provide the most convenient customer experience to a wider base of pet parents across every channel."

\section{Panel B: Excerpt from the Coach press release on Stuart Weitzman acquisition}

Victor Luis, Chief Executive Officer, Coach, Inc., said, "Stuart Weitzman is a leading American luxury designer footwear brand with a solid growth trajectory and further significant domestic and international development potential. Importantly, the size, scope and vibrancy of the Stuart Weitzman brand, along with the continuity of its management team, allows for a seamless transition to Coach ownership, as we continue to focus on Coach's brand transformation. Over the medium term, we look forward to advancing the Stuart Weitzman brand's global development, especially by leveraging Coach's international infrastructure and expertise in handbags and accessories. In addition, we look forward to benefiting from the Stuart Weitzman team's expertise in footwear development where they're proven leaders in fashion and fit. Our strong balance sheet provides the flexibility to take advantage of this opportunity while re-investing in our core business and continuing to maintain our dividend at current levels."

\section{Panel C: Excerpt from the Amazon press release on WholeFoods acquisition}

"Millions of people love Whole Foods Market because they offer the best natural and organic foods, and they make it fun to eat healthy," said Jeff Bezos, Amazon founder and CEO. "Whole Foods Market has been satisfying, delighting, and nourishing customers for nearly four decades - they're doing an amazing job and we want that to continue."

\section{Panel D: Excerpt from the Microsoft press release on LinkedIn acquisition}

"The LinkedIn team has grown a fantastic business centered on connecting the world's professionals," Nadella said. "Together we can accelerate the growth of LinkedIn, as well as Microsoft Office 365 and Dynamics as we seek to empower every person and organization on the planet." 


\section{Appendix B: Experimental Materials}

\section{Panel A: Background information}

Assume that you are a prospective investor evaluating Sterling Inc. You obtained the following background information about Sterling Inc.

Sterling Inc., incorporated on January 15, 1976, is a headphone manufacturer and retail company that offers a range of headphone products, such as over-the-head, in-ear, on-ear, and wireless headphones. Sterling also sells other audio equipment and accessories such as microphones, speakers, sound bars, and amplifiers.

The Company's headquarters are in Denver, Colorado. As of August 31, 2017, the Company has total assets of $\$ 14.9$ billion and net assets of $\$ 6.2$ billion. The Company's fiscal year end is December 31.

You then obtained the following information about an upcoming acquisition for Sterling.

\section{Sterling Inc. to Acquire Kit Shoes}

DENVER, Colorado-September 25, 2017-Sterling Inc. and Kit Shoes today announced that they have entered into a definitive agreement under which Sterling will acquire Kit Shoes in an all-cash transaction. Kit Shoes is a footwear manufacturer and retailer with products in a variety of materials, such as tennis shoes, track shoes, running shoes, walking shoes, and hiking boots. Sterling Inc. will acquire Kit Shoes for a total of $\$ 2.58$ billion, inclusive of Kit Shoes' net cash. 


\section{Panel B: Goodwill only and non-strategic narrative condition}

During your research, you read more information about Sterling's acquisition of Kit Shoes.

\section{Acquired Assets}

Of the total acquisition purchase price of $\$ 2.58$ billion, approximately half is for acquired cash and other physical assets. The other half, approximately $\$ 1.29$ billion, is for the acquired asset listed below:

- Goodwill

\section{Statement from Sterling}

Mark Stiller, Chief Executive Officer of Sterling Inc., stated, "Kit Shoes is a fantastic company. They have sold many wonderful shoes over the years, such as tennis shoes, track shoes, running shoes, walking shoes, hiking boots, and many others.

The most famous creation of Kit is the Kit Stride series, which uses both leather and mesh cloth materials, and is available in more than 25 unique design patterns. These shoes have soft cushioning, strong arch support, solid construction, and comfortable fit. Even I have multiple pairs of Kit Stride myself.

Sterling is great, too. Since 1976, Sterling has had a long history of providing good headphones to the market. We offer a variety of headphones with many different styles, such as over-the-head, in-ear, on-ear, and wireless headphones. We now also sell other audio equipment such as microphones, speakers, sound bars, and amplifiers. We look forward to working with Kit Shoes in the future." 


\section{Panel C: Goodwill only and strategic narrative condition}

During your research, you read more information about Sterling's acquisition of Kit Shoes.

\section{Acquired Assets}

Of the total acquisition purchase price of $\$ 2.58$ billion, approximately half is for acquired cash and other physical assets. The other half, approximately $\$ 1.29$ billion, is for the acquired asset listed below:

- Goodwill

\section{Statement from Sterling}

Mark Stiller, Chief Executive Officer of Sterling Inc., stated, "Our goal of this acquisition is to use the strength of Kit Shoes to help us develop and sell a new wireless headphone product for runners, swimmers, and other athletic individuals.

The acquired assets of this acquisition can help us achieve our goal. Specifically, we plan to incorporate Kit's secret technology in treating materials such as leather and mesh cloth into our new headphones. These waterproof and flexible materials are part of Kit's most famous creation, the Kit Stride series. We also plan to leverage Kit's big name and close relationships with the athletic communities to help us broaden our market base. Millions of customers already love Kit.

We will benefit from this acquisition of Kit by being able to develop a new headphone product, target the athletic communities, and expand our market share. We look forward to working with Kit Shoes in the future." 


\section{Panel D: Goodwill with intangibles and non-strategic narrative condition}

During your research, you read more information about Sterling's acquisition of Kit Shoes.

\section{Acquired Assets}

Of the total acquisition purchase price of $\$ 2.58$ billion, approximately half is for acquired cash and other physical assets. The other half, approximately $\$ 1.29$ billion, is for the acquired assets listed below:

- Trade name

- Trademarks

- Trade secrets about proprietary processes

- In-process research and development

- Customer relationships

- Customer database

- Goodwill

\section{Statement from Sterling}

Mark Stiller, Chief Executive Officer of Sterling Inc., stated, "Kit Shoes is a fantastic company. They have sold many wonderful shoes over the years, such as tennis shoes, track shoes, running shoes, walking shoes, hiking boots, and many others.

The most famous creation of Kit is the Kit Stride series, which uses both leather and mesh cloth materials, and is available in more than 25 unique design patterns. These shoes have soft cushioning, strong arch support, solid construction, and comfortable fit. Even I have multiple pairs of Kit Stride myself.

Sterling is great, too. Since 1976, Sterling has had a long history of providing good headphones to the market. We offer a variety of headphones with many different styles, such as over-the-head, in-ear, on-ear, and wireless headphones. We now also sell other audio equipment such as microphones, speakers, sound bars, and amplifiers. We look forward to working with Kit Shoes in the future." 


\section{Panel E: Goodwill with intangibles and strategic narrative condition}

During your research, you read more information about Sterling's acquisition of Kit Shoes.

\section{Acquired Assets}

Of the total acquisition purchase price of $\$ 2.58$ billion, approximately half is for acquired cash and other physical assets. The other half, approximately $\$ 1.29$ billion, is for the acquired assets listed below:

- Trade name

- Trademarks

- Trade secrets about proprietary processes

- In-process research and development

- Customer relationships

- Customer database

- Goodwill

\section{Statement from Sterling}

Mark Stiller, Chief Executive Officer of Sterling Inc., stated, "Our goal of this acquisition is to use the strength of Kit Shoes to help us develop and sell a new wireless headphone product for runners, swimmers, and other athletic individuals.

The acquired assets of this acquisition can help us achieve our goal. Specifically, we plan to incorporate Kit's secret technology in treating materials such as leather and mesh cloth into our new headphones. These waterproof and flexible materials are part of Kit's most famous creation, the Kit Stride series. We also plan to leverage Kit's big name and close relationships with the athletic communities to help us broaden our market base. Millions of customers already love Kit.

We will benefit from this acquisition of Kit by being able to develop a new headphone product, target the athletic communities, and expand our market share. We look forward to working with Kit Shoes in the future." 


\section{Appendix C: Intangible Assets Categorized as Hard, Semi-Soft, and Soft}

\begin{tabular}{|c|c|c|}
\hline Hard & Semi-Soft & Soft \\
\hline $\begin{array}{l}\text { Artistic or digital contents (e.g. plays, } \\
\text { operas, ballets, books, magazines, } \\
\text { newspapers, literary works, musical } \\
\text { works, pictures, videos, motives, TV } \\
\text { programs), operating and broadcast rights, } \\
\text { and royalty; } \\
\text { Lease agreements and servicing contracts } \\
\text { (e.g. mortgage servicing); } \\
\text { Patents; software; mask works; and } \\
\text { database with copyright. }\end{array}$ & $\begin{array}{l}\text { Trademarks, tradenames, trade dress, } \\
\text { mastheads, internet domain names, trade } \\
\text { secret with copyright; } \\
\text { Noncompetition agreements, standstill } \\
\text { agreements, and employment contracts; } \\
\text { Order or production backlogs, customer } \\
\text { contracts*, and contractual customer } \\
\text { relationships*; } \\
\text { Advertising, construction, management, } \\
\text { service, or supply contracts; } \\
\text { Licensing; franchise agreements; } \\
\text { construction permits; and use rights (e.g. } \\
\text { drilling, water, air). }\end{array}$ & $\begin{array}{c}\text { Customer lists*; } \\
\text { Non-contractual customer relationships*; } \\
\text { Unpatented technology, in-process } \\
\text { research and development; } \\
\text { Database without copyright; } \\
\text { Trade secret without copyright; } \\
\text { Title plants. }\end{array}$ \\
\hline
\end{tabular}

Hard: These assets typically are based on contractual obligation or other legal rights, and are easily separable on an individual basis that can be transferred, sold, exchanged, rented, or generate separate cash flows.

Semi-Soft: These assets typically based on contractual obligations or other legal rights, but are not easily separable on an individual basis, or can be easily separable on an individual basis, but are not based on contractual obligations or other legal rights. Almost all intangibles in this semi-soft category are difficult to be separable on an individual basis but have some legal protections.

Soft: These assets typically are not easily separable on an individual basis and are not based on contractual obligation or other legal rights.

*Note: Private companies can now subsume these intangibles into goodwill, except for those that can be independently exchanged or sold (e.g. if there is no confidentiality agreement that prevents transfer of the customer information). Though some customer relationships might be contractbased, rarely are these relationships separable on an individual basis. They could still meet the separable criterion of SFAS 141R if they can be exchanged/sold together with a related contract, identifiable asset, or liability, but rarely meet the criterion individually. Thus, ASU 2014-18 effectively narrowed down the scope and definition of the separable criterion for recognition for private companies. 


\section{Appendix D: Dependent Measures}

Panel A: Main dependent measures (for both pre-and post-manipulation judgments)

\begin{tabular}{|c|c|}
\hline Dependent Variable & Question and Scale \\
\hline Likelihood to Benefit & $\begin{array}{ll}\text { "I believe that Sterling is } & \text { to benefit from this } \\
\text { acquisition of Kit Shoes." } & \\
\text { 0: Not at all Likely } & 100 \text { : Very Likely }\end{array}$ \\
\hline Futu & $\begin{array}{l}\text { "Given the acquisition information, I believe that Sterling has } \\
\text { future prospects." } \\
\text { 0: Very Weak }\end{array}$ \\
\hline Valuation & $\begin{array}{l}\text { "Given the acquisition information, my valuation of Sterling is } \\
\text { 0: Very Low }\end{array}$ \\
\hline $\begin{array}{l}\text { Investment } \\
\text { Desirability }\end{array}$ & $\begin{array}{l}\text { "Given the acquisition information, I think an investment in } \\
\text { Sterling is } \\
\text { 0: Not at all Desirable }\end{array}$ \\
\hline
\end{tabular}


Panel B: Process measures

\begin{tabular}{|c|c|}
\hline $\begin{array}{l}\text { Dependent } \\
\text { Variable }\end{array}$ & Question and Scale \\
\hline Ease of Simulation & $\begin{array}{l}\text { "Based on the available information, it was } \\
\text { me to think about ways that Sterling could benefit from this } \\
\text { acquisition of Kit Shoes." } \\
\text { 0: Very Difficult } \\
100 \text { : Very Easy }\end{array}$ \\
\hline Potential Actions & $\begin{array}{l}\text { "Based on the available information, it was } \\
\text { me to think about potential actions that Sterling could take after } \\
\text { this acquisition of Kit Shoes." } \\
\text { 0: Very Difficult } \\
100 \text { : Very Easy }\end{array}$ \\
\hline Abstract/Concrete & $\begin{array}{l}\text { "When I thought about the potential actions that Sterling could } \\
\text { take after the acquisition, my thoughts were } \\
0 \text { : Very Abstract } 100 \text { : Very Concrete }\end{array}$ \\
\hline General/Specific & $\begin{array}{l}\text { "When I thought about the potential actions that Sterling could } \\
\text { take after the acquisition, my thoughts were } \\
0: \text { Very General } \\
\end{array}$ \\
\hline Narrative Simulation & $\begin{array}{l}\text { "While reading the Sterling CEO's statement, it was } \\
\text { for me to think about how Sterling could work } \\
\text { with Kit Shoes after the acquisition." } \\
\text { 0: Very Difficult } \\
100 \text { : Very Easy }\end{array}$ \\
\hline Asset Usefulness & $\begin{array}{l}\text { "While reading the acquired asset list, I thought that the acquired } \\
\text { asset list could be to Sterling after the } \\
\text { acquisition." } \\
\begin{array}{ll}\text { 0: Not at all Useful } & 100 \text { : Very Useful }\end{array}\end{array}$ \\
\hline Asset Reason & $\begin{array}{l}\text { "I believe that the acquired asset list is } \\
\text { main reason for Sterling's acquisition of Kit Shoes." } \\
\text { 0: Not at all Likely }\end{array}$ \\
\hline CEO Reason & $\begin{array}{l}\text { "I believe that the CEO's personal preference for Kit Shoes is } \\
\text { of Kit Shoes." } \\
\text { 0: Not at all Likely }\end{array}$ \\
\hline $\begin{array}{l}\text { Management } \\
\text { Transparency }\end{array}$ & $\begin{array}{l}\text { "In my opinion, Sterling's management was } \\
\text { about this acquisition." } \\
\text { 0: Not at all Transparent } \\
\end{array}$ \\
\hline $\begin{array}{l}\text { Management } \\
\text { Trustworthy }\end{array}$ & $\begin{array}{l}\text { "In my opinion, Sterling's management is } \\
0: \text { Not at all Trustworthy } \\
100 \text { : Very Trustworthy }\end{array}$ \\
\hline $\begin{array}{l}\text { Management } \\
\text { Competence }\end{array}$ & $\begin{array}{l}\text { "In my opinion, Sterling's management is } \\
0: \text { Not at all Competent }\end{array}$ \\
\hline Overpayment & $\begin{array}{l}\text { "I believe it is } \\
\text { acquisition." }\end{array}$ \\
\hline
\end{tabular}




\section{Panel C: Manipulation questions}

1. Recall the acquired asset list of this acquisition. Which one of the following lists did you see?

A.

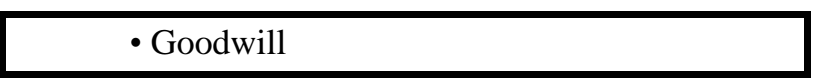

B.

- Trade name

- Trademarks

- Trade secrets about proprietary processes

- In-process research and development

- Customer relationships

- Customer database

- Customer database

- Goodwill

2. Which one of the following statements is part of the information you read earlier about this acquisition?

A.

Mark Stiller, Chief Executive Officer of Sterling Inc., stated, "Our goal of this acquisition is to use the strength of Kit Shoes to help us develop and sell a new wireless headphone product for runners, swimmers, and other athletic individuals..."

B.

Mark Stiller, Chief Executive Officer of Sterling Inc., stated, "Kit Shoes is a fantastic company. They have sold many wonderful shoes over the years, such as tennis shoes, track shoes, running shoes, walking shoes, hiking boots, and many others..."

3. How clearly did Sterling communicate the company's goal of this acquisition, methods to achieve such goal, and expected benefits of this acquisition?

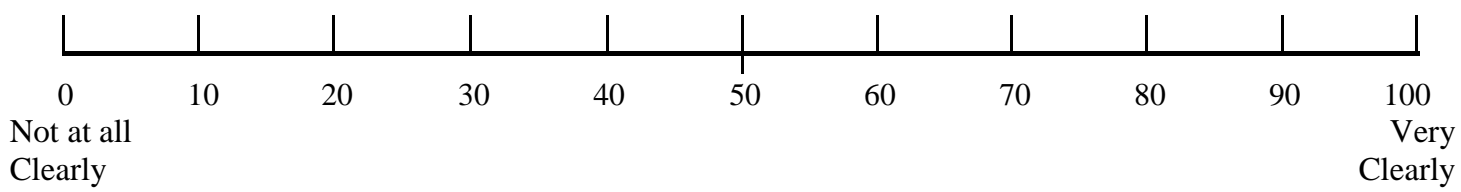




\section{Panel D: Post-Experiment Questionnaire}

1. Are you an MPA or MBA student?

2. What is the major of your undergraduate degree?

3. Have you ever made investments in the common stock of a company? If yes, approximately how many times?
MPA

MBA

4. Do you plan to invest in the common stock of a company in the future?

YES NO

5. Have you ever made investments in a common stock mutual fund?

YES NO

6. How many undergraduate and graduate accounting and finance courses have you taken, including those you are taking this semester?

Accounting

Finance

7. How many years of full-time work experience do you have? years

8. Have you ever worked in the following capacities?

If yes, fill in the number of years. If no, leave blank.

Corporate finance

Corporate accounting

Public accounting

Investment analyst

Management

Other

9. Do you have any other comments about the case materials or the questions you answered? years

years

years

years

years

years 


\section{References}

AAA Financial Accounting Standards Committee. 2001. Equity valuation models and measuring goodwill impairment. Accounting Horizons 15(2): 161-170.

Aaker, D. A., and Keller, K. L. 1990. Consumer evaluations of brand extensions. The Journal of Marketing: 27-41.

Amazon.com, Inc. 2017. Amazon to Acquire Whole Foods Market. Available at http://phx.corporate-ir.net/phoenix.zhtml?c=176060\&p=irol-newsArticle \&ID=22 81414.

Amazon.com, Inc. 2018. Amazon.com, Inc. Form 10-K for the Fiscal Year Ended December 31, 2017. Retrieved from SEC filing database.

Aboody, D., and Lev, B. 1998. The value relevance of intangibles: the case of software capitalization. Journal of Accounting Research 36: 161-191.

Accounting Principles Board (APB). 1970a. Business Combinations. APB Opinion No. 16. New York, NY: AICPA.

Accounting Principles Board (APB). 1970b. Intangible Assets. APB Opinion No. 17. New York, NY: AICPA.

Allee, K. D., and DeAngelis, M. D. 2015. The structure of voluntary disclosure narratives: Evidence from tone dispersion. Journal of Accounting Research 53(2): 241-274.

Amir, E., and Lev, B. 1996. Value-relevance of nonfinancial information: The wireless communications industry. Journal of Accounting and Economics 22(1): 3-30.

Barth, M. E., and Schipper, K. 2008. Financial reporting transparency. Journal of Accounting, Auditing and Finance 23(2): 173-190.

Bertsch, S., Pesta, B. J., Wiscott, R., and McDaniel, M. A. 2007. The generation effect: A meta-analytic review. Memory and Cognition 35(2): 201-210.

Bettman, J. R., Johnson, E. J., and Payne, J. W. 1990. A componential analysis of cognitive effort in choice. Organizational Behavior and Human Decision Processes 45(1): 111-139. 
Bloomfield, R., Hodge, F., Hopkins, P., and Rennekamp, K. 2014. Does coordinated presentation help credit analysts identify firm characteristics? Contemporary Accounting Research 32(2): 507-527.

Bonner, S. E., Clor-Proell, S. M., and Koonce, L. 2014. Mental accounting and disaggregation based on the sign and relative magnitude of income statement items. The Accounting Review 89(6): 2087-2114.

Bozanic, Z., and Thevenot, M. 2015. Qualitative disclosure and changes in sell-side financial analysts' information environment. Contemporary Accounting Research 32(4): 1595-1616.

Brazell, D.W., Dworin, L., and Walsh, M. 1989. A History of Federal Tax Depreciation Policy. Available at https://www.treasury.gov/resource-center/tax-policy/taxanalysis/Documents/WP-64.pdf.

Brown, L. D., Call, A. C., Clement, M. B., and Sharp, N. Y. 2017. Managing the Narrative: Investor Relations Officers and Corporate Disclosure. Working paper. Available at https://papers.ssrn.com/sol3/papers.cfm?abstract_id=2934937.

Byrne, B. M. 1994. Structural Equation Modeling with EQS and EQS/Windows: Basic Concepts, Applications, and Programming. Thousand Oaks, CA: Sage Publications.

Canadian Institute of Chartered Accountants (CICA). 2014. Management's Discussion and Analysis: Guidance on Preparation and Disclosure. Ottawa, CA: CICA.

Chalmers, K., G. Clinch and J. M. Godfrey. 2008. Adoption of International Financial Reporting Standards: Impact on the value relevance of intangible assets. Australian Accounting Review 18(3): 237-247.

Chen, C. X., Rennekamp, K. M., and Zhou, F. H. 2015. The effects of forecast type and performance-based incentives on the quality of management forecasts. Accounting, Organizations and Society 46: 8-18.

Clor-Proell, S. M., Proell, C. A., and Warfield, T. D. 2014. The effects of presentation salience and measurement subjectivity on nonprofessional investors' fair value judgments. Contemporary Accounting Research 31(1): 45-66.

Collins, D. W., and Kim, J. 2015. The persistence and pricing of merger-related transitory growth and its implications for growth anomalies and asset pricing models. Working paper. Available at https://ssrn.com/abstract=2172843. 
Committee on Accounting Procedure (CAP). 1944. Accounting for Intangible Assets. Accounting Research Bulletin No. 24. New York, NY: AICPA.

Committee on Accounting Procedure (CAP). 1950. Business Combinations. Accounting Research Bulletin No. 40. New York, NY: AICPA.

Committee on Accounting Procedure (CAP). 1957. Business Combinations. Accounting Research Bulletin No. 48. New York, NY: AICPA.

Coach, Inc. 2017. Coach to Acquire Luxury Designer Footwear Brand Stuart Weitzman from Sycamore Partners. Available at http://phx.corporate-ir.net/phoenix.zhtml?c $=122587 \& \mathrm{p}=$ irol-newsArticle \&ID=2003397.

Colley, J. R., and Volkan, A. G. 1988. Accounting for goodwill. Accounting Horizons 2(1): $35-41$.

Creyer, E. H., Bettman, J. R., and Payne, J. W. 1990. The impact of accuracy and effort feedback and goals on adaptive decision behavior. Journal of Behavioral Decision Making 3(1): 1-16.

Dahmash, F. N., Durand, R. B., and Watson, J. 2009. The value relevance and reliability of reported goodwill and identifiable intangible assets. The British Accounting Review 41(2): 120-137.

Davis, A. K., Piger, J. M., and Sedor, L. M. 2012. Beyond the numbers: Measuring the information content of earnings press release language. Contemporary Accounting Research 29(3): 845-868.

Dicksee, L. R., and Tillyard, F. 1906. Goodwill and its Treatment in Accounts. London, UK: Gee \& Company.

Elliott, W. B., Hobson, J. L., and Jackson, K. E. 2011. Disaggregating management forecasts to reduce investors' susceptibility to earnings fixation. The Accounting Review 86(1): 185-208.

Elliott, W. B., Rennekamp, K. M., and White, B. J. 2015. Does concrete language in disclosures increase willingness to invest?. Review of Accounting Studies 20(2): 839-865.

Escalas, J. E. 2004. Imagine yourself in the product: Mental simulation, narrative transportation, and persuasion. Journal of Advertising 33(2): 37-48. 
Escalas, J. E. 2006. Self-referencing and persuasion: Narrative transportation versus analytical elaboration. Journal of Consumer Research 33(4): 421-429.

European Financial Reporting Advisory Group (EFRAG). 2014. Should Goodwill Still not be Amortised?. Brussels, Belgium: EFRAG.

European Financial Reporting Advisory Group (EFRAG). 2015. Should Goodwill Still not be Amortised?. Feedback Statement: Responses to the Discussion Paper. Brussels, Belgium: EFRAG.

European Financial Reporting Advisory Group (EFRAG). 2016. What Do We Know about Goodwill? A Quantitative Study. Brussels, Belgium: EFRAG.

Financial Accounting Standards Advisory Council (FASAC). 2016. Minutes of Meeting for June 16, 2016. Norwalk, CT: FASB.

Financial Accounting Standards Board (FASB). 1984. Recognition and Measurement in Financial Statements of Business Enterprises. Statement of Financial Accounting Concepts No.5. Norwalk, CT: FASB.

Financial Accounting Standards Board (FASB). 1999. Business Combinations and Intangible Assets. Exposure Draft 201-A. Norwalk, CT: FASB.

Financial Accounting Standards Board (FASB). Accounting Standards Codification Master Glossary. Available at https://asc.fasb.org/glossary.

Financial Accounting Standards Board (FASB). 2001a. Using Cash Flow Information and Present Value in Accounting Measurements. Statement of Financial Accounting Concepts No.7. Norwalk, CT: FASB.

Financial Accounting Standards Board (FASB). 2001b. Business Combinations. Statement of Financial Accounting Standards No. 141. Norwalk, CT: FASB.

Financial Accounting Standards Board (FASB). 2001c. Goodwill and Other Intangible Assets. Statement of Financial Accounting Standards No. 142. Norwalk, CT: FASB.

Financial Accounting Standards Board (FASB). 2001d. Business Combinations and Intangible Assets-Accounting for Goodwill. Exposure Draft 201-R. Norwalk, CT: FASB. 
Financial Accounting Standards Board (FASB). 2001e. Improving Business Reporting: Insights into Enhancing Voluntary Disclosures. Steering Committee Report, Business Reporting Research Project. Norwalk, CT: FASB.

Financial Accounting Standards Board (FASB). 2006. Fair Value Measurements. Statement of Financial Accounting Standards No. 157 (As Amended). Norwalk, CT: FASB.

Financial Accounting Standards Board (FASB). 2007. Business Combinations. Statement of Financial Accounting Standards No. 141(Revised). Norwalk, CT: FASB.

Financial Accounting Standards Board (FASB). 2011. Intangibles-Goodwill and Others (Topic 350): Testing Indefinite-Lived Intangible Assets for Impairment. Accounting Standards Update No. 2011-08. Norwalk, CT: FASB.

Financial Accounting Standards Board (FASB). 2012. Intangibles-Goodwill and Others (Topic 350): Testing Indefinite-Lived Intangible Assets for Impairment. Accounting Standards Update No. 2012-02. Norwalk, CT: FASB.

Financial Accounting Standards Board (FASB). 2013. Post-Implementation Review Report on FASB Statement No.141 (Revised 2007), Business Combination. Norwalk, CT: FASB.

Financial Accounting Standards Board (FASB). 2014a. Business Combinations (Topic 805): Accounting for Identifiable Intangible Assets in a Business Combination (A Consensus of the Private Company Council). Accounting Standards Update No. 2014-18. Norwalk, CT: FASB.

Financial Accounting Standards Board (FASB). 2014b. Consideration of New Alternative (Alternative A). Memo No. Issue Summary No.1, Supplement No. 7. Norwalk, CT: FASB.

Financial Accounting Standards Board (FASB). 2014c. Intangibles, Goodwill, and Other (Topic 350): Accounting for Goodwill (A Consensus of the Private Company Council). Accounting Standards Update No. 2014-02. Norwalk, CT: FASB.

Financial Accounting Standards Board (FASB). 2016. Project Update: Accounting for Identifiable Intangible Assets in a Business Combination for Public Business Entities and Not-For-Profit Entities. Norwalk, CT: FASB. 
Financial Accounting Standards Board (FASB). 2017. Objectives of Research Projects: Accounting for Certain Identifiable Intangible Assets in a Business Combination and Subsequent Accounting for Goodwill for Public Business Entities and Not-forProfits. Norwalk, CT: FASB.

Fontanella-Khan, J., and Massoudi, A. 2015. Global Dealmaking Breaks 2007 Record. Financial Times. Available at https://www.ft.com/content/ccb6f428-a7d0-11e5-95 5c-1e1d6de94879.

Förster, J., Friedman, R. S., and Liberman, N. 2004. Temporal construal effects on abstract and concrete thinking: consequences for insight and creative cognition. Journal of Personality and Social Psychology 87(2): 177-189.

Francis, J., and Schipper, K. 1999. Have financial statements lost their relevance? Journal of Accounting Research 37(2): 319-352.

Freeman, H. C. 1921. Some considerations involved in the valuation of goodwill. Journal of Accountancy 32(4): 247-264.

Garcia, C. 2007. How Accounting for Goodwill relies on Underlying Assumptions: A Historical Approach. European Accounting Association, Proceedings of the Annual $30^{\text {th }}$ Conference.

Green, M. C., and Brock, T. C. 2000. The role of transportation in the persuasiveness of public narratives. Journal of Personality and Social Psychology 79(5): 701-721.

Griffin, M., Miles, K., Stefanowski T., and De Simone M. 2017. 2016 Purchase Price Allocation Study. Available at https://www.hl.com/us/insightsandideas/12884902 608.aspx.

Guthrie, E. 1898. Goodwill. The Accountant 24: 425-431.

Hales, J. W., Venkataraman, S., and Wilks, T. J. 2011. Accounting for lease renewal options: the informational effects of unit of account choices. The Accounting Review 87(1): 173-197.

Hales, J., Kuang, X. J., and Venkataraman, S. 2011. Who believes the hype? An experimental examination of how language affects investor judgments. Journal of Accounting Research 49(1): 223-255. 
Halsey, R., and Hopkins, P. 2017. Advanced Accounting, $3^{\text {rd }}$ Edition. Westmont, IL: Cambridge Business Publishers.

Hatfield, H. R. 1909. Modern Accounting: Its Principles and Some of Its Problems. New York, NY: D. Appleton and Company.

Hellman, N., Andersson, P., Fröberg, E. 2016. The impact of IFRS goodwill reporting on financial analysts' equity valuation judgements: Some experimental evidence. Accounting and Finance 56: 113-157.

Hirst, D., Koonce, L., and Venkataraman, S. 2007. How disaggregation enhances the credibility of management earnings forecasts. Journal of Accounting Research 45(4): 811-837.

Hu, L. T., and Bentler, P. M. 1999. Cutoff criteria for fit indexes in covariance structure analysis: Conventional criteria versus new alternatives. Structural Equation Modeling: A Multidisciplinary Journal 6(1): 1-55.

Hughes, H. 1982. Goodwill in Accounting: A History of the Issues and Problems. Atlanta GA: Business Publication Division, College of Administration, Georgia State University.

International Accounting Standards Board (IASB). 2012. Business Combinations. IFRS 3. London, UK: IASB.

International Accounting Standards Board (IASB). 2014. Intangible Assets. IAS 38. London, UK: IASB.

International Accounting Standards Board (IASB). 2015. Post-implementation Review of IFRS 3 Business Combinations. Report and Feedback Statement. London, UK: IASB.

Ji, X. and Lu, W. 2014. The value relevance and reliability of intangible assets: Evidence from Australia before and after adopting IFRS. Asian Review of Accounting 22(3): 182-216.

Johnson, L. T., and Petrone, K. R. 1998. Is goodwill an asset?. Accounting Horizons 12(3): 293-303.

Jones, D. A. 2007. Voluntary disclosure in R\&D - Intensive industries. Contemporary Accounting Research 24(2): 489-522. 
Jones, S. 2011. Does the capitalization of intangible assets increase the predictability of corporate failure?, Accounting Horizons 25(1): 41-70.

Kadous, K., and Zhou, Y. D. 2016. Maximizing the contribution of JDM-Style experiments in accounting. Working paper. Available at https://papers.ssrn.com/sol3/papers.cf m?abstract_id=2887033.

Kahneman, D., and Tversky, A. 1982. The simulation heuristic. Judgment Under Uncertainty: Heuristics and Biases: 201-208. New York, NY: Cambridge University Press.

Kanodia, C., Sapra, H., and Venugopalan, R. 2004. Should intangibles be measured: What are the economic trade-offs?. Journal of Accounting Research 42(1): 89-120.

Kline, R. B. 2015. Principles and Practice of Structural Equation Modeling. New York, NY: Guilford publications.

Koonce, L., Leitter, Z. J., and White, B. J. 2017. Linked financial statement presentation. Working paper. Available at https://ssrn.com/abstract=2983195.

Koonce, L., Lipe, M. G., and McAnally, M. L. 2005. Judging the risk of financial instruments: Problems and potential remedies. The Accounting Review 80(3): 871895.

Koonce, L., Lipe, M. G., and McAnally, M. L. 2008. Investor reactions to derivative use and outcomes. Review of Accounting Studies 13(4): 571-597.

Kutner, M. H., Nachtsheim, C. J., Neter, J., and Li, W. 2005. Applied Linear Statistical Models, $5^{\text {th }}$ Edition. New York, NY: McGraw-Hill Companies.

Laroche, M., Bergeron, J., and Goutaland, C. 2001. A three-dimensional scale of intangibility. Journal of Service Research 4(1): 26-38.

Lev, B. 2001. Intangibles: Management, Measurement, and Reporting. Washington, D.C.: Brookings Institution Press.

Lev, B., and Sougiannis, T. 1996. The capitalization, amortization, and value-relevance of R\&D. Journal of Accounting and Economics 21(1): 107-138.

Libby, R. and Brown, T. 2012. Financial statement disaggregation decisions and auditors' tolerance for misstatement. The Accounting Review 88(2): 641-665. 
Libby, R., and Emett, S. A. 2014. Earnings presentation effects on manager reporting choices and investor decisions. Accounting and Business Research 44(4): 410-438.

Libby, R., and Luft, J. 1993. Determinants of judgment performance in accounting settings: Ability, knowledge, motivation, and environment. Accounting, Organizations and Society 18(5): 425-450.

MacInnis, D. J., and Price, L. L. 1987. The role of imagery in information processing: Review and extensions. Journal of Consumer Research 13(4): 473-491.

Maines, L. A., and McDaniel, L. S. 2000. Effects of comprehensive-income characteristics on nonprofessional investors' judgments: The role of financial-statement presentation format. The Accounting Review 75(2): 179-207.

McDougall, G. H., and Snetsinger, D. W. 1990. The intangibility of services: measurement and competitive perspectives. Journal of Services Marketing 4(4): 27-40.

McInnis, J., and Monsen, B. 2017. Are the recorded value of acquired intangible assets indicative of their future payoffs?. Working paper. Available at https://papers.ssr n.com/sol3/papers.cfm?abstract_id=2956669.

Merkley, K. J. 2013. Narrative disclosure and earnings performance: Evidence from R\&D disclosures. The Accounting Review 89(2): 725-757.

Microsoft News Center. June 13, 2016. Microsoft to Acquire LinkedIn. Available at https://news.microsoft.com/2016/06/13/microsoft-to-acquire-linkedin/\#3Dgdu3gj DTSKrpkF.97.

Nathan, K. 1988. Do firms pay to pool?: Some empirical evidence. Journal of Accounting and Public Policy 7(3): 185-200.

Nunes, C., Roland, G., Todorova, M., Warner, J. 2016. 2016 U.S. Goodwill Impairment Study. Available at http://www.duffandphelps.com/assets/pdfs/publications/valuati on/gwi/2016-us-goodwill-impairment-study.pdf.

Officer, M. S., Poulsen, A. B., and Stegemoller, M. 2009. Target-firm information asymmetry and acquirer returns. Review of Finance 13(3): 467-493.

Paugam, L., Astolfi, P., and Ramond, O. 2015. Accounting for business combinations: Do purchase price allocations matter?. Journal of Accounting and Public Policy 34(4): 362-391. 
Payne, J. W. 1982. Contingent decision behavior. Psychological Bulletin 92(2): 382-402.

Pennington, N., and Hastie, R. 1988. Explanation-based decision making: Effects of memory structure on judgment. Journal of Experimental Psychology: Learning, Memory, and Cognition 14(3): 521-533.

Pennington, N., and Hastie, R. 1992. Explaining the evidence: Tests of the Story Model for juror decision making. Journal of Personality and Social Psychology 62(2): 189206.

Peterson, R. A. 1994. A meta-analysis of Cronbach's coefficient alpha. Journal of Consumer Research 21(2): 381-391.

PetSmart, Inc. 2017. PetSmart Announces Agreement to Acquire Chewy, a Leading Online Pet Retailer. Available at http://phx.corporate-ir.net/phoenix.zhtml?c=196265\&p= irol-newsArticle\&ID=2262570.

Pham, L. B., and Taylor, S. E. 1999. From thought to action: Effects of process-versus outcome-based mental simulations on performance. Personality and Social Psychology Bulletin 25(2): 250-260.

Pitz, B., Fitgerald, B., Misek P., O'Shea T., Khattar S., and Velikov S. January 30, 2014. Lenovo to Acquire Motorola for $\$ 2.91 B$. Retrieved from Thomson One database.

Private Company Council (PCC). 2013. Agenda Report 2013.02.12. Norwalk, CT: FASB.

Private Company Council (PCC). 2014. Accounting for Identifiable Intangible Assets in a Business Combination. Issue Summary No.1, Supplement No. 3 (PCC Issue No. 13-01A). Norwalk, CT: FASB.

Ramanna, K. 2008. The implications of unverifiable fair-value accounting: Evidence from the political economy of goodwill accounting. Journal of Accounting and Economics 45(2): 253-281.

Rennekamp, K. 2012. Processing fluency and investors' reactions to disclosure readability. Journal of Accounting Research 50(5): 1319-1354.

Robinson, J. R., and Shane, P. B. 1990. Acquisition accounting method and bid premia for target firms. The Accounting Review (65): 25-48. 
Rodrigues, U., and Stegemoller, M. 2007. An inconsistency in SEC disclosure requirements? The case of the "insignificant" private target. Journal of Corporate Finance 13(2-3): 251-269.

Roland, G., and Kernick, G. 2014. Chapter 30: Cost of capital for fair value reporting of intangible assets. Cost of Capital: Applications and Examples, $5^{\text {th }}$ Edition: 757-778. Hoboken, NJ: John Wiley \& Sons Publishing Company.

Securities and Exchange Commission (SEC). 2004. Additional Form 8-K Disclosure Requirements and Acceleration of Filing Date Form 8-K. Release Nos. 33-8400; 34-49424; File No. S7-22-02. Washington, D.C.: SEC

Securities and Exchange Commission (SEC). 2017. Form 8-K. Washington, D.C.: SEC

Securities and Exchange Commission (SEC). 2018a. Regulation S-K (17 CFR 229). Washington, D.C.: SEC

Securities and Exchange Commission (SEC). 2018b. Regulation S-X (17 CFR 210). Washington, D.C.: SEC

Sedor, L. M. 2002. An explanation for unintentional optimism in analysts' earnings forecasts. The Accounting Review 77(4): 731-753.

Shalev, R. 2009. The information content of business combination disclosure level. The Accounting Review 84(1): 239-270.

Shalev, R., I. Zhang, and Y. Zhang. 2013. CEO compensation and fair value accounting: Evidence from purchase price allocation. Journal of Accounting Research 51(4): 819-854.

Shleifer, A., and Vishny, R. W. 2003. Stock market driven acquisitions. Journal of Financial Economics 70(3): 295-311.

Skinner, D. J. 2008. Accounting for intangibles - a critical review of policy recommendations. Accounting and Business Research 38(3): 191-204.

Sloman, S. A., and Lagnado, D. 2015. Causality in thought. Annual Review of Psychology 66: 223-247.

Taylor, S. E., and Pham, L. B. 1999. The effect of mental simulation on goal-directed performance. Imagination, Cognition and Personality 18(4): 253-268. 
Taylor, S. E., Pham, L. B., Rivkin, I. D., and Armor, D. A. 1998. Harnessing the imagination: Mental simulation, self-regulation, and coping. American Psychologist 53(4): 429-439.

Thompson, D. V., Hamilton, R. W., and Petrova, P. K. 2009. When mental simulation hinders behavior: The effects of process-oriented thinking on decision difficulty and performance. Journal of Consumer Research 36(4): 562-574.

Trope, Y., and Liberman, N. 2010. Construal-level theory of psychological distance. Psychological Review 117(2): 440-463.

Turner, L. 1999. Initiatives for Improving the Quality of Financial Reporting. Remarks of the Chief Accountant to the New York Society of Security Analysts. US Securities and Exchange Commission, Washington, DC.

U.S. Department of the Treasury. Internal Revenue Service (IRS). 2016. Publication 535: Business Expenses (Cat. No. 15065Z). Washington, DC: IRS.

U.S. House. 2000. Accounting for Business Combinations: Should Pooling be Eliminated? Hearing before the Subcommittee on Finance and Hazardous Materials of the Committee on Commerce. Serial No. 106-100. GPO, Washington, DC.

U.S. Senate. 2000. Pooling Accounting. Hearing before the Committee on Banking, Housing and Urban Affairs. S. Hrg. 106-1035. GPO, Washington, DC.

Wahlen, J. M., Boatsman, J. R., Herz, R. H., Jennings, R. G., Jonas, G. J., Palepu, K., and Schipper, K. 1999. Response to FASB invitation to comment on methods of accounting for business combinations: Recommendations of the G4+1 for achieving convergence. Accounting Horizons 13(3): 299-303.

Weiss, K., Gorham, M., and Lowe, J. S. September 4, 2013. Nokia Expands Opportunity, But Also Risk-Moving to EW. Retrieved from Thomson One database.

Wyatt, A. 2005. Accounting recognition of intangible assets: theory and evidence on economic determinants. The Accounting Review 80(3): 967-1003.

Wyatt, A. 2008. What financial and non-financial information on intangibles is valuerelevant? A review of the evidence. Accounting and Business Research 38(3): 217256. 
Zhang, I. X., and Zhang, Y. 2017. Accounting discretion and purchase price allocation after acquisitions. Journal of Accounting, Auditing and Finance 32(2): 241-270.

Zhao, M., Hoeffler, S., and Zauberman, G. 2007. Mental simulation and preference consistency over time: The role of process-versus outcome-focused thoughts. Journal of Marketing Research 44(3): 379-388. 


\section{Vita}

Zheng Jiang Leitter was born in Shanghai, China. At the age of eighteen, she came to the United States to pursue higher education. In 2010, she obtained a Bachelor of Science in Business Administration degree from the University of Central Florida, with double majors in Accounting and Finance, and a minor in Hospitality Management. Prior to joining the Ph.D. program, Zheng worked as an auditor for Cherry, Bekaert \& Holland.

Zheng's research interest is to examine how financial statement preparers and users generate, transmit, and interpret information. She is particularly interested in studying how different accounting standards and regulations can affect investors' ability to retrieve and understand financial accounting information. She is also interested in learning how managers make reporting and real decisions due to different accounting treatments. To date, her work has mainly focused on investigating the potential effects of alternative accounting standards, and how different regulations might affect investors' judgments.

Zheng's email address is Zheng.Leitter@gmail.com. This dissertation was typed by the author. 